\title{
Assessment of cognition, time perception, and motivation in children
}

Citation for published version (APA):

Peijnenborgh, J. C. A. W. (2016). Assessment of cognition, time perception, and motivation in children. [Doctoral Thesis, Maastricht University]. Ipskamp Drukkers B.V., Enschede.

https://doi.org/10.26481/dis.20161222jp

Document status and date:

Published: 01/01/2016

DOI:

10.26481/dis.20161222jp

Document Version:

Publisher's PDF, also known as Version of record

\section{Please check the document version of this publication:}

- A submitted manuscript is the version of the article upon submission and before peer-review. There can be important differences between the submitted version and the official published version of record.

People interested in the research are advised to contact the author for the final version of the publication, or visit the DOI to the publisher's website.

- The final author version and the galley proof are versions of the publication after peer review.

- The final published version features the final layout of the paper including the volume, issue and page numbers.

Link to publication

\footnotetext{
General rights rights.

- You may freely distribute the URL identifying the publication in the public portal. please follow below link for the End User Agreement:

www.umlib.nl/taverne-license

Take down policy

If you believe that this document breaches copyright please contact us at:

repository@maastrichtuniversity.nl

providing details and we will investigate your claim.
}

Copyright and moral rights for the publications made accessible in the public portal are retained by the authors and/or other copyright owners and it is a condition of accessing publications that users recognise and abide by the legal requirements associated with these

- Users may download and print one copy of any publication from the public portal for the purpose of private study or research.

- You may not further distribute the material or use it for any profit-making activity or commercial gain

If the publication is distributed under the terms of Article $25 \mathrm{fa}$ of the Dutch Copyright Act, indicated by the "Taverne" license above, 
Assessment of cognition, time perception, and motivation in children 
(C) Copyright J.C.A.W. Peijnenborgh, Maastricht 2016

J.C.A.W. Peijnenborgh Assessment of cognition, time perception, and motivation in children

Layout Tiny Wouters

Cover design Myrte Willems

Print Ipskamp Drukkers, Enschede

ISBN

978-94-028-0402-7

Financial support for the printing of this thesis was kindly provided by the Department of Research and Development Kempenhaeghe, De Berkenschutse and the School for Mental Health and Neuroscience (MHeNS) Maastricht University. 


\title{
Assessment of cognition, time
}

perception, and motivation

\author{
in children
}

\section{Proefschrift}

Ter verkrijging van de graad van doctor aan de Universiteit Maastricht, op gezag van de Rector Magnificus, Prof. Dr. Mr. Rianne M. Letschert, volgens het besluit van het College van Decanen, in het openbaar te verdedigen

op donderdag 22 december 2016 om 12.00 uur

door

Janneke Cornelia Anna Wilhelmina Peijnenborgh

Geboren op 11 november 1984 te Herten 


\section{Promotores}

Prof. dr. J.S.H. Vles

Prof. dr. A.P. Aldenkamp

\section{Copromotores}

Dr. J.G.M. Hendriksen

Dr. P.P.M. Hurks

\section{Beoordelingscommissie}

Prof. dr. R.J. van Oostenbrugge (voorzitter)

Prof. dr. S.A. Kotz

Prof. dr. W.C.M. Resing (Universiteit Leiden)

Prof. dr. L.M.E. Smit (Universiteit van Amsterdam)

Prof. dr. L.J.I. Zimmermann 


\section{Contents}

$\begin{array}{lll}\text { Chapter } 1 & \text { General introduction } & 7\end{array}$

Chapter 2 A study on the validity of a computer-based game to assess 17 cognitive processes, reward mechanisms, and time perception in children aged 4-8 years JCAW Peijnenborgh, PPM Hurks, AP Aldenkamp, ED van der Spek, GWM Rauterberg, JSH Vles, \& JGM Hendriksen. JMIR Serious Games 2016; Sep 22;4(2):e15

Chapter 3 Psychometric properties of the Children's Time Awareness Questionnaire: a 20-item questionnaire measuring time perception JCAW Peijnenborgh, PPM Hurks, $R$ Wassenberg, AP Aldenkamp, JSH Vles, \& JGM Hendriksen. Submitted

Chapter 4 Can IQ predict parent-reported behavioral and emotional problems in children with neurological deficiencies? JCAW Peijnenborgh, AM van Abeelen, PPM Hurks, AM Laridon, $S$ Klinkenberg, AP Aldenkamp, JSH Vles, \& JGM Hendriksen. Eur J Paediatr Neurol 2016 (in press)

Chapter 5 Diagnostic overshadowing in a population of children with neurological disabilities: A cross sectional descriptive study on acquired ADHD

JGM Hendriksen, JCAW Peijnenborgh, AP Aldenkamp, \& JSH Vles. Eur J Paediatr Neurol 2015;19, 521-524

Chapter 6 Efficacy of working memory training in children and adolescents with learning disabilities: A review study and meta-analysis JCAW Peijnenborgh, PPM Hurks, AP Aldenkamp, JSH Vles, \& JGM Hendriksen. Neuropsychol Rehabil 2016;26, 645-672

$\begin{array}{lll}\text { Chapter } 7 & \text { General discussion } & 105\end{array}$

$\begin{array}{lll}\text { Chapter } 8 & \text { Summary } & 117\end{array}$

$\begin{array}{lll}\text { Chapter } 9 & \text { Samenvatting } & 123\end{array}$

$\begin{array}{lll}\text { Chapter } 10 & \text { Valorisation } & 129\end{array}$

Dankwoord (Acknowledgements) $\quad 137$

Curriculum Vitae 143 

Chapter 1

General introduction 


\section{General introduction}

When the cognitive development (e.g., in terms of learning or speech) of a child deviates from the typical trajectory, it may lead to social, educational, or behavioral problems (Shaffer \& Kipp, 2013). It therefore is not surprising, that parents or teachers raise the alarm when a child shows a deviant cognitive development trajectory. Usually, this results in consulting a professional (such as the general practitioner, a pediatrician, a psychologist, or the Center for Youth and Families [in Dutch: Centrum voor Jeugd en Gezin]) to gain more insights in the cause(s) of the deviating development. When there are concerns about the cognitive development of the child, a professional can advise to do a (clinical) neuropsychological assessment with the child. Lezak, Howieson, Bigler, and Tranel (2012) defined the discipline "clinical neuropsychology" as an applied science concerned with the behavioral expression of brain dysfunction. Although there are different conceptualizations of the term "behavior", in this thesis we choose to differentiate three aspects: the first aspect is cognition, which includes both the information handling aspect of behavior and how behavior is expressed (Lezak et al., 2012). These cognitive functions are described as the capacities to process information and to control behavior, and can be divided over several function domains, such as perception, regulation of attention, memory, social cognitions, executive functions, motivation, etc. (Swaab, Bouma, Hendriksen, \& König, 2016). The second aspect is emotionality, "which concerns feelings and motivation" (Lezak et al., 2012), and the third aspect is time perception, which is also known as temporal processing, and consists of knowledge on time related concepts (such as knowledge of time units, patterns of days and months, and a distinction between past, present, and future [Friedman, 1978, 1989, 2003]), and the ability to estimate, produce, and reproduce time intervals (Block, Zakay, \& Hancock, 1999). By studying these three aspects of behavior, professionals aim to gain insights into daily functioning by assessing cognitive functions of the child. The focus of this thesis is the measurement of these cognitive functions, with a special focus on attention, motivation, and time perception. Can we reliably measure these aspects of behavior in (young) children? Is it useful to measure these in children? Can we e.g., use these measurements to identify children who are at risk for learning problems or to identify other inter- and intra-individual differences in children (i.e., validity)? Can we improve the current neuropsychological assessments e.g., in terms of ecological validity? And finally can we identify treatment effects while using these instruments?

\section{Children with a neurological learning disorder}

One group of children that is at risk for a deviant development in terms of behavior (i.e., cognitive functioning, motivation, and/or time perception) is the group of children with a neurological condition. Neurological conditions are defined as conditions of the brain, spinal cord, nerves, and/or muscles (Menkes, Sarnat, \& Maria, 
2006). It is not surprising that these behavioral deficits are common in children with a neurological condition, since the mediating structure that is responsible for the development of these behaviors is the brain (Lenroot \& Giedd, 2006). Several studies in this thesis aim to get insight into aspects of behavior (e.g., the cognitive functioning) of this group of children. Most research took place at the Center of Neurological Learning Disabilities, a tertiary outpatient clinic in Heeze, The Netherlands. The patient population of the center consists of children between 4 to 18 years of age with a broad range of neurological conditions or deficiencies, such as congenital conditions (e.g., cerebral malformations, cerebral palsy, Duchenne muscular disorder, specific language disorders) or acquired conditions caused by a disease (e.g., meningitis, brain tumor) or by an accident (e.g., traumatic brain injury). Children with a neurological condition can be referred to the center by a medical specialist if the (academic) development does not match with the capacities, there is a need for insight in the learning abilities of the child, there is a need to gain insight on the effects of the neurological condition on the learning or developmental abilities of the child, or there is a need for a second opinion. Referred children are examined by a child neurologist and clinical neuropsychologist. A neuropsychological assessment is usually part of the clinical care, with the goal of gaining information on the learning abilities of the child and to formulate a profile of strengths and weaknesses. Based on this assessment, a tailored treatment is advised (e.g., medical treatment, individual treatment to help the child in the weaknesses, or advise for parents or teachers in how to help the child).

\section{Distinct profiles of cognitive deficits in children with ADHD}

Attention problems are commonly associated with children with neurological learning disabilities. Attention is an umbrella term for several processes that are involved in the detection and selection of sensory information (Posner \& Raichle, 1994). Posner and Raichle (1994) state that are three attention networks: the alertness network, the orienting network, and the executive attention network. Without attention, it is not possible to notice information (the alertness network), process it (the orienting network), and respond to it (the executive attention network) (Shaffer \& Kipp, 2013). Several brain regions are related to attention. Three brain networks can be distinguished, matching the three attention networks by Posner and Raichle (1994). The first is the network for alertness, which is related to the reticular formation, the brainstem, locus coeruleus, specific thalamus cores, and the frontal cortex. The second is the network of orienting aspects of attention, which is related to the back parts of the superior parietal and superior temporal cortex, the temporo-parietal cortex and the superior colliculus. The third network is the executive attention network, which is related to the prefrontal cortex, the anterior cingulate gyrus and the basal ganglia. Deficits or deviations in these brain structures might lead to attention problems (Krain \& Castellanos, 2006). 
When problems in attention (i.e., in any of these networks) arise and impede the development of the child, it might lead to a diagnosis of AttentionDeficit/Hyperactivity Disorder (ADHD). ADHD is a developmental disorder which is associated with academic difficulties and social disadvantage (Swanson et al., 1998). According to the DSM-5 (American Psychiatric Association, 2013), ADHD can be diagnosed when "a persistent pattern of inattention and/or hyperactivity-impulsivity interferes with functioning or development". The prevalence of ADHD is believed to be $5.29 \%$ worldwide (Polanczyk, de Lima, Horta, Biederman, \& Rohde, 2007). Studies on the etiology of ADHD showed that several factors might cause ADHD. ADHD can be caused by familiar heredity, but can also be acquired due to lesions of the brain (also called "acquired ADHD") or by environmental factors (Spencer, Biederman, \& Mick, 2007).

Previous research has found that cognitive difficulties, and more specifically in the domain of executive functions (i.e., inhibitory control, working memory, and cognitive flexibility [Dickstein, Bannon, Castellanos, \& Milham, 2006]), intelligence and attention, occur in children with ADHD (Gonzalez-Garrido et al., 2008; Martinussen, Hayden, Hogg-Johnson, \& Tannock, 2005). However, not all children with ADHD experience difficulties on this field (Nigg, Blaskey, Huang-Pollock, \& Rappley, 2002), resulting in a heterogeneous group of different profiles of cognitive and behavioral difficulties. The relation between cognitive functions and the brain is described in the triple pathway model of ADHD by Sonuga-Barke, Bitsakou, and Thompson (2010). This model explains the three pathways of patterns of deficits in cognition in children with ADHD. Each pathway has its own neural substrate and results in different behavioral problems. In the first pathway "executive dysfunctioning", which is dorsal frontostratial grounded, deficits are explained due to a dysregulation of thought and action, which results in executive function problems in for instance the working memory. The second pathway is "motivation", which is located in ventral fronto-stratial circuits. This pathway explains deficits due to the altered motivational style of children with ADHD: children with ADHD prefer small, immediate rewards over large but delayed rewards. The last pathway is "time perception", which shares neural components (i.e., basal ganglia) with the first two, but is also located in the cerebellum. This pathway describes timing problems in children with ADHD. These three pathways are core, but independent, characteristics of ADHD. Children might be affected in only one pathway, or a combination of pathways. Sonuga-Barke and colleagues (2010) found that only $6.4 \%$ of the children had purely problems in executive dysfunctioning, while deviations in motivation (19.5\%) and time perception (24.7\%) occur more as a unique problem. In this thesis, we therefore focus on not only executive dysfunctioning, but are interested whether aspects of motivation and time perception can be measured in children. 


\section{Measuring cognitive functions in children}

A neuropsychological assessment can be advised to examine potential cognitive and behavioral problems. As mentioned above, the aim of a neuropsychological assessment is to collect information, and interpret this information based on the brain-behavior model, which implies that the behavior of a child is made possible by the functioning of the brain (Swaab, 2011). A neuropsychological assessment therefore consists of measurement instruments on several behaviors, including cognitive functions, motivation, and/or time perception.

A neuropsychological assessment usually is preceded by an intelligence test. Wechsler described intelligence as "the aggregate or global capacity of the individual to act purposefully, to think rationally, and to deal effectively with the environment" (Wechsler, 1939, p.3). Without knowledge on the intelligence quotient (IQ) of the child, it is difficult to interpret other cognitive problems or problems in daily functioning (Geelhoed \& Moesker, 2011). In other words, does the child have problems in attention during a task, or is the task too difficult for the child in the first place? Does the child have problems in remembering instructions in class, or are the instructions too difficult?

The goal of the neuropsychological assessment is to gain information on specific cognitive domains and underlying cognitive functions that might exhibit problems. These cognitive functions are closely intertwined with each other. If it is difficult to sustain your attention during an instruction, it automatically could lead to problems in remembering the instruction. Vice versa, it is more difficult to sustain your attention during a task when the instructions are not remembered correctly. Based on the three aspects that can be differentiated in behavior, it is necessary to focus on cognition, emotionality (feelings and motivation) and time perception, to get a complete picture of the behavioral functioning of the child (Lezak et al., 2012).

Interestingly, neuropsychological assessments often only focus on the first pathway of the triple pathway model by Sonuga-Barke and colleagues (2010), or only the first aspect that Lezak and colleagues (2012) mention. This is surprising, since possible deficits in the other two pathways may be overlooked. It is important to identify deficits in the other two pathways of the triple pathway model as well, since problems in motivation may result in inattentive, overactive and impulsive behavior. Alternatively, deficits in time perception may result in planning problems. Assessment instruments on motivation and time perception are however scarce. For this purpose, two neuropsychological measurement instruments were developed by our team. The data on psychometric properties are reported in this thesis (Chapter 2 and 3).

The first is a computerized diagnostic tool, named Timo's Adventure, which assesses cognitive functions (such as working memory, planning, or inhibition) in combination with tasks on motivation and time perception. The second is a questionnaire, named the Children's Time Awareness Questionnaire (CTAQ), in which time perception can be assessed in children above the age of four. In this thesis, it will be examined whether clinical care could benefit from the development and use of such 
measurement instruments, by collecting information on potential strengths and weaknesses of the child.

\section{Treatment options for cognitive problems in children}

When cognitive problems are diagnosed, several treatment options can be advised. These might focus indirectly on the child (e.g., advising parents and teachers how to help the child), or the focus might be directly on the child (e.g., medication to reduce ADHD-symptoms). One form of treatment for the child is the use of computerized cognitive training programs. Of all the cognitive training studies to date, the vast majority focuses on improving working memory (Rapport, Orban, Kofler, \& Friedman, 2013). Working memory is the cognitive system responsible for storing, integrating and manipulation of information during complex and demanding activities (Baddeley, 2000; Baddeley \& Hitch, 1974). Consequently, working memory is believed to be one of the more fundamental cognitive functions. From working memory, higher order cognitive functions are built such as reasoning, problem solving abilities, and planning (Diamond, 2013; Klingberg et al., 2005). The effectiveness of these working memory training programs however is topic of debate. Previous review studies concluded that it is too early to draw conclusions on the effectiveness of the training programs. These reviews included a broad range of participants however, consisting of both adults and children, and healthy participants and participants with a broad range of disabilities. The reviews did not focus on one type of participants (Jaeggi, Buschkuehl, Jonides, \& Shah, 2011; Melby-Lervag \& Hulme, 2013; Shipstead, Redick, \& Engle, 2012). In this thesis we will examine whether there are benefits for children with learning disorders in following such a training program (Chapter 6). Possibly, children with learning disorders could benefit from working memory training programs, since learning disorders may arise from constraints in the working memory at the point of learning new skills (Gathercole, Alloway, Willis, \& Adams, 2006; St Clair-Thompson, Stevens, Hunt, \& Bolder, 2010).

\section{Aim and outline of this thesis}

The aim of this thesis is threefold. Firstly, based on the model by Sonuga-Barke and colleagues, we will examine whether it is possible to examine cognition, time perception, and motivation in children in a valid and reliable way. Secondly, we will examine the role of attention problems in children with neurological deficiencies. Finally, we will examine whether cognitive functions can be trained in children with learning disorders.

The outline of this thesis is as follows. Chapter 2, 3, and 4 focus on the assessment of cognitive functions (i.e., time perception, attention, motivation, and intelligence). For each assessment tool, the psychometric properties will be examined. For this purpose, 
we will examine normally developing children, as well as children who are at risk for cognitive or behavioral problems. Different ages will be examined.

Chapter 2 focusses on Timo's Adventure, a diagnostic computer game that was developed by our team in collaboration with the University of Technology in Eindhoven and which aims at measuring cognitive processes (e.g., attention, working memory, planning), motivation, and time perception in young children. The use of a computerized tool offers the possibility to enhance the motivation of the child by use of a context, storyline, and rewards. As a result the child does not perceive itself being tested. By using a computerized game, information on cognitive functions, motivation, and time perception can be easily collected, in a non-invasive way. The goal of this chapter is to examine the validity of this computerized diagnostic tool.

Chapter 3 examines the psychometric properties of the Children's Time Awareness Questionnaire (CTAQ). This questionnaire was developed by our team to assess time perception skills and deficits in children in an ecological valid way. To our knowledge, this is the first questionnaire on time perception that is suitable for children. Validity and reliability will be examined, and normative data will be provided.

Chapter 4 focusses on possible discrepancies in intelligence (significant better verbal capacities than performance capacities, or vice versa) as measured with the WISC-IIINL. The aim of this chapter is to examine to what extent children with a discrepancy in intelligence are at risk for emotional and behavioral problems.

Chapter 5 describes and studies an important clinical mechanism, diagnostic overshadowing, in our patient population. This pitfall in the diagnostic process was originally detected in studies of people with a mental retardation. We examine our data for diagnostic overshadowing and show that in dealing with children with a neurological condition this is an important diagnostic principle to take into consideration. In this chapter, we will examine how many children with neurological deficiencies also have an underlying attention problem.

In Chapter 6, we review the literature on the impact of working memory training programs on the capacity of the working memory. These working memory training programs are computerized training programs and the participants were trained daily for several weeks. A meta-analysis and systematic review will be executed to compare several studies on the efficacy of working memory training in children with learning or developmental problems.

Finally, in Chapter 7, the main findings are discussed. Chapter 8 provides a summary of the thesis, and a Dutch translation of the summary can be found in Chapter 9. 


\section{References}

American Psychiatric Association. (2013). Diagnostic and statistical manual of mental disorders (5th ed.). Washington, DC: Author.

Baddeley, A. (2000). The episodic buffer: a new component of working memory? Trends cogn sci, 4(11), 417-423. doi: 10.1016/S1364-6613(00)01538-2

Baddeley, A. D., \& Hitch, G. (1974). Working memory. In G. H. Bower (Ed.), The psychology of learning and motivation: Advances in research and theory (Vol. 8, pp. 47-89). New York: Academic press.

Block, R. A., Zakay, D., \& Hancock, P. A. (1999). Developmental changes in human duration judgments: a meta-analytic review. Dev Rev, 19, 183-211. doi: 10.1006/drev.1998.0475

Diamond, A. (2013). Executive functions. Annu rev psychol, 64, 135-168. doi: 10.1146/annurev-psych113011-143750

Dickstein, S. G., Bannon, K., Castellanos, F. X., \& Milham, M. P. (2006). The neural correlates of attention deficit hyperactivity disorder: an ALE meta-analysis. J child psychol psyc, 47(10), 1051-1062. doi: 10.1111/j.1469-7610.2006.01671.x

Friedman, W. J. (1978). Development of time concepts in children. In: H. W. Reese \& L. P. Lipsitt (Eds.), Advances in child development and behavior (Vol. 12, pp. 267-298). New York: Academic Press.

Friedman, W. J. (1989). The representation of temporal structure in children, adolescents and adults. In: I. Levin \& D. Zakay (Eds.), Time and human cognition: A life-span approach. Amsterdam: Elsevier Science Publishers B. V.

Friedman, W. J. (2003). The development of a differentiated sense of the past and the future. Adv Child Dev Behav, 31, 229-269.

Gathercole, S. E., Alloway, T. P., Willis, C., \& Adams, A. M. (2006). Working memory in children with reading disabilities. J exp child psychol, 93(3), 265-281. doi: 10.1016/j.jecp.2005.08.003

Geelhoed, J., \& Moesker, M. (2011). Intelligentie. In H. Swaab, A. Bouma, J. Hendriksen \& C. König (Eds.), Klinische kinderneuropsychologie. Amsterdam: Boom.

Gonzalez-Garrido, A. A., Gomez-Velazquez, F. R., Zarabozo, D., Lopez-Elizalde, R., Ontiveros, A., MaderaCarrillo, H., .. Tuya, J. M. (2008). Time reproduction disturbances in ADHD children: an ERP study. Int J Neurosci, 118(1), 119-135. doi: 10.1080/00207450601042177

Jaeggi, S. M., Buschkuehl, M., Jonides, J., \& Shah, P. (2011). Short- and long-term benefits of cognitive training. P Natl Acad Sci USA, 108(25), 10081-10086. doi: 10.1073/pnas.1103228108

Klingberg, T., Fernell, E., Olesen, P. J., Johnson, M., Gustafsson, P., Dahlstrom, K., . . Westerberg, H. (2005). Computerized training of working memory in children with ADHD- a randomized, controlled trial. $J$ Am Acad Child Adolesc Psychiatry, 44(2), 177-186. doi: 10.1097/00004583-200502000-00010

Krain, A. L., \& Castellanos, F. X. (2006). Brain development and ADHD. Clin Psychol Rev, 26(4), 433-444. doi: 10.1016/j.cpr.2006.01.005

Lenroot, R. K., \& Giedd, J. N. (2006). Brain development in children and adolescents: insights from anatomical magnetic resonance imaging. Neurosci Biobehav Rev, 30(6), 718-729. doi: 10.1016/j.neubiorev.2006.06.001

Lezak, M. D., Howieson, D. B., Bigler, E. D., \& Tranel, D. (2012). Neuropsychological Assessment (5th ed.). New York: Oxford University Press.

Martinussen, R., Hayden, J., Hogg-Johnson, S., \& Tannock, R. (2005). A meta-analysis of working memory impairments in children with attention-deficit/hyperactivity disorder. J Am Acad Child Adolesc Psychiatry, 44(4), 377-384. doi: 10.1097/01.chi.0000153228.72591.73

Melby-Lervag, M., \& Hulme, C. (2013). Is working memory training effective? A meta-analytic review. Dev psychol, 49(2), 270-291. doi: 10.1037/a0028228

Menkes, J. H., Sarnat, H. B., \& Maria, B. L. (2006). Child neurology (7th ed.). Philadelphia, PA: Lippincott, Williams, \& Wilkins.

Nigg, J. T., Blaskey, L. G., Huang-Pollock, C. L., \& Rappley, M. D. (2002). Neuropsychological executive functions and DSM-IV ADHD subtypes. J Am Acad Child Adolesc Psychiatry, 41(1), 59-66. doi: 10.1097/00004583-200201000-00012 
Polanczyk, G., de Lima, M. S., Horta, B. L., Biederman, J., \& Rohde, L. A. (2007). The worldwide prevalence of ADHD: a systematic review and metaregression analysis. Am J Psychiatry, 164(6), 942-948. doi: 10.1176/ajp.2007.164.6.942

Posner, M. I., \& Raichle, M. E. (1994). Images of mind. New York: Scientific American Library.

Rapport, M. D., Orban, S. A., Kofler, M. J., \& Friedman, L. M. (2013). Do programs designed to train working memory, other executive functions, and attention benefit children with ADHD? A meta-analytic review of cognitive, academic, and behavioral outcomes. Clin psychol rev, 33(8), 1237-1252. doi: 10.1016/j.cpr.2013.08.005

Shaffer, D. R., \& Kipp, K. (2013). Developmental psychology: childhood \& adolescence (9th ed.). Belmont, CA: Wadsworth.

Shipstead, Z., Redick, T. S., \& Engle, R. W. (2012). Is working memory training effective? Psychol bull, 138(4), 628-654. doi: 10.1037/a0027473

Sonuga-Barke, E., Bitsakou, P., \& Thompson, M. (2010). Beyond the dual pathway model: evidence for the dissociation of timing, inhibitory, and delay-related impairments in attention-deficit/hyperactivity disorder. J Am Acad Child Adolesc Psychiatry, 49(4), 345-355. doi:10.1016/j.jaac.2009.12.018

Spencer, T. J., Biederman, J., \& Mick, E. (2007). Attention-deficit/hyperactivity disorder: diagnosis, lifespan, comorbidities, and neurobiology. J Pediatr Psychol, 32(6), 631-642. doi: 10.1093/jpepsy/jsm005

St Clair-Thompson, H. L., Stevens, R., Hunt, A., \& Bolder, E. (2010). Improving children's working memory and classroom performance. Educ Psychol-UK, 30(2), 203-219. doi: 10.1080/01443410903509259

Swaab, H. (2011). Diagnostiek. In H. Swaab, A. Bouma, J. Hendriksen \& C. König (Eds.), Klinische kinderneuropsychologie. Amsterdam: The Netherlands: Boom.

Swaab, H., Bouma, A., Hendriksen, J., \& König, C. (2016). Klinische Kinderneuropsychologie. Amsterdam: Boom.

Swanson, J. M., Sergeant, J. A., Taylor, E., Sonuga-Barke, E. J., Jensen, P. S., \& Cantwell, D. P. (1998). Attention-deficit hyperactivity disorder and hyperkinetic disorder. Lancet, 351(9100), 429-433. doi: 10.1016/S0140-6736(97)11450-7

Wechsler, D. (1939). The measurement of adult intelligence. Baltimore, MD: Williams \& Wilkins. 


\section{Chapter 2}

A study on the validity of a computer-based game to assess cognitive processes, reward mechanisms, and time perception in children aged $4-8$ years

JCAW Peijnenborgh, PPM Hurks, AP Aldenkamp, ED van der Spek, GWM Rauterberg, JSH Vles \& JGM Hendriksen JMIR Serious Games 2016; Sep 22;4(2):e15 


\section{Abstract}

\section{Background}

An interactive computer game, named Timo's Adventure, was developed to assess specific cognitive functions (e.g., attention, planning, and working memory), time perception, and reward mechanisms in young school age children. The game consists of six interactive minigames, embedded in a storyline and including fairytale figures to enhance motivation.

\section{Objective}

Aim of the current study was to investigate the validity of Timo's Adventure in normally developing children, and in children with ADHD.

\section{Method}

A total of 96 normally developing children aged 4-8 years and 40 children with ADHD were investigated with the game. Clinical validity was investigated by examining the effects of age on performances within the normally developing children, as well as performance differences between the healthy controls and the ADHD-group.

\section{Results}

Our analysis in the normally developing children showed developmental effects; i.e., older children made lesser inhibition mistakes $(r=-.33, p=.001)$, had faster (and therefore better) reaction times $(r=-.49, p<.001)$ and were able to produce time intervals more accurately than younger children $\left(r_{s}=.35, p<.001\right)$. Discriminant analysis showed that Timo's Adventure was accurate in the majority of the classifications whether a child belonged to the ADHD-group or the normally developing group: $78 \%$ of the children were correctly classified as having ADHD or as being in the normally developing group. The classification results showed that $72 \%$ children in the control group were correctly classified, and $88 \%$ of the children in the ADHD-group were correctly classified as having ADHD. Sensitivity of Timo's Adventure was satisfying (0.89), as well as specificity (0.69).

\section{Conclusion}

Interactive computer games seem to be a valid tool to assess specific strengths and weaknesses in young children with ADHD. 


\section{Introduction}

Assessment of children's cognitive strengths and weaknesses is an important focus of clinical child neuropsychological research and clinical care worldwide (Swaab, Bouma, Hendriksen, \& König, 2016). Cognitive abilities are quantified traditionally, by use of e.g., paper and pencil performance tests, and more recently with computer assisted tools (Assef, Capovilla, \& Capovilla, 2007; Messina, Tiedemann, de Andrade, \& Primi, 2006). Performances on traditional cognitive tests are believed to be influenced significantly by non-cognitive functions, such as motivation and perseverance (Luciana \& Nelson, 2002). Therefore, a lower score on for instance a working memory test might indicate a memory problem but also e.g., a decreased motivation. This overall performance score therefore only limitedly reflects the underlying 'cause' in case of a decreased performance, which makes this score difficult to interpret. In order to test one's cognitive abilities more purely, it would be preferable (1) to optimize motivation in the test situation and (2) to assess motivation in a separate test additionally - unfortunately, tests measuring motivation in children are relatively scarcely used in the clinics.

Based on literature, it is known that introducing immediate (versus delayed) rewards and the adaptation of item difficulty levels to the child's abilities are likely to increase motivation in children and helps the child to stay focused on the tasks that $\mathrm{s} /$ he needs to do (Bioulac, Arfi, \& Bouvard, 2008). Also, introducing a context (e.g., by introducing cognitive tests in the context of a story) may increase motivation, although data on the effects of including a storyline on motivation or engagement in games is so far inconclusive (Wouters, Van Nimwegen, Van Oostendorp, \& Van der Spek, 2013). The introduction of a storyline improves the child's feeling of being part of a gaming environment (Gorini, Capideville, De Leo, Mantovani, \& Riva, 2011). In addition, the use of intrinsic fantasy elements has been found to improve motivation to conduct a specific task (Habgood \& Ainsworth, 2011; Van der Spek, Sidorenkova, Porskamp, \& Rauterberg, 2014).

The above-mentioned increase in popularity of computer assisted assessment tools is partly caused by the fact that it is relatively easy to implement these immediate rewards, to adapt difficulty levels, to implement a story, and to use intrinsic fantasy elements. This leads to a situation in which the child does not have the feeling of doing an assessment, but instead thinks that $\mathrm{s} /$ he is playing a game (Gongsook et al., 2014). This is especially important in tests that are designed for children, since it is known that children can behave differently when they know they are being studied (also known as the Hawthorne effect [McCarney, et al., 2007]). For this purpose, we developed Timo's Adventure, an interactive computer game that consists of six minigames. These mini-games aim to assess different cognitive processes, e.g., attention, planning, and working memory, delay aversion - as a measure of motivation -, and time perception (see below). The aim of the present study was to examine the validity of Timo's Adventure in assessing strengths and weaknesses in the above-mentioned 
domains of young children, aged four to eight years. Proof of validity was sought by studying group differences in performance on the mini-games. Two types of relevant group comparisons were made. First, the age of the child is believed to be a relevant variable and was therefore studied in relation to performances on the mini-games: we expected younger children ( $<6$ years) to perform less well than older children on all mini- games (in line with studies on e.g., cognitive development [Diamond, 2006] and time perception [Friedman \& Lyon, 2005; Pouthas \& Jacquet, 1987]). For this purpose, age relating differences in a group of normally developing children $(N=96)$ was examined.

Next, the scores on the mini-games of normally developing children were compared to those of children with Attention-Deficit/Hyperactivity Disorder (ADHD, N=40). ADHD is a developmental disorder which is associated with academic difficulties and social disadvantage (Swanson et al., 1998). According to the DSM-5 (American Psychiatric Association, 2013) two main areas of impairment in children with ADHD exist: inattention (e.g., difficulty in maintaining attention during a task or problems in dividing attention) and hyperactivity and impulsive behavior (e.g., acting out before thinking about the consequences). Previous research has found for one that cognitive difficulties, and more specifically in the domain of working memory and attention, occur in children with ADHD (Gonzalez-Garrido et al., 2008). However, according to the triple pathway model of Sonuga-Barke, Bitsakou, and Thompson (2010), not all children with ADHD have cognitive weaknesses. In this model three distinct patterns of ADHD deficits are distinguished. The first pathway is related to cognitive functions, and is called the inhibitory based executive dysfunctioning. This pathway views ADHD as a disorder of dysregulation of thought and action associated with diminished inhibitory control (i.e., executive functions). In the second pathway, ADHD is explained as a motivational style associated with fundamental alterations in reward mechanisms. Children with ADHD are assumed to prefer small immediate rewards over large delayed rewards, which results in inattentive, overactive and impulsive behaviors (Barkley, 1997). The third pathway states that deficits in time perception are another component of ADHD, for instance deficits in distinguishing two time intervals, producing time intervals and estimating time. Indeed, time perception deficits have been reported for children with ADHD (Hurks \& Hendriksen, 2011), however, the results are not consistent, i.e., some authors report no ADHD related deficits (Bauermeister et al., 2005). All three pathways are believed to have their own neural substrate (Sonuga-Barke et al., 2010). Sonuga-Barke and colleagues (2010) found in children with ADHD between 6 to 17 years that delay aversion, poor executive functions and poor time perception are core, but unrelated and independent characteristics of ADHD. A person with ADHD can have deficits in one of the pathways, or a combination of pathways. Neuropsychological measurements (which are used to examine possible deficits on one of the pathways), usually focus primarily on just one of the pathways, while one can conclude from Sonuga-Barke's model that it is necessary to gain information on possible deficits in all three 
pathways. Sonuga-Barke and colleagues used several distinctive computerized tasks to collect information about the three pathways. These were however not connected in a fantasy gaming environment or by a storyline. In our game, a storyline was included, in order to immerse the player in an intrinsic fantasy, and possibly improve the reliability of the diagnosis. To our knowledge no computerized diagnostic tools exist in which all three pathways are included in combination with all motivationenhancing elements discussed above (including a story line or fantasy game elements), although some training tools with a storyline exist (for instance Braingame Brian [Prins et al., 2010]). In Timo's Adventures storyline, distracting factors are included to measure real life distraction. Previous research found that distractors in a computerized continuous performance test resulted in more distractibility in children with ADHD than in their healthy peers (Cassuto, Ben-Simon, \& Berger, 2013).

In sum, the aim of the current study is to investigate the clinical validity of Timo's Adventure.

\section{Method}

\section{Participants}

\section{Normally developing children}

Parents of all children enrolled in the first four grades of four Dutch elementary schools were informed by a letter about the study. Informed consents of 102 children were acquired. Four children were excluded because they were not native speakers and instructions in Timo's Adventure were in the Dutch language. Two children were excluded because they had a DSM-5 diagnosis. The final dataset consisted of 96 children (43 boys), ranging from four to eight years. An overview of characteristics for this group can be found in Table 2.1.

All children were tested individually in a private room at their school. Approval for testing this sample was given by the Ethical Committee of the Faculty of Psychology and Neuroscience of Maastricht University, The Netherlands.

\section{Children with $A D H D$}

Parents of patients of the outpatient clinic Center for Neurological Learning Disabilities were asked to participate in this study by their medical specialist. In parallel, parents of children enrolled in a special needs program for children with behavioral problems were informed by a letter about the study and asked to participate, via the children's school. Informed consents of 62 children with a diagnosis of ADHD were acquired. 22 Children did not meet the inclusion criteria, because they had a comorbid DSM-5 diagnosis $(N=4)$, used medication for attentional problems and hyperactive behavior (stimulants, atomoxetine, tricyclic antidepressants 
or clonidine; $N=6)$, or a combination of these exclusion criteria $(N=12)$. The final dataset of the ADHD-group consisted of 40 children (30 boys), all with a diagnosis of Attention-Deficit/Hyperactivity Disorder (ADHD) according to DSM-5. These diagnoses were made on the basis of a protocol formulated by Goldman, Genel, Bezman, and Slanetz (1998) which includes 1) extensive history taking, 2) cognitive testing, 3) general physical and neurological examination of the child and 4) systematic assessment of ADHD-characteristics by means of structured questions based on the most recent version of the DSM (American Psychiatric Association, 2013). Age range of the clinical sample was six to eight years. An overview of characteristics for the ADHD-group can be found in Table 2.1.

Children enrolled in the special needs program for children with behavioral problems were tested individually in a private room at their school. The children who were patients of the Center of Neurological Learning Disabilities were seen for neuropsychological testing as part of clinical care.

Approval for testing this sample was given by the Medical Ethical Board of Kempenhaeghe.

Table 2.1 Characteristics for all participants.

\begin{tabular}{lcc}
\hline & Typically developing children & ADHD-group \\
\hline$N$ & 96 & 40 \\
Boys/Girls & $43 / 53$ & $30 / 10$ \\
Age range & $4-8$ & $6-8$ \\
Mean age (SD) & $5.85(1.33)$ & $6.90(0.74)$ \\
Verbal IQ (WPPSI-III-NL Vocabulary) (SD) & $94.74(10.79)$ & $87.92(13.05)$ \\
\hline
\end{tabular}

Note: $N$ = number of participants; SD = Standard deviation; WPPSI-III-NL = Dutch version of the Wechsler Preschool and Primary Scale of Intelligence.

\section{Materials}

\section{Computer game Timo's Adventure}

Timo's Adventure is a single player game. All tasks are embedded in a storyline: The main character in Timo's Adventure is Timo, a friendly alien whose rocket has run out of fuel (Sallustro, 2013). He asks the child to go on an adventure together, to collect stars which can be used as fuel. To complete all tasks takes approximately 20 minutes. The game is categorized as a serious game; a game designed for specific purposes beyond entertainment (Bellotti, Berta, \& De Gloria, 2010). The game has a first person view, to stimulate the feeling of presence; to make the child feel like it is inside the game world.

Development of the game was divided over three stages: design, implementation, and evaluation, as based on the iterative software cyclic model and the spiral model (Boehm, 1998; Rauterberg, 1992; Rauterberg, Strohm, \& Kirsch, 1995). Besides the designers of the University of Technology in Eindhoven, users were invited in the 
design proces. Users in this case were children (who helped us by explaining what they would like and by making drawings) and psychologists from Kempenhaeghe (who participated towards the functionalities of the game, the visual graphics, and storyline that needed to match the age of the children). In the implementation phase, the functionalities of the game were created (by engineers of the University of Technology in close collaboration with the psychologists from Kempenhaeghe). During the evaluation phase (consisting of a user test with a paper prototype technique, and an interactive prototype), the game was played and evaluated by children, and psychologists who were not part of the development team. This feedback was used to improve the game, and remove small bugs (Gongsook, 2015).

The computer game consists of six different tasks (i.e., six mini-games) which each measure different neurocognitive functions and thus give information about possible deficits. The six tasks measure aspects of executive functions, time perception and reward mechanisms, to represent the three pathways of Sonuga-Barke's model. All tasks were developed due to the need to measure the specific function, and modeled after the theoretic background of the triple pathway model.

\section{- Pathway 1: Executive Functions}

All irrelevant mouse clicks are being measured, and thus give information on impulsivity and hyperactive behavior of the child. Furthermore, the following minigames are included to assess impairments in this pathway:

Mini-game Dressing up - Planning: The first task is set in the bedroom of the child. Timo tells the child that $s /$ he needs to get dressed before the adventure can start. Several garments are spread through the room, which can be selected by clicking them (see Figure 2.1). After clicking, the garment moves towards the reflection of the child in the mirror and the child is getting dressed. This task gives information on the planning and organization skills of the child. The order in which the child selects clothes is measured, to see whether the child is capable of planning its actions in the right order. The child can get a total score of two points: one for being completely dressed and one for using an executable and correct manner.

Mini-game Sandwich - Working memory: The second task is set in the kitchen (see Figure 2.2). Timo tells the child that something to eat is necessary before starting the adventure, and he shows the child pictures of the ingredients. The child needs to remember these ingredients and select them in the same order as presented by Timo. The first sandwich starts with two ingredients, adding up to five ingredients in the last sandwich. This task is a measurement for the capacity of the visual working memory. According to Craeynest (2010) the capacity of the working memory develops from remembering two targets when the child is 2.5 years, to 3 targets when it is 3 years old and 5 targets when the child is 7 years old. Martinussen, Hayden, HoggJohnson, and Tannock (2005) found that the capacity of the working memory in children with ADHD is markedly lower. In this task, the child can get a total score of 5 points: one for each correct sandwich. 


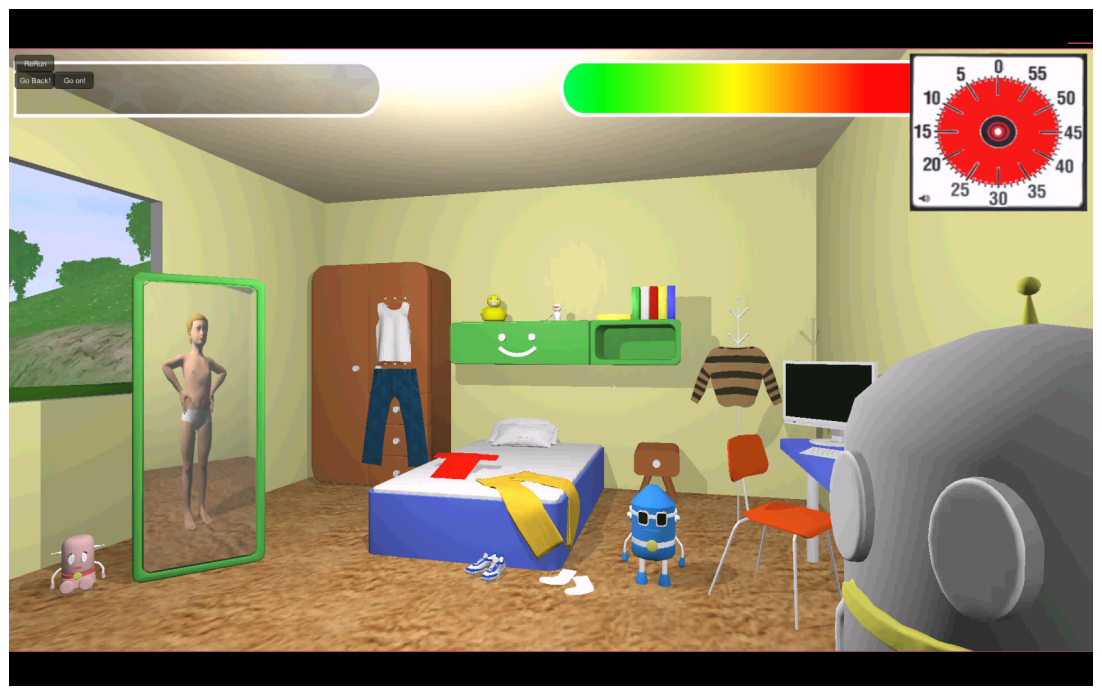

Figure 2.1 Screenshot mini-game Dressing up (Planning).

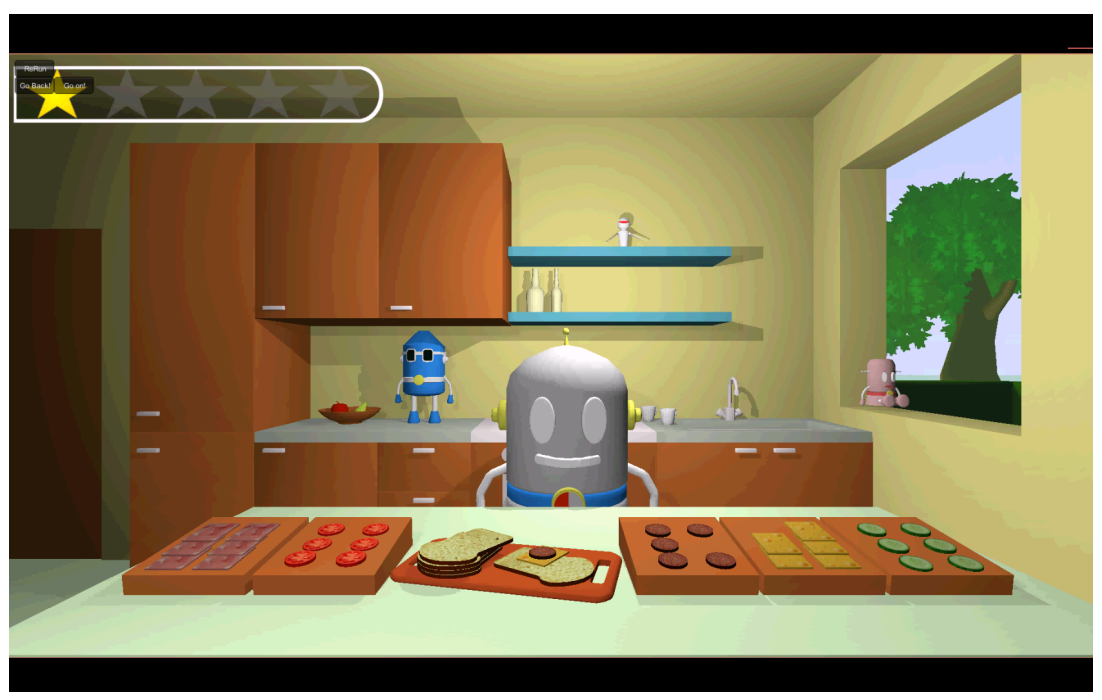

Figure 2.2 Screenshot mini-game Sandwich (Working memory).

Mini-game Monkey - Inhibition: In this task, a monkey has thrown banana peels on the road (see Figure 2.3). To cross the road, the child needs to swipe the banana peels and clear the road. However, if the monkey sees the child swiping banana peels, it will undo its actions. The monkey is playing hide and seek, and appears suddenly. The child needs to wait for the moment that the monkey has 
disappeared. This is a go/no-go task which gives information on the response inhibition of the child: is the child capable of inhibiting its response until the monkey is hidden? Children with ADHD have deficits in this response inhibition and they can be inclined to react impulsive (Barkley, 1997). Number of failures (i.e., when the monkey sees the action of the child) is the outcome variable of this task; the higher this score, the worse the inhibition skills.

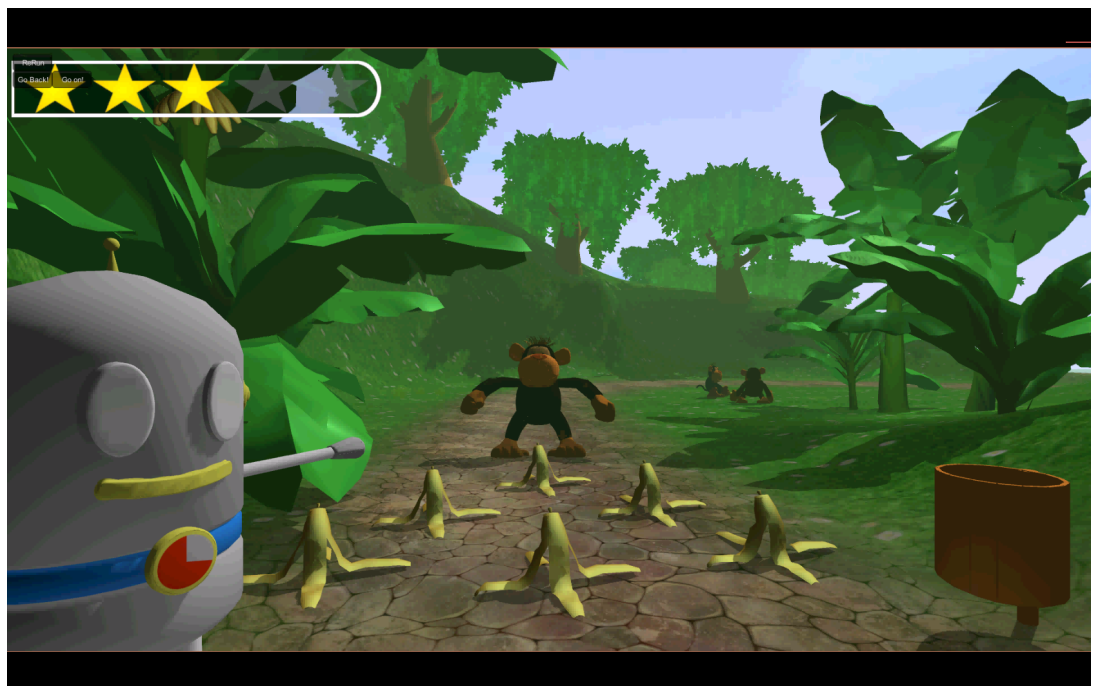

Figure 2.3 Screenshot mini-game Monkey (Inhibition).

Mini-game Magic Land - Simple reaction time: In the magic land, stars will shoot upwards from magic holes (see Figure 2.4). The child needs to collect these stars. If the child does not react within two seconds, the stars will disappear. The task ends after 50 stars. Outcome variables in this task are the number of collected stars (with a maximum of 50) and average reaction time for collected stars. Slower and more variable reaction times have been found to be a characteristic of ADHD (Gooch, Snowling, \& Hulme, 2012).

\section{- Pathway 2: Reward Mechanisms}

Mini-game Rocket - Delay aversion: In this task (see Figure 2.5), the child gets a choice between an immediate, but small reward (ending of the task) or a delayed, but bigger reward (a flight in the rocket, after two minutes of waiting). The child can end the task at any moment. Impulsive behavior occurs when responding produces more immediate, relatively smaller rewards at the cost of delayed, larger rewards (Grey, Healy, Leader, \& Hayes, 2009). Outcome variables are whether the child chooses a small or big reward and how long (in seconds) the child waited. 


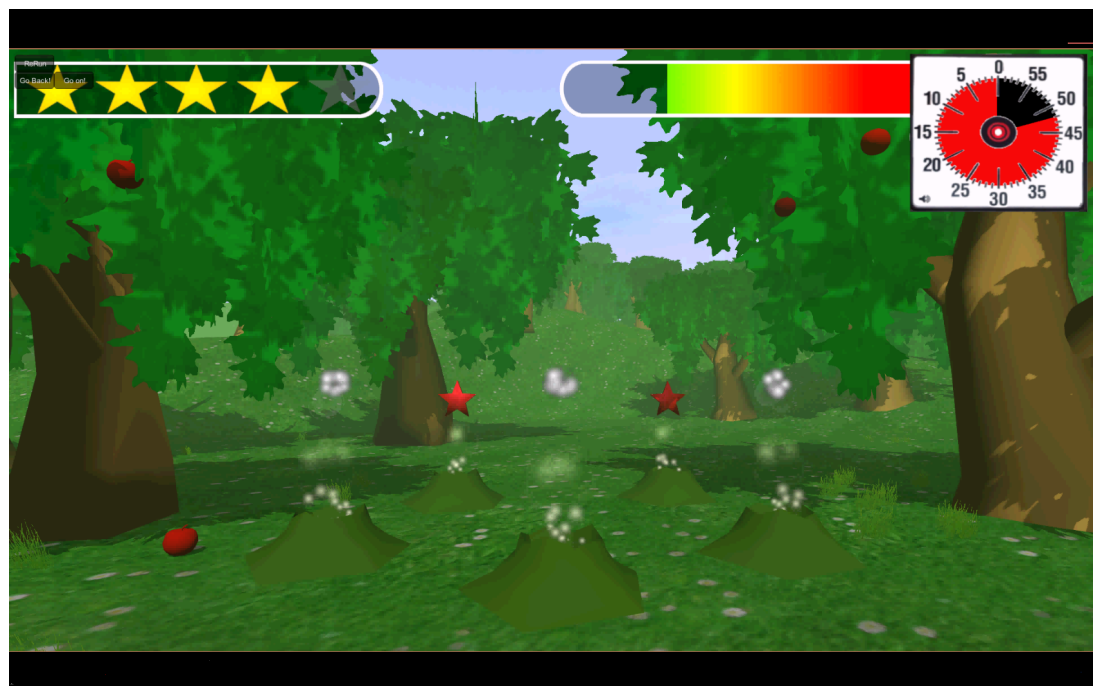

Figure 2.4 Screenshot mini-game Magic Land (Simple reaction time).

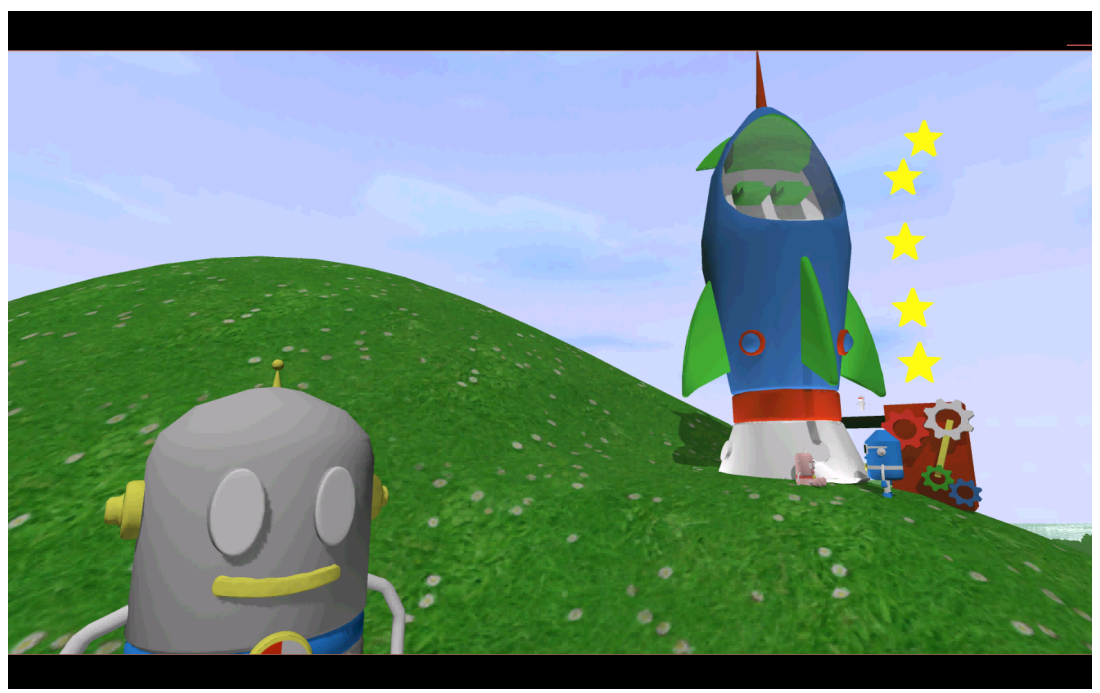

Figure 2.5 Screenshot mini-game Rocket (Reward mechanisms).

- Pathway 3: Time perception.

Mini-game Balloon - Time production: This task is set at a river with a broken bridge (see Figure 2.6). To cross the river, the child needs to inflate a balloon with the balloon machine, by producing a time interval of ten seconds. A produced interval between 9 and 11 seconds results in a perfect balloon. When the produced interval is 
smaller than 9 seconds the balloon falls into the water, and a produced interval larger than 11 seconds results in a balloon that flies away. The child can make a maximum of three perfect balloons, or the task will end after three minutes with a perfect balloon (in spite of what the interval was). Barkley, Koplowitz, Anderson, and McMurray (1997) suggested that the estimation of temporal intervals are deviant in children with ADHD. The number of correct balloons is an outcome variable. Furthermore, the average production interval for the first three balloons is measured by subtracting ten seconds of each of the first three balloons, transforming these scores to absolute scores, count these scores and then divide them by three. The higher this score, the less precise the mean produced intervals are.

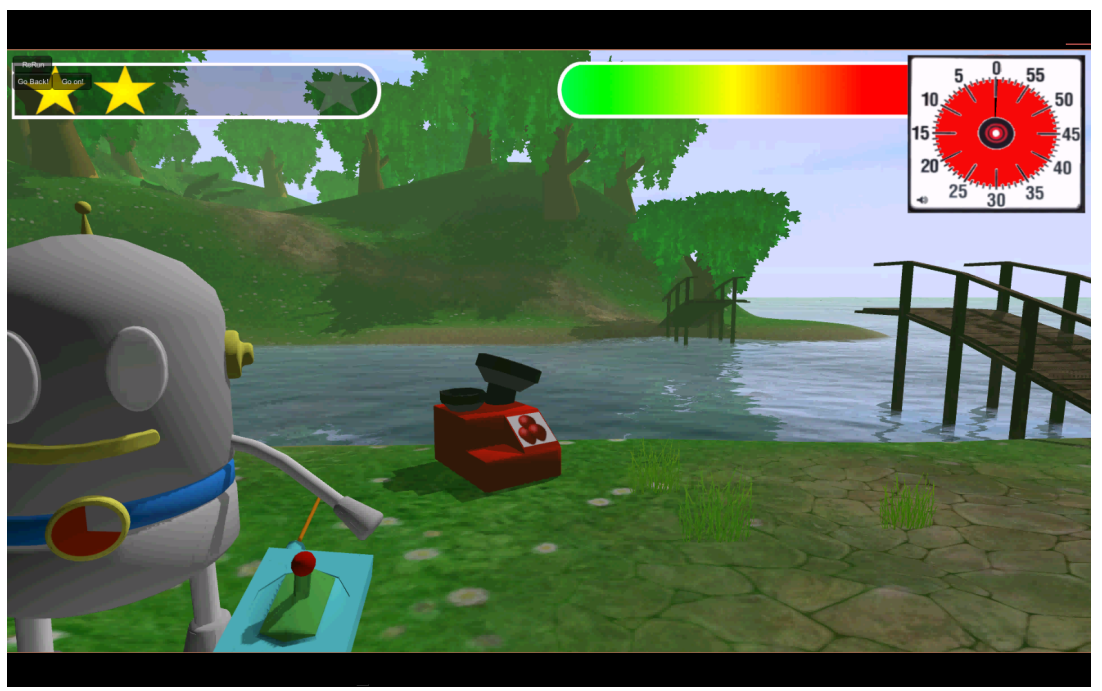

Figure 2.6 Screenshot mini-game Balloon (Time perception).

\section{Vocabulary}

This subscale of the Dutch version of the Wechsler Preschool and Primary Scale of Intelligence (WPPSI-III-NL [Wechsler, 2010]) was used to estimate verbal intelligence (Alloway, 2012). In this task, the child was asked to give definitions of words, such as 'umbrella' or 'shoe'. The total score can be transformed to IQ-scores, with 100 as the mean $(S D=15)$.

\section{Statistics}

Data were analyzed with IBM SPSS statistics version 21.0.0.0. All outliers (scores with z >3.29) within the concerned group (i.e., normally developing children, and the ADHD- 
group) were replaced by the mean + three times standard deviation as advised by Field (2012). Means and standard deviations of all variables were measured.

Potential age related differences on Timo's Adventure within the sample of normally developing children were examined by conducting Pearson correlations (for scale outcome measurements; e.g., number of irrelevant mouse clicks, time used to complete the task, etc.) and Spearman correlations (for the ordinal outcome measurements; e.g., correct/incorrect, did the child choose the large or small reward, etc.). Age was used as a continuous variable in these analyzes.

Secondly, a discriminant analysis was performed, to investigate to which level the variables of the game can discriminate whether a child belongs to the ADHD-group or the normally developing children. Sensitivity and specificity were measured. All children $<6$ years of age in the sample of normally developing children were excluded from these analyzes, in order to match with the age of the children in the ADHDgroup, resulting in a control group of 57 children. An independent samples $t$-test revealed that children in the ADHD-group and children in the normally developing group were equal in terms of Vocabulary scores (ADHD-group: $M=87.92, S D=13.05$; Control group: $M=94.74, S D=10.79 ; t(67)=1.92, p=.11)$, therefore it was not necessary to correct for IQ in further analyzes.

Finally, it was analyzed on which variables children with ADHD scored significantly different from normally developing children. Again, all children $<6$ years of age in the sample of normally developing children were excluded from these analyzes, in order to match with the age of the children in the ADHD-group. Three types of analyzes were used: For the continuous variables, General Linear Model (GLM) univariate analyzes were used. In four variables, the assumption of homogeneity in variances was violated, therefore nonparametric $t$-tests (Mann-Whitney) were used in these variables. In the categorical variables, Pearson's Chi-square analyzes were performed.

\section{Results}

\section{Descriptive statistics of all variables}

Means and standard deviations for all variables of both groups are reported together with the analyzes of group differences. All reported results are after correction for outliers.

\section{Developmental effects}

An overview of all correlation analyzes between age and variables of Timo's Adventure can be found in Table 2.2. 
Table 2.2 Correlations between results on Timo's Adventure and age for normally developing children $(N=96)$.

\begin{tabular}{lcc}
\hline & Age & $P$ \\
\hline Pathway 1 Executive Functions & & .46 \\
Dressing up total score & $r_{\mathrm{s}}=-.08$ & .66 \\
Dressing up clicks & $r=-.05$ & .05 \\
Sandwich total score & $r_{\mathrm{s}}=.21$ & .71 \\
Sandwich clicks & $r=.09$ & .18 \\
Balloon clicks & $r=.14$ & .00 \\
Monkey failures & $r=-.33$ & .45 \\
Monkey clicks & $r=.08$ & .00 \\
Magic land number of collected stars & $r=.60$ & .00 \\
Magic Land average time for collected stars & $r=-.49$ & .14 \\
Magic Land clicks & $r=.16$ & .65 \\
Pathway 2 Reward Mechanisms & & .50 \\
Rocket reward & $r_{\mathrm{s}}=.05$ & \\
Rocket time waited & $r=.07$ & .00 \\
Pathway 3 Time perception & & .01 \\
Balloon correct & $r_{\mathrm{s}}=.35$ & $r=-.25$ \\
Balloon average time for attempts & $r$ & \\
\hline
\end{tabular}

Note: $N$ = number of children; $p=$ significance; $r=$ Pearson's correlation; $r_{s}=$ Spearman's correlation.

Pathway 1 Executive Functions.

Pearson correlation analyzes with age as a continuous variable showed significant correlations on two tasks: in the inhibition task (Monkey), older children had significantly lesser inhibition failures $(r=-.33, p=.001)$; and in the reaction time task (Magic Land), older children collected significantly more stars $(r=.60, p<.001)$ and were faster in collecting these stars $(r=-.49, p<.001)$.

Pathway 2 Reward mechanisms.

No significant correlations were found in this pathway, indicating that age does not influence reward mechanisms.

Pathway 3 Time perception.

In the time production task (Balloon), older children produced significantly more correct balloons $\left(r_{\mathrm{s}}=.35, p<.001\right)$ and had more precise time productions than younger children $(r=-.25, p=.01)$.

\section{Differences between children with ADHD and healthy controls}

\section{Discriminant analysis}

All variables were included in a discriminant analysis, to investigate whether Timo's Adventure can discriminate the groups into children with ADHD and the healthy 
controls. A significant differentiation between the groups was found: Wilk's $\Lambda=.51$, $\chi^{2}(14)=50.76, p<.001$. The structure matrix (see Table 2.3 ) revealed that especially the number of mouse clicks in several tasks, and the mini-game on reaction time (Magic Land), inhibition (Monkey), and planning (Dressing up) were potential predictors. The classification results showed that $72 \%(N=41)$ children in the control group were correctly classified, and $88 \%$ of the children in the ADHD-group were correctly classified as having ADHD ( $N=35)$. Overall $78 \%$ of the children were correctly classified as being in the ADHD-group or in the control group. Sensitivity of Timo's Adventure was 0.89 , and specificity was 0.69 .

Table 2.3 Structure Matrix in Discriminant Analysis.

\begin{tabular}{lc}
\hline & $\begin{array}{c}\text { Pooled within-groups correlations } \\
\text { between discriminating variables } \\
\text { and standardized canonical } \\
\text { discriminant functions }\end{array}$ \\
\hline Magic Land number of clicks & -.82 \\
Magic Land number of collected stars & .40 \\
Balloon number of clicks & .34 \\
Monkey number of failures & .31 \\
Dressing up total score & .29 \\
Rocket time waited & -.27 \\
Balloon number of correct balloons & -.18 \\
Sandwich total score & .17 \\
Sandwich number of clicks & .14 \\
Magic Land average reaction time for collected stars & .11 \\
Rocket small (=0) or large (=1) reward & -.10 \\
Monkey number of clicks & .09 \\
Balloon average time used to produce balloons & -.02 \\
Dressing up number of clicks & .01 \\
\hline
\end{tabular}

\section{Group differences on individual variables}

Since the combination of all variables was useful in discriminating between ADHD and normally developing children, it was examined on which specific variables children with ADHD had a different result than normally developing children. All significant differences between children with ADHD and healthy controls will be reported.

\section{Pathway 1 Executive functions}

Results of this pathway can be found in Table 2.4. There was a significant association between the group (ADHD or control) and the score on the Dressing up task (Planning; $\left.\chi^{2}(2)=11.41, p=.003, V=0.35\right)$, indicating that typically developing children had better scores than children with ADHD on a planning task. In the Magic Land (Simple reaction time), children with ADHD used more mouse clicks in collecting stars than children in the control group $(U=389.50, p<.001, r=-0.55)$. 
Table 2.4 Results on Timo's Adventure age for normally developing children in the control group $(N=56)$ and children in the ADHD-group $(N=40)$ on Pathway 1 Executive Functions.

\begin{tabular}{|c|c|c|c|c|c|c|}
\hline \multicolumn{2}{|l|}{ Variable } & Mean & SD & Statistic & $p$ & Effect size \\
\hline \multirow[t]{2}{*}{ Dressing up total score (0-2) } & Controls & 1.18 & 0.56 & $\chi^{2}=11.41$ & .00 & $V=0.35$ \\
\hline & ADHD & 0.93 & 0.81 & & & \\
\hline \multirow{2}{*}{$\begin{array}{l}\text { Dressing up number of clicks (minimum for a } \\
\text { satisfying result is } 4 \text { clicks) }\end{array}$} & Controls & 17.59 & 14.32 & $U=895.00$ & .09 & $r=-0.17$ \\
\hline & ADHD & 26.14 & 22.61 & & & \\
\hline \multirow[t]{2}{*}{ Sandwich total score $(0-5)$} & Controls & 0.89 & 1.10 & $F=0.47$ & .50 & $\eta_{p}{ }^{2}=0.01$ \\
\hline & ADHD & 1.05 & 0.97 & & & \\
\hline Sandwich number of clicks & Controls & 87.49 & 51.12 & $U=823.00$ & .25 & $r=-0.12$ \\
\hline (minimum for 5 correct sandwiches is 22 clicks) & ADHD & 92.57 & 53.48 & & & \\
\hline Balloon number of clicks & Controls & 108.52 & 93.91 & $U=945.50$ & .24 & $r=-0.12$ \\
\hline (minimum for three correct balloons is 6 ) & ADHD & 206.87 & 227.87 & & & \\
\hline Monkey number of failures & Controls & 0.77 & 1.33 & $F=2.97$ & .09 & $\eta_{p}^{2}=0.03$ \\
\hline (minimum is 0 ) & ADHD & 1.26 & 1.48 & & & \\
\hline Monkey number of clicks & Controls & 29.72 & 2.20 & $F=0.82$ & .37 & $\eta_{p}^{2}=0.01$ \\
\hline (minimum to complete the task is 6 ) & ADHD & 33.83 & 1.62 & & & \\
\hline Magic Land number of collected stars & Controls & 37.61 & 10.87 & $F=2.92$ & .09 & $\eta_{p}^{2}=0.03$ \\
\hline (maximum is 50 ) & ADHD & 41.41 & 8.33 & & & \\
\hline Magic Land average reaction time for collected & Controls & 2.25 & 0.55 & $F=0.02$ & .88 & $\eta_{p}^{2}=0.00$ \\
\hline Stars & ADHD & 2.22 & 0.48 & & & \\
\hline \multirow[t]{2}{*}{ Magic Land number of clicks } & Controls & 76.27 & 19.52 & $U=389.50$ & .00 & $r=-0.55$ \\
\hline & $A D H D$ & 155.65 & 89.68 & & & \\
\hline
\end{tabular}

Note: $\mathrm{ADHD}=$ Attention-Deficit/Hyperactivity Disorder; $\chi 2=$ Chi-square test; $\eta_{\mathrm{p} 2}=$ partial variance explained; $F=F$-test; $N=$ number of children; $p=$ significance; $r=$ Pearson's correlations coefficient; SD = Standard deviation; $U=$ Mann-Whitney test; $V=$ Cramer's V.

\section{Pathway 2 Reward mechanisms}

Results of this pathway can be found in Table 2.5. In the Rocket task, a significant association between the group (ADHD or control) and whether or not a child chose the delayed reward was found $\left(\chi^{2}(1)=7.32, p=.01, V=0.28\right)$. Also, the total time that the child waited before $s /$ he ended the task was significantly different: Children in the control group were able to wait longer for the delayed reward than the children in the ADHD-group $\left(F(1,92)=5.52, p=.02, \eta_{p}^{2}=0.06\right)$.

Table 2.5 Results on Timo's Adventure age for normally developing children in the control group $(N=56)$ and children in the ADHD-group ( $N=40)$ on Pathway 2 Reward Mechanisms.

\begin{tabular}{llrrrrl}
\hline Variable & & Mean & SD & Statistic & $p$ & Effect size \\
\hline Rocket small (=0) or large (=1) & Controls & 0.55 & 0.50 & \multirow{2}{*}{$\chi^{2}=7.32$} & .01 & $V=0.28$ \\
reward & ADHD & 0.28 & 0.46 & & & \\
Rocket time waited (minimum is 0 & Controls & 80.98 & 50.05 & $F=5.52$ & .02 & $\eta_{p}^{2}=0.06$ \\
\hline
\end{tabular}

Note: $\mathrm{ADHD}=$ Attention-Deficit/Hyperactivity Disorder; $\chi^{2}=$ Chi-square test; $\eta \mathrm{p}^{2}=$ partial variance explained; $F=F$-test; $N=$ number of children; $p=$ significance; $r=$ Pearson's correlations coefficient; SD = Standard deviation; $V=$ Cramer's $V$. 


\section{Pathway 3 Time perception}

Results of this pathway can be found in Table 2.6. No significant differences between children with ADHD and normally developing children were found on the time production task.

Table 2.6 Results on Timo's Adventure age for normally developing children in the control group $(N=56)$ and children in the ADHD-group ( $N=40)$ on Pathway 3 Time perception.

\begin{tabular}{lllllll}
\hline Variable & & Mean & SD & Statistic & $p$ & Effect size \\
\hline Balloon number of correct balloons & Controls & 2.25 & 1.09 & \multirow{2}{*}{$F=0.07$} & .80 & $\eta_{p}{ }^{2}=0.00$ \\
(minimum is 0, maximum is 3) & ADHD & 2.21 & 1.06 & & & \\
Balloon average time used to & Controls & 4.33 & 4.05 & \multirow{2}{*}{$F=1.69$} & .20 & $\eta_{p}{ }^{2}=0.02$ \\
produce balloons & ADHD & 3.38 & 2.01 & & \\
\hline
\end{tabular}

Note: $\mathrm{ADHD}=$ Attention-Deficit/Hyperactivity Disorder; $\eta \mathrm{p}^{2}=$ partial variance explained; $\mathrm{F}=\mathrm{F}$-test; $N=$ number of children; $p=$ significance; $\mathrm{SD}=$ Standard deviation.

\section{Discussion}

Recently, the development and use of computerized tasks in measuring e.g., neurocognitive abilities is increasing and results in promising effects in the field of interventions. For instance, children with ADHD benefit from game-based training tools on executive functions such as Braingame Brian and CogMed, as was reported in a review study by Peijnenborgh, Hurks, Aldenkamp, Vles, and Hendriksen (2016). An important element of these training tools is believed to be the use of fantasy, a storyline, adaptation of the degree of difficulty, and the use of immediate rewards. However, most studies focus on training tools, while in the current research a diagnostic tool is being studied. This computerized diagnostic tool, named Timo's Adventure, was developed for young children (between four and eight years old) to investigate the presence of the three distinct patterns of possible deficits in ADHD as described in the triple pathway model by Sonuga-Barke and colleagues. To our knowledge, this is the first computerized tool in which all three pathways are being assessed. Aim of the current study was to investigate the clinical validity of Timo's Adventure.

First proof of validity was found in the developmental effects of the game. In a population of 96 normally developing children between four and eight years old, we found significant correlations with age on two of the three pathways. The older the child, the faster s/he is in completing the tasks. Furthermore, it was found that older children are better in inhibiting their response on a go/no-go task. This is in line with previous research (e.g., Davidson, Amso, Anderson, \& Diamond, 2006; Gathercole, Pickering, Ambridge, \& Wearing, 2004). Also, in a reaction time task, older children have better responses on alertness and have better reactions to visual presented 
stimuli after a visual warning signal. Again, this is in line with previous research (e.g., Thomas \& Nelson, 2001). Furthermore, age related differences were found on the third pathway (i.e., Time perception), indicating that the older the child, the better $\mathrm{s} /$ he is in producing a predetermined time interval. This is in line with research by e.g., Friedman and Laycock (1989) and Pouthas and Jacquet (1987) stating that development of time perception skills takes a spurt at an early age (i.e., before the age of seven) and refines in the last grades of elementary school. Interestingly, no developmental effects were found on the second pathway (Reward mechanisms), indicating that age does not influence the choice between immediate or delayed rewards. This might be caused by the fact that this aspect might be fully developed before the age of four, as the findings by Mischel (1989) suggest.

Further proof for clinical validity was found in satisfying results on the discriminant analysis, indicating that Timo's Adventure was correct in the majority of the classifications. Sensitivity and specificity of the measurement were satisfying. Our results are similar to, and sometimes even more promising than other diagnostic measurements. For instance, Williams and colleagues (2010) could classify $68 \%$ of the children with ADHD correctly when using IntegNeuro. However, only two of the three pathways are included in IntegNeuro, and it is not suitable for young children.

When looking more closely at the individual variables that help to differentiate between children with and without ADHD, we found several significant differences between both groups. On the first pathway (Executive functions), we found that children with ADHD have significantly more irrelevant mouse clicks on the Magic Land task (reaction time) than healthy peers. This indicates impulsiveness, motor restlessness and hyperactive behavior, as also is suggested by Hervey and colleagues (2006). Also, children with ADHD had lower planning skills than healthy controls had, what might be expected since planning and organization is affected in children with ADHD (Gau \& Chiang, 2013). In several tasks, we found results that tend to significance (e.g., children with ADHD tend to have more inhibition mistakes in the Monkey task, and collect more stars in the Magic Land than typically developing children). This seems promising for the future: maybe, with some adjustments to the tasks, sensitivity and specificity can even increase.

Evidence was also found for differences between the ADHD-group and the controls on the second pathway (Reward mechanisms): children with ADHD chose the large but delayed reward less often than the control group, and did not wait as long as the control group before deciding to end the task. This is in line with previous research, which states that children with ADHD have an aversion for delay (Bitsakou, Psychogiou, Thompson, \& Sonuga-Barke, 2009). No significant differences were found on the third pathway of Sonuga-Barke's model (Time perception). Although timing deficits are known in children with ADHD, it is not uncommon that time production tasks do not result in significant effects (Zakay, 1990). Further research is necessary to gain more information on this aspect of possible ADHD-related deficits. 
Finally, we found that user experiences were positive: when asked afterwards, $81 \%$ of the children said they liked the game very much, and an extra $14 \%$ of the children said that they liked the game.

One limitation of the current study is that information on reliability cannot be reported at this moment. Since Timo's Adventure consists of several independent functions, analysis of Cronbach's $\alpha$ would automatically result in low consistency between the items. It would be interesting to measure children several times, to collect data for test-retest reliability analyzes. Further research is necessary to examine the reliability of this instrument. Another interesting question for future research might be to investigate possible effects of use of medication. In the current analysis all medicated ADHD children (18 in total) were excluded, but it might be possible that medication does influence only one (or a combination) of the pathways. Finally, it would be interesting to determine which (or a combination of) tasks and corresponding outcome measurements are especially sensitive for the diagnosis of ADHD. Possibly, a total score and norm data can be measured, which can be used to determine a profile of ADHD-symptoms. Future research is necessary to determine such a profile or total score.

\section{Conclusions}

This is the first time that all three pathways of Sonuga-Barke's model are included in one diagnostic computerized tool with a context of rewards and storyline. In clinical care, diagnostic instruments on time perception and reward mechanisms are scarce, but it is necessary to gain information on these aspects to complete an analysis of strengths and weaknesses of the child. Proof for validity of Timo's Adventure was found in developmental effects and group differences between normally developing children and children with ADHD, and Timo's Adventure was satisfying accurately in the use of classifying. This suggests that Timo's Adventure can be of added value in the diagnosing of ADHD, since it helps in formulating a profile of strengths and weaknesses. Further research is necessary to confirm these findings and to examine potential effects of medication.

\section{Acknowledgement}

The authors are grateful for the collaboration with dr. P. Gongsook, PhD, C. Sallustro, and dr. J. Hu, PhD from the University of Technology (Eindhoven, The Netherlands) in the development of Timo's Adventure. 


\section{References}

Alloway, T. (2012). Can interactive working memory training improve learning? Journal of Interactive Learning Research, 23(3), 197-207.

American Psychiatric Association. (2013). Diagnostic and statistical manual of mental disorders (5th ed.). Washington, DC: Author.

Assef, E. C., Capovilla, A. G., \& Capovilla, F. C. (2007). Computerized stroop test to assess selective attention in children with attention deficit hyperactivity disorder. Span J Psychol, 10(1), 33-40.

Barkley, R. A. (1997). Behavioral inhibition, sustained attention, and executive functions: constructing a unifying theory of ADHD. Psychol bull, 121(1), 65-94.

Barkley, R. A., Koplowitz, S., Anderson, T., \& McMurray, M. B. (1997). Sense of time in children with ADHD: effects of duration, distraction, and stimulant medication. J Int Neuropsychol Soc, 3(4), 359-369.

Bauermeister, J. J., Barkley, R. A., Martinez, J. V., Cumba, E., Ramirez, R. R., Reina, G., . . Salas, C. C. (2005). Time estimation and performance on reproduction tasks in subtypes of children with attention deficit hyperactivity disorder. J Clin Child Adolesc Psychol, 34(1), 151-162. doi: 10.1207/s15374424jccp3401_14

Bellotti, F., Berta, R., \& De Gloria, A. (2010). Designing Effective Serious Games: Opportunities and Challenges for Research. International Journal of Emerging Technologies in Learning 5(S13), 22-35. doi: doi:10.3991/ijet.v5s3.1500

Bioulac, S., Arfi, L., \& Bouvard, M. P. (2008). Attention deficit/hyperactivity disorder and video games: a comparative study of hyperactive and control children. Eur Psychiatry, 23(2), 134-141. doi: 10.1016/j.eurpsy.2007.11.002

Bitsakou, P., Psychogiou, L., Thompson, M., \& Sonuga-Barke, E. J. (2009). Delay Aversion in Attention Deficit/Hyperactivity Disorder: an empirical investigation of the broader phenotype. Neuropsychologia, 47(2), 446-456. doi: 10.1016/j.neuropsychologia.2008.09.015

Boehm, B. (1998). A spiral mode of software development and enhancement. Computer, 21(5), 61-72. doi: $10.1109 / 2.59$

Cassuto, H., Ben-Simon, A., \& Berger, I. (2013). Using environmental distractors in the diagnosis of ADHD. Front Hum Neurosci, 7, 805. doi: 10.3389/fnhum.2013.00805

Craeynest, P. (2010). Psychologie van de levensloop. Leuven: Acco.

Davidson, M. C., Amso, D., Anderson, L. C., \& Diamond, A. (2006). Development of cognitive control and executive functions from 4 to 13 years: evidence from manipulations of memory, inhibition, and task switching. Neuropsychologia, 44(11), 2037-2078. doi: 10.1016/j.neuropsychologia.2006.02.006

Diamond, A. (2006). The early development of executive functions. In E. Bialystok \& F. I. M. Craik (Eds.), Lifespan Cognition - Mechanisms of Change. New York: Oxford University Press.

Friedman, W. J., \& Laycock, F. (1989). Children's analog and digital clock knowledge. Child Dev, 60(2), 357371. doi: $10.2307 / 1130982$

Friedman, W. J., \& Lyon, T. D. (2005). Development of temporal-reconstructive abilities. Child Dev, 76(6), 1202-1216. doi: 10.1111/j.1467-8624.2005.00845.x

Gathercole, S. E., Pickering, S. J., Ambridge, B., \& Wearing, H. (2004). The structure of working memory from 4 to 15 years of age. Dev Psychol, 40(2), 177-190. doi: 10.1037/0012-1649.40.2.177

Gau, S. S., \& Chiang, H. L. (2013). Association between early attention-deficit/hyperactivity symptoms and current verbal and visuo-spatial short-term memory. Res Dev Disabil, 34(1), 710-720. doi: 10.1016/j.ridd.2012.10.005

Goldman, L. S., Genel, M., Bezman, R. J., \& Slanetz, P. J. (1998). Diagnosis and treatment of attentiondeficit/hyperactivity disorder in children and adolescents. Council on Scientific Affairs, American Medical Association. JAMA, 279(14), 1100-1107.

Gongsook, P. (2015). Interactive diagnostic game for time perception. Eindhoven: Technische Universiteit.

Gongsook, P., Peijnenborgh, J. C. A. W., Sallustro, C., Van der Spek, E. D., Hu, J., Bellotti, F., ... Hendriksen, J. G. M. (2014). A Diagnostic Tool on Time Perception of Children with ADHD. Paper presented at the Games and Learning Alliance.

Gonzalez-Garrido, A. A., Gomez-Velazquez, F. R., Zarabozo, D., Lopez-Elizalde, R., Ontiveros, A., MaderaCarrillo, H., ... Tuya, J. M. (2008). Time reproduction disturbances in ADHD children: an ERP study. Int J Neurosci, 118(1), 119-135. doi: 10.1080/00207450601042177 
Gooch, D., Snowling, M. J., \& Hulme, C. (2012). Reaction time variability in children with ADHD symptoms and/or dyslexia. Dev Neuropsychol, 37(5), 453-472. doi: 10.1080/87565641.2011.650809

Gorini, A., Capideville, C. S., De Leo, G., Mantovani, F., \& Riva, G. (2011). The role of immersion and narrative in mediated presence: the virtual hospital experience. Cyberpsychol Behav Soc Netw, 14(3), 99-105. doi: 10.1089/cyber.2010.0100

Grey, I., Healy, O., Leader, G., \& Hayes, D. (2009). Using a Time Timer to increase appropriate waiting behavior in a child with developmental disabilities. Res Dev Disabil, 30(2), 359-366. doi: 10.1016/j.ridd.2008.07.001

Habgood, M. J., \& Ainsworth, S. E. (2011). Motivating children to learn effectively: Exploring the value of intrinsic integration in educational games. Journal of the Learning Sciences, 20(2), 169-206.

Hervey, A. S., Epstein, J. N., Curry, J. F., Tonev, S., Eugene Arnold, L., Keith Conners, C., . . . Hechtman, L. (2006). Reaction time distribution analysis of neuropsychological performance in an ADHD sample. Child Neuropsychol, 12(2), 125-140. doi: 10.1080/09297040500499081

Hurks, P. P., \& Hendriksen, J. G. (2011). Retrospective and prospective time deficits in childhood ADHD: The effects of task modality, duration, and symptom dimensions. Child neuropsychol, 17(1), 34-50. doi: 10.1080/09297049.2010.514403

Luciana, M., \& Nelson, C. A. (2002). Assessment of neuropsychological function through use of the Cambridge Neuropsychological Testing Automated Battery: performance in 4- to 12-year-old children. Dev Neuropsychol, 22(3), 595-624. doi: 10.1207/S15326942DN2203_3

Martinussen, R., Hayden, J., Hogg-Johnson, S., \& Tannock, R. (2005). A meta-analysis of working memory impairments in children with attention-deficit/hyperactivity disorder. I Am Acad Child Adolesc Psychiatry, 44(4), 377-384. doi: 10.1097/01.chi.0000153228.72591.73

McCarney, R., Warner, J., Iliffe, S., van Haselen, R., Griffin, M., \& Fisher, P. (2007). The Hawthorne Effect: a randomised, controlled trial. BMC Med Res Methodol, 7, 30. doi: 10.1186/1471-2288-7-30

Messina, F., Tiedemann, K. B., de Andrade, E. R., \& Primi, R. (2006). Assessment of working memory in children with attention-deficit/hyperactivity disorder. J Atten Disord, 10(1), 28-35. doi: $10.1177 / 108705284299$

Mischel, W., Shoda, Y., \& Rodriguez, M. I. (1989). Delay of gratification in children. Science, 244(4907), 933938.

Peijnenborgh, JCAW, Hurks, PPM, Aldenkamp, AP, Vles, JSH, \& Hendriksen, JGM. (2016). Efficacy of working memory training in children and adolescents with learning disabilities: a review study and metaanalysis. Neuropsychol Rehabil, 26, 645-672. doi: 10.1080/09602011.2015.1026356.

Pouthas, V., \& Jacquet, A. Y. (1987). A developmental study of timing behavior in $41 / 2$ - and 7-year-old children. J Exp Child Psychol, 43(2), 282-299.

Prins, P. J. M., Brink, E. L., Dovis, S., Ponsioen, A., Geurts, H. M., De Groot, H., . . Van der Oord, S. (2010). Braingame Brian: Een Executieve Functie training met game-elementen voor kinderen met cognitieve controleproblemen. Amsterdam: Universiteit van Amsterdam; Lucertis; \& Shosho.

Rauterberg, G. W. M. (1992). An iterative-cyclic software process model. Proceedings Fourth International Conference on Software Engineering and Knowledge Engineering, 600-607. doi: 10.1109/SEKE.1992.227899

Rauterberg, G. W. M., Strohm, O., \& Kirsch, C. (1995). Benefits of user-oriented software development based on an iterative cyclic process model for simultaneous engineering. Int J Ind Ergonom, 16, 391410.

Sallustro, C. (2013). Timo\&Friends: A Diagnostic Tool on the Time Perception of Children with ADHD. Eindhoven University of Technology, Eindhoven.

Sonuga-Barke, E., Bitsakou, P., \& Thompson, M. (2010). Beyond the dual pathway model: evidence for the dissociation of timing, inhibitory, and delay-related impairments in attention-deficit/hyperactivity disorder. J Am Acad Child Adolesc Psychiatry, 49(4), 345-355.

Swaab, H., Bouma, A., Hendriksen, J., \& König, C. (2016). Klinische Kinderneuropsychologie. Amsterdam: Boom.

Swanson, J. M., Sergeant, J. A., Taylor, E., Sonuga-Barke, E. J., Jensen, P. S., \& Cantwell, D. P. (1998). Attention-deficit hyperactivity disorder and hyperkinetic disorder. Lancet, 351(9100), 429-433.

Thomas, K. M., \& Nelson, C. A. (2001). Serial reaction time learning in preschool- and school-age children. J Exp Child Psychol, 79(4), 364-387. 
Van der Spek, E. D., Sidorenkova, T., Porskamp, P., \& Rauterberg, M. (2014). The Effect of Familiar and Fantasy Aesthetics on Learning and Experience of Serious Games Entertainment Computing-ICEC 2014 Berlin Heidelberg: Springer.

Wechsler, D. (2010). WPPSI-III-NL Nederlandse bewerking: Technische Handleiding (2nd ed.). Amsterdam: Netherlands: Pearson Assessment and Information BV.

Williams, L. M., Hermens, D. F., Thein, T., Clark, C. R., Cooper, N. J., Clarke, S. D., . . Kohn, M. (2010). Using Brain-Based Cognitive Measures to Support Clinical Decisions in ADHD. Pediatr Neurol, 42(2), 118126. doi: 10.10.16/j.pediatrneurol.2009.08.010

Wouters, P., Van Nimwegen, C., Van Oostendorp, H., \& Van der Spek, E. D. (2013). A Meta-Analysis of the Cognitive and Motivational Effects of Serious Games. Journal of Educational Psychology, 105(2), 249.

Zakay, D. (1990). The evasive art of subjective time measurement: Some methodological dilemmas. In R. A. Block (Ed.), Cognitive models of psychological time. Hillsdale: Lawrence Erlbaum Associates. 


\section{Chapter 3}

\section{Psychometric properties of the Children's Time Awareness Questionnaire:}

a 20 -item questionnaire measuring time perception

JCAW Peijnenborgh, PPM Hurks, R Wassenberg, AP Aldenkamp, JSH Vles, \& JGM Hendriksen

Submitted 


\section{Abstract}

The aim of the current study was to provide normative data and to investigate the reliability and validity of the Children's Time Awareness Questionnaire (CTAQ; Hendriksen, 2004), a 20 -item questionnaire designed to assess children's time perception in an ecological valid way. With respect to normative data, a multiple regression model showed that the demographic variables 'age' and 'sex' contributed significantly to CTAQ performance, whereas the Level of Parental Education did not. Therefore, the CTAQ normative data presented in this paper were corrected for the demographic influences of age and sex. Internal consistency, as a measure of reliability, examined in a population of normally developing children between 4 and 12 years of age $(N=334)$, was found to be modest but acceptable (Cronbach's $\alpha$ : 0.7$)$. Positive correlations between CTAQ scores and parent-reports and performance tests measuring time perception in children were found. In line with temporal processing deficits reported in literature, children with ADHD $(N=35)$ scored significantly lower on the CTAQ in comparison to normally developing children. Sensitivity of the CTAQ was 0.67 and specificity was 0.73 . In conclusion, the CTAQ may be used in clinical and/or research settings to provide a valid and reliable assessment of time perception in young children. 


\section{Introduction}

Recent years have seen an increase in studies exploring individual differences in children's ability to perceive time (Hurks \& van Loosbroek, 2014). Time perception, also known as temporal processing, facilitates our ability to predict, anticipate, and respond competently to daily living, and contributes to independency in daily living (Booth \& Siegler, 2006; Piaget, 1946). As such, deficits in time perception are assumed to have a major influence on daily functioning of children. When assessing time perception, it is preferable to examine one's ability to perceive time with an ecologically valid instrument, including events that are familiar to a child (Wassenberg et al., 2007). Methods frequently used in this context are: verbal time estimation tasks, in which children verbally report how long a sample duration lasted in terms of conventional seconds (e.g., "the picture was displayed for 9 seconds"), and time reproduction tasks, where children are shown durations via some means (e.g., by turning a light bulb on and off) and then must "replicate" these durations (Hurks \& van Loosbroek, 2014). These tasks measure multiple cognitive processes, such as timing, attention, working memory, self-control, and self-monitoring (Block \& Zakay, 1997; Shallice \& Evans, 1978). Block, Zakay, and Hancock (1999) found that, compared to older children and adults, normally developing children under the age of 13 years overestimated the duration of a time interval in the verbal time estimation task and showed underproduction when the child had to reproduce the duration of a time interval in a time reproduction task. The time intervals used in these studies are often (very) short, ranging from milliseconds to only a few minutes, which leads to the question whether this is representative for time perception in every day events.

Asides from these tasks to estimate or to (re)produce relatively short time intervals, a questionnaire method used in studying perception in general, and time perception more specifically, in adults is the Biber Cognitive Estimation Test (BCET; Bullard et al., 2004). While administering the BCET, individuals are instructed to "attempt to provide reasonable answers to questions for which relevant knowledge, but not the specific answer, is available" to the participants (Axelrod \& Millis, 1994; Bullard et al., 2004; Shallice \& Evans, 1978). This 20-item questionnaire contains 5 items related to time, in which one has to answer time duration questions regarding everyday events, such as, 'how long would it take an adult to hand write a one-page letter?'. The BCET not only asks individuals to answer questions on time perception, but also includes 15 items on other aspects of cognitive estimation, such as providing estimates in terms of length (in $\mathrm{cm}$ ), number, and weight (in $\mathrm{kg}$ ). Developmental differences have been reported for the BCET total score, calculated over 20 items. Performance on the BCET in general seems to rapidly develop between the ages of five and nine (Harel, Cillessen, Fein, Bullard, \& Aviv, 2007). Bullard et al. (2004) found that children aged $\geq 9$ are able to perform this task at the same level as an adult. An individual is unable to know the 'exact' answer to the BCET questions, therefore filtering out the influence of fact knowledge as much as possible. However, the questionnaire was originally developed 
for adults, and children are often unfamiliar to many of the events covered in the BCET. For instance, one item asks participants to estimate how long it would take an adult man to build a house. Also, as mentioned above, the questionnaire does not only measure time perception. Therefore, one may question the ecological validity of the BCET for measuring time perception in children. For this reason, the Children's Time Awareness Questionnaire (CTAQ; Hendriksen, 2004) was developed. The CTAQ is a questionnaire assessing knowledge on aspects of time perception while asking children questions regarding events that are familiar to them. In total, the CTAQ consists of 20 items. The aim of the present study was to investigate the internal consistency (as a measure of reliability), to examine the validity of the CTAQ, and to establish normative data regarding the performance on the CTAQ.

In order to establish the normal range of performance on the CTAQ, it is needed to "identify the demographic variables that are associated with test performance (e.g., age, sex, and parental education), so that the normative data can be appropriately corrected for the relevant demographic influences" (Van der Elst, Hurks, Wassenberg, Meijs, \& Jolles, 2011). With respect to these demographic variables, we expected that the age of the child would have a significant influence on the CTAQ outcome. For instance, Friedman (1986, 1990, 2000) found that, around the age of 4 to 6 years, children first develop some "sense of time" in daily activities, e.g., 'Do you eat lunch before or after breakfast?'. Around 8 years, the child can order the days of the weeks and months, but, in general, it takes until 15 years of age before the child has an optimal knowledge on specific cyclic time patterns and is able to answer questions such as 'which month is 3 months before September?'. Based on various fMRI studies, Droit-Volet (2013) concluded in her review that these developmental improvements in time perception are associated with the structural and functional maturation of the fronto-striatal system and its connections with other structures, such as the cerebellum and the inferior frontal and prefrontal cortex. Furthermore, another demographic factor interesting in this context is the intelligence of the child. Fink and Neubauer (2001) found a significant, positive correlation between a time estimation task - similar to the task discussed above - and intelligence. Since time perception also consists of some knowledge aspects (e.g., knowledge on reading the clock, knowledge on abstract concepts such as 'now' or 'later'), one might hypothesize that intelligence might influence time perception abilities. For this purpose, the influence of the level of parental education was examined. This factor has not yet been studied in relation to time perception, however, in literature, a higher level of parental education has been associated with higher cognitive capacities in their offspring (Van der Elst et al., 2011). Based on this, it might be expected that these children also have better time perception skills. Finally, the sex of the child is another relevant demographic factor here. Previous research showed that, in adults, men had better time perception skills than women (e.g., Rammsayer \& Lustnauer, 1989). The CTAQ normative data was based on a sample of $N=334$ healthy native Dutch-speaking children aged 4-12 years. In this study, we used the regression-based normative method, which is used "to 
compute the expected test scores of an individual" (Van der Elst et al., 2011). Here, the influence of age, sex, and parental level of education on CTAQ performance was evaluated and corrected for if necessary (in line with the methods described by Van der Elst et al., 2011).

Proof of validity of the CTAQ was sought in two ways. The convergent validity was assessed by correlating CTAQ performances to scores on tests claiming to measure related constructs. In this context, both parent reports on time perception as well as the time estimation tests, a clock reading test, and the BCET were included as timerelated tests. We expected to find high correlations between the CTAQ and these other time perception tests. Furthermore, proof of validity was sought by studying group differences in performance on the CTAQ. For this purpose, CTAQ performance of normally developing children was compared to that of children with AttentionDeficit/Hyperactivity Disorder (ADHD). Children with ADHD are assumed to have time perception deficits, possibly due to known ADHD-related impairments in the frontostriatal system mentioned above (Droit-Volet, 2013). Indeed, Sonuga-Barke, Bitsakou, and Thompson (2010) found for instance that timing, as well as poor inhibitory control and delay aversion, are core deficits in children with ADHD: more specifically, these authors found that timing deficits occur in $44.2 \%$ of the children with ADHD. This is in line with other studies that found time perception difficulties to occur in children with ADHD (e.g., Gonzalez-Garrido et al., 2008; Hurks \& Hendriksen, 2011). Based on this, we expected that children with ADHD perform less well than normally developing children on the CTAQ. In this context, we also examined the sensitivity and specificity of the CTAQ in classifying ADHD versus normally developing children.

\section{Method}

\section{Participants}

Two groups of children were studied: i.e., normally developing children and children with ADHD. An overview of characteristics for all participants can be found in Table 3.1.

\section{Normally developing children}

Parents of all children enrolled in six Dutch elementary schools (grades 1 to 8) were approached. Together with the information letter and the informed consent, these parents received a questionnaire on demographical variables via the children's school. Informed consent of 395 normally developing children was acquired. Exclusion criteria were a DSM-5 diagnosis $(N=37)$ or having repeated a grade $(N=24)$. The final dataset consisted of 334 normally developing children (168 boys). Mean age of the sample was $8.46(S D=2.22)$, ranging from 4 to 12 years. Level of parental education was analyzed for the parent with the highest level of education (Kalff et al., 2001). The 
majority of the sample consisted of middle to highly educated parents: only 9 families (3.7\%) had a low level of education (elementary school or lower vocational education), 90 families (37.3\%) had a middle level of education (secondary general education or secondary vocational education), and 142 families (58.9\%) had a high level of education (higher professional education or university degree). In total, 93 families did not report on their level of education. All children were tested individually in a private room at their school. Approval for testing this sample was given by the Ethical Committee of the Faculty of Psychology and Neuroscience of Maastricht University, The Netherlands.

Table 3.1 Characteristics for all participants.

\begin{tabular}{lcc}
\hline & $\begin{array}{c}\text { Normally developing } \\
\text { children }\end{array}$ & ADHD-group \\
\hline$N$ & 334 & 35 \\
Boys/Girls & $168 / 166$ & $26 / 9$ \\
Age range & $4-12$ & $6-8$ \\
Mean age (SD) & $8.5(2.2)$ & $6.9(0.7)$ \\
Parental level of education $(N)$ & & \\
Low & $9(3.7 \%)$ & $3(8.8 \%)$ \\
Middle & $90(37.3 \%)$ & $16(47.1 \%)$ \\
High & $142(58.9 \%)$ & $15(44.1 \%)$ \\
\hline
\end{tabular}

Note: $N=$ number of participants; SD = Standard deviation.

\section{Children with ADHD}

Parents of patients of the outpatient clinic Center for Neurological Learning Disabilities were asked to participate in this study by their specialist. In parallel, parents of children enrolled in a special needs program for children with behavioral problems were informed by a letter about the study and asked to participate, via the children's school. Informed consents of 57 children with a diagnosis of ADHD were acquired. A total of 22 children did not meet the inclusion criteria: four children because they had a comorbid DSM-5 diagnosis (all autism spectrum disorder), 13 children were excluded because they used medication (stimulants, atomoxetine, tricyclic antidepressants, or clonidine), and five children had a comorbid diagnosis and used medication.

The final dataset of the ADHD-group consisted of 35 children (26 boys), all with a diagnosis of Attention-Deficit/Hyperactivity Disorder (ADHD) according to DSM-5. These diagnoses were made on the basis of a protocol formulated by Goldman, Genel, Bezman, and Slanetz (1998) which includes 1) extensive history taking, 2) cognitive testing, 3) general physical and neurological examination of the child, as well as 4) systematic assessment of ADHD-characteristics by means of structured questions based on the most recent version of the DSM (American Psychiatric Association, 2013). The mean age of the clinical sample was 6.9 years $(S D=0.7)$, ranging between 6 and 8 . The majority of parents in this sample had a middle level of education 
(16 families, $47.1 \%$ ). Three families had a low level of education (8.8\%), and 15 families had a high level of education (44.1\%). Data on parental education from one family was not available.

Children enrolled in the special needs program for children with behavioral problems were tested in a private room at their school. The children who were patients of the Center of Neurological Learning Disabilities were seen for neuropsychological testing as part of clinical care. The used tasks were part of this neuropsychological testing, and again all tests were done in a private room accompanied by the experimenter. Location of testing did not influence results on the several tasks.

Approval for testing this sample was given by the Medical Ethical Board of Kempenhaeghe.

\section{Materials}

Children's Time Awareness Questionnaire (CTAQ; Hendriksen, 2004). The CTAQ was administered to all participants. The questionnaire consisted of 20 questions. All CTAQ items were newly developed on the basis of literature of time awareness in children, except for three items that were derived from the Temporal Judgement Test subtest of the Behavioural Assessment of the Dysexecutive Syndrome (BADS; Gillespie, Evans, Gardener, \& Bowen, 2002; Wilson, Alderman, Burgess, Emslie, \& Evans, 2003), in which participants are asked to estimate the duration of events (a routine dental examination, the life expectancy of a dog, inflating a party balloon). In total, the CTAQ consisted of 11 open ended questions in which the child gave an estimation of how long (in seconds, minutes, weeks or years) an event would take, and 9 close-ended questions (e.g., which lasts longer: a week or a month). Scoring of the open-ended questions was similar to the scoring of the BCET (Bullard et al., 2004): all answers that fell between the $5^{\text {th }}$ and $96^{\text {th }}$ percentile (based on the normative sample of 248 adults calculated by Wassenberg et al., [2007]) were scored as 1, whereas scores outside this range receive are scored as 0 . Close-ended questions were scored as 0 (incorrect) or 1 (correct). Total score of the CTAQ is 20; the higher the score, the better the child's performance.

Reading digital and analogue clocks: Four questions on clock reading (Hendriksen, 2004) were administered: two pictures of digital clocks (13:15 and 18:25) and two pictures of analogue clocks (three o'clock and ten o'clock). For each correctly read clock, the child earned 1 point.

Biber Cognitive Estimation Test (BCET; Bullard et al., 2004). This self-report questionnaire consisted of 20 estimation questions equally divided over four categories: time/duration, quantity, weight, and distance. All questions concerned topics to which one is not supposed to know the exact answer to (e.g., "how long would it take an adult to hand write a one-page letter?'). All answers that fell between the $5^{\text {th }}$ and $96^{\text {th }}$ percentile (as based on the normative sample of 118 adults by Bullard et al. [2004]) received a score of 1 , whereas scores outside this range received a score 
of 0 . Maximum total score was 20 (i.e., the higher the score, the better the child's performance). In a sample of 315 children and adolescents, Harel et al. (2007) found that the internal reliability was satisfactory for the BCET (Cronbach's $\alpha$ : 0.77$)$. This task was administered only to the normally developing children older than 7 years.

Five to Fifteen (FTF; Kadesjo et al., 2004). This parent questionnaire contained questions on developmental and behavioral problems. Only the FTF subscale on time perception (i.e., 4 items, e.g., 'My child has only a vague idea about what time it is, whether it is morning or afternoon, whether it is time or not to go to school') was administered. Parents had to indicate whether statements on time perception were applicable to their child on a five point scale, ranging from 'always' to 'never'. The higher the score, the lesser the child's time perception abilities, according to the parents. Cronbach's $\alpha$ for this subscale was 0.83 (Kadesjö et al., 2004). This task was only administered to parents of normally developing children younger than 8 years.

Verbal time estimation task (Hurks \& Hendriksen, 2011). In this verbal time estimation task, the child had to verbally estimate a time duration. After a fixed interval (500 ms), a picture of a carrot appears on the screen, which is replaced by a picture of a rabbit after a fixed interval (1000 ms). After a variable time interval the rabbit disappeared. The child had to report verbally how long s/he thinks the rabbit was present on the screen. Six different time intervals were presented in a randomized order: 3, 6, 12, 15, 30 , and 45 seconds. The child was not allowed to use a clock, watch or stopwatch. Estimation of each interval was subtracted from the presented time interval. Absolute scores for each interval were then divided by number of intervals (i.e., six) to calculate the mean time estimation. The higher this score, the less precise the time estimation of the child. Cronbach's $\alpha$ 's reported for verbal estimation tasks are ranging from 0.67 to 0.79 (White et al., 1994). This task was only administered to normally developing children aged 8 years and older.

Vocabulary. This subscale of the Dutch version of the Wechsler Preschool and Primary Scale of Intelligence (WPPSI-III-NL; Wechsler, 2010) was used to estimate verbal intelligence (Alloway, 2012). In this task, the child was asked to give definitions of words, such as 'umbrella' or 'shoe'. Cronbach's $\alpha$ for this subscale was 0.78 (Wechsler, 2010). This task was administered to normally developing children 4-8 years and children with ADHD.

\section{Statistics}

Data were analyzed with IBM SPSS statistics version 21.0.0.0. For each used measurement (i.e., for each age separately calculated), all outliers (scores with $z>$ 3.29) were replaced by the mean + three times standard deviation as advised by Field (2009).

Internal consistency of the CTAQ was investigated by computing Cronbach's $\alpha$.

The effects of demographic variables on the CTAQ were analyzed with multiple linear regression analyzes. The full regression models included age, sex, interaction between 
sex and age, and parental level of education as predictors. Age was centered (calendar age - mean age in the sample). Sex was dummy coded as $0=$ male, and $1=$ female. Two dummies were made for parental level of education: dummy 1 was $0=$ low level of education and $1=$ middle level of education; dummy 2 was $0=$ low level of education and $1=$ high level of education.

Validity of the CTAQ in the healthy population was investigated by measuring Spearman correlations between the CTAQ on one hand and the other tasks on the other hand (BCET, verbal time estimation task, the time-related subscale of the FTF, and vocabulary scores).

To measure differences between the ADHD-group and healthy children, a control group was created by matching normally developing children (of the sample discussed above) to ADHD children on age and sex. An independent samples $t$-test revealed that both groups were equal in terms of Vocabulary scores (ADHD-group: $M=89.23$, $S D=13.36$; Control group: $M=94.60, S D=11.05 ; t(49)=1.44, p>.05)$. Since the assumption of normal distribution was violated in the CTAQ scores, non-parametric $t$-tests (Mann-Whitney) were used for further analyzes. Finally, sensitivity and specificity of the CTAQ were calculated, in order to examine to which extent the CTAQ is capable of discriminating whether a child belonged to the ADHD-group or to the normally developing children (again, the matched control group was used). Sensitivity and specificity were measured.

\section{Results}

\section{Internal consistency}

A reliability analysis was conducted to examine the internal consistency of the CTAQ. Cronbach's $\alpha$ was 0.69 . Deletion of individual items did not result in a higher reliability coefficient, so all items were used in further analyzes.

\section{Multiple regression based normative data}

The final multiple linear regression models are shown in Table 3.2. The interaction of age and sex and the parental level of education were not significant, and therefore excluded from further analyzes. Age significantly predicted outcome of the CTAQ, i.e., older children performed better on the CTAQ. Also, the sex of the child significantly predicted the outcome of the CTAQ, i.e., boys outperformed girls on the CTAQ. Together, the two predictor variables explained a significant proportion of variance in CTAQ scores $\left(R^{2}=.58, F(2,331)=230.97, p<.001\right)$. 
Table 3.2 Regression model of the CTAQ in normally developing children $(N=334)$.

\begin{tabular}{lccc}
\hline & $B$ & $S E B$ & $\beta$ \\
\hline Constant & 15.58 & 0.19 & \\
Age & 1.29 & 0.06 & $.76^{* *}$ \\
Sex & -0.78 & 0.27 & $-.10^{* *}$ \\
\hline
\end{tabular}

Note: $N=$ Number of participants; $R^{2}=.58, \Delta R^{2}=.58(p<.001)$. ${ }^{* *} p<.01$.

\section{Validity}

\section{Convergent validity}

All correlation coefficients between the CTAQ and other tests assessing (aspects of) time perception in the sample of normally developing children (see Table 3.3) were significant. The correlation between the total score of the CTAQ and knowledge of clock reading was high $(r=.66, p<.01)$, indicating that the better the child was able to read the clock, the better the score on the CTAQ. Verbal time estimation correlated low but significant with the CTAQ $(r=-.19, p<.01)$, indicating that the better the score on the CTAQ, the more precise the performance on the verbal time estimation task. Furthermore, a negative correlation was found between the CTAQ and the parent rated time subscale of the FTF as might be expected: the higher the score on the FTF (which indicates low capacities as rated by the parents), the lower the score on the CTAQ $(r=-.30, p<.01)$. The correlation coefficient between the CTAQ and the BCET was also significant $(r=.34, p<.01)$, indicating that the better the result on the CTAQ, the better the result on the BCET.

Finally, no correlation was found between the CTAQ and verbal capacities ( $r=.06$, $p=.55$ ), indicating that the level of verbal cognitive capacities does not correlate with performance on the CTAQ in young children $<8$ years.

Table 3.3 Correlation coefficients between the CTAQ and other tasks claiming to measure time perception or estimation in general.

\begin{tabular}{lc}
\hline & CTAQ total \\
\hline Tasks measuring time perception & $-.19^{* *}$ \\
Verbal time estimation task $(N=225)$ & $-.30^{* *}$ \\
Five-to-Fifteen Time $(N=99)$ & $.66^{* *}$ \\
Clock reading $(N=326)$ & $.34^{* *}$ \\
Tasks measuring cognitive estimation & .06 \\
BCET Total $(N=210)$ & .06 \\
Tasks measuring cognitive capacities & \\
Vocabulary $(V I Q ; N=101)$ & \\
\hline
\end{tabular}

Note: $\mathrm{BCET}=$ Biber Cognitive Estimation Test; $\mathrm{CTAQ}=$ Children's Time Awareness Questionnaire; $N=$ number of participants. ${ }^{*}$ Correlation is significant at the 0.05 level (2-tailed) $* *$ Correlation is significant at the 0.01 level (2-tailed). 
Relevant group differences: CTAQ and $A D H D$

Group differences on the CTAQ were tested comparing normally developing children to children with ADHD. Analyzes revealed that children with ADHD performed significantly less well on the CTAQ than normally developing children (Control group: $M=14.31, S D=2.68$; ADHD-group: $M=11.29, S D=2.68 ; U=324.50, z=-3.40, p<.01, r=-.41$ ). To investigate whether the CTAQ is capable of differentiating between normally developing children and children with ADHD, a discriminant analysis was performed. A significant differentiation between the groups was found: Wilk's $\Lambda=.83, \chi^{2}(1)=14.13$, $p<.001$. The classification results showed that $76 \%(N=29)$ children in the control group were correctly classified, and $63 \%$ of the children in the ADHD-group were correctly classified as having ADHD ( $N=24)$. Overall, $70 \%$ of the children were correctly classified as being in the ADHD-group or in the control group. Sensitivity of the CTAQ was 0.67 , and specificity was 0.73 .

\section{Discussion}

The aim of the present study was to examine the psychometric properties and provide normative data of the CTAQ, a questionnaire which aims to quantify time perception in children aged 4 to 12 . In a population of 334 normally developing children aged 4 to 12 , we found an, according to the criteria set by Hair, Black, Babin, Anderson, and Tatham (2006), modest, but acceptable internal consistency (Cronbach's alpha is 0.69) of this 20-item questionnaire, indicating that the CTAQ is a reliable measurement instrument.

When examining which factors can predict CTAQ performances, we found that, as expected, the age of the child had the largest influence. Previous studies also found developmental differences in time perception. For instance, Block et al. (1999) found that, compared to older children and adults, normally developing children aged $<13$ years overestimated the duration of a time interval in the verbal time estimation task and showed underproductions when the child had to reproduce the duration of a time interval in a time reproduction task. Another significant predictor of CTAQ performance was the sex of the child: boys showed better time perception skills than girls, independent of the age of the child. This is in line with for instance Rammsayer and Lustnauer (1989) who found, in adults, that men had better time perception skills than women. Interestingly, and contrary to our expectations, no significant correlation was found between the CTAQ and a measurement of verbal cognitive capacities (in young children), indicating that time perception skills are independent of the verbal abilities in children. This may be an important finding suggesting that verbal capacities are not predictive for time perception. Further research is needed to test whether performance/spatial capacities are more predictive. In line with the finding on verbal capacities, we found that parental educational level did not have a significant 
influence on the CTAQ, supporting the assumption that intelligence might be a completely different construct than time perception. Based on these results, we decided to correct the CTAQ normative data for the demographic influences of age and sex.

Next, we investigated the validity of the CTAQ, for one by correlating CTAQ scores to scores on tests measuring other components of time perception - including both children's performance tests as well as parental reports on their children's time perception abilities. In line with our expectations, we found significant correlations between the CTAQ and these alternative measures, thereby supporting the validity of the CTAQ in children.

As further proof for the validity of the CTAQ, we found significant differences between children with $A D H D$ and a matched control group on the CTAQ, showing that children with ADHD have more difficulties in time perception as measured by the CTAQ than normally developing children. This is in line with prior research that indicated that time perception deficits are more common in children with ADHD (e.g., Hurks \& Hendriksen, 2011; Sonuga-Barke et al, 2010). Furthermore, we found that the CTAQ is capable of discriminating between children with ADHD and normally developing children. Sensitivity and specificity were both satisfactory.

We also examined whether there is a correlation between the CTAQ scores and the BCET scores, as a measure of cognitive estimation. In this context, cognitive estimation was defined as "the attempt to provide reasonable answers to questions for which relevant knowledge, but not the specific answer, is available to the subject" (Axelrod \& Millis, 1994; Bullard et al., 2004; Shallice \& Evans, 1978). We found a significant correlation between the CTAQ and the total score of the BCET. This indicates that the CTAQ might also measure (at least to some extent) cognitive estimation in general, instead of specifically only time perception. This is in line with Appollonio et al. (2003), who found that time perception and cognitive estimation are (more or less) the same construct. In this context, Walsh (2003) hypothesized that there is "a single, fully shared representational magnitude system that underpins the processing of time, size, number, quantity, and space (i.e., a theory of magnitude, or ATOM)". Later, Cappalletti, Freeman, and Cipolotti (2009) concluded based on experimental work that "this single, fully shared representational magnitude system is only partly shared among magnitude dimensions (such as time or space) and that each of them is also implemented by dimension-specific processes". Future studies should examine the correlations between the CTAQ and cognitive estimation tasks further and to what extent time perception abilities overlap with more general cognitive estimation abilities.

In addition, two points worth mentioning with respect to the study design are related to the tests included to measure convergent validity and age. The measurements used to study convergent validity were not suitable for all children due to their age, and thus not all tasks were administered to all children. To compensate for this limitation, we used comparable tasks over different ages where possible. A further 
recommendation for future research is to expand the age range of the ADHD-group. The ADHD-group (and thus the matched control group) consisted of children ranging from 6 to 8 years. As the results showed that age is of influence on results of the CTAQ in the normally developing children, it would be interesting to investigate aspects of CTAQ performances in older children with ADHD. In line with this, Barkley et al. (2001) e.g., found significant time perception deficits in adolescents with ADHD. We expect therefore that the CTAQ can also be useful in assessing time perception problems in children with ADHD above the age of eight.

Altogether our data supports our hypothesis that the CTAQ can be used to validly and reliably measure time perception in children. Use of the CTAQ could be helpful in clinical practice and in research to classify potential time perception problems in normally developing children and more specifically in children with ADHD. A psychometric sound classification of poor time perception skills is important since problems in this area are believed to negatively influence a broad range of other skills as well (e.g., social skills, educational functioning, and adaptive behaviors [Meaux \& Chelonis, 2003]). 


\section{References}

Alloway, T. (2012). Can interactive working memory training improve learning? Journal of Interactive Learning Research, 23(3), 197-207.

American Psychiatric Association. (2013). Diagnostic and statistical manual of mental disorders (5th ed.). Washington, DC: Author.

Appollonio, I. M., Russo, A., Isella, V., Forapani, E., Villa, M. L., Piolti, R., \& Frattola, L. (2003). Cognitive [correction of cognitve] estimation: comparison of two tests in nondemented parkinsonian patients. Neurol Sci, 24(3), 153-154. doi: 10.1007/s10072-003-0105-3

Axelrod, B. N., \& Millis, S. R. (1994). Preliminary standardization of the cognitive estimation test. Assessment, 1(3), 269-274. doi: 10.1177/107319119400100307

Barkley, R. A., Edwards, G., Laneri, M., Fletcher, K., \& Metevia, L. (2001). Executive functioning, temporal discounting, and sense of time in adolescents with attention deficit hyperactivity disorder (ADHD) and oppositional defiant disorder (ODD). J Abnorm Child Psychol, 29(6), 541-556.

Bartels, M., Rietveld, M. J., Van Baal, G. C., \& Boomsma, D. I. (2002). Genetic and environmental influences on the development of intelligence. Behav Genet, 32(4), 237-249.

Block, R. A., \& Zakay, D. (1997). Prospective and retrospective duration judgments: A meta-analytic review. Psychon Bull Rev, 4(2), 184-197. doi: 10.3758/BF03209393

Block, R. A., Zakay, D., \& Hancock, P. A. (1999). Developmental changes in human duration judgments: a meta-analytic review. Dev Rev, 19, 183-211.

Booth, J. L., \& Siegler, R. S. (2006). Developmental and individual differences in pure numerical estimation. Dev psychol, 42(1), 189-201. doi: 10.1037/0012-1649.41.6.189

Bullard, S. E., Fein, D., Gleeson, M. K., Tischer, N., Mapou, R. L., \& Kaplan, E. (2004). The Biber Cognitive Estimation Test. Arch Clin Neuropsychol, 19(6), 835-846. doi: 10.1016/j.acn.2003.12.002

Cappalletti, M., Freeman, E. D., \& Cipolotti, L. (2009). Dissociations and interactions between time, numerosity and space processing. Neuropsychologia, 47(13), 2732-2748.

Droit-Volet, S. (2013). Time perception in children: a neurodevelopmental approach. Neuropsychologia, 51(2), 220-234. doi: 10.1016/j.neuropsychologia.2012.09.023

Field, A. (2009). Discovering statistics using IBM SPSS statistics (3rd ed.): Sage Publications Ltd.

Fink, A., \& Neubauer, A. C. (2001). Speed of information processing, psychometric intelligence and time estimation as an index of cognitive load. Pers Indiv Differ, 30, 1009-1021.

Friedman, W. J. (1986). The development of children's knowledge of temporal structure. Child Dev, 57(6), 1386-1400.

Friedman, W. J. (1990). Children's representations of the pattern of daily activities. Child Dev, 61(5), 13991412.

Friedman, W. J. (2000). The development of children's knowledge of the times of future events. Child Dev, 71(4), 913-932.

Gillespie, D. C., Evans, R. I., Gardener, E. A., \& Bowen, A. (2002). Performance of older adults on tests of cognitive estimation. J Clin Exp Neuropsychol, 24(3), 286-293. doi: 10.1076/jcen.24.3.286.988

Goldman, L. S., Genel, M., Bezman, R. J., \& Slanetz, P. J. (1998). Diagnosis and treatment of attentiondeficit/hyperactivity disorder in children and adolescents. Council on Scientific Affairs, American Medical Association. JAMA, 279(14), 1100-1107.

Gonzalez-Garrido, A. A., Gomez-Velazquez, F. R., Zarabozo, D., Lopez-Elizalde, R., Ontiveros, A., MaderaCarrillo, H., ... Tuya, J. M. (2008). Time reproduction disturbances in ADHD children: an ERP study. Int J Neurosci, 118(1), 119-135. doi: 10.1080/00207450601042177

Hair, J., Black, B., Babin, B., Anderson, R., \& Tatham, R. (2006). Multivariate data analysis (6th ed.). Upper Saddle River, NJ: Prentice-Hall.

Harel, B. T., Cillessen, A. H., Fein, D. A., Bullard, S. E., \& Aviv, A. (2007). It takes nine days to iron a shirt: the development of cognitive estimation skills in school age children. Child Neuropsychol, 13(4), 309-318. doi: 10.1080/09297040600837354

Hendriksen, J. G. M. (2004). Development of the Children's Time Awareness Questionnaire Maastricht: Maastricht University. 
Hurks, P. P., \& Hendriksen, J. G. (2011). Retrospective and prospective time deficits in childhood ADHD: The effects of task modality, duration, and symptom dimensions. Child neuropsychol, 17(1), 34-50. doi: 10.1080/09297049.2010.514403

Hurks, P. P., \& van Loosbroek, E. (2014). Time estimation deficits in childhood mathematics difficulties. J Learn Disabil, 47(5), 450-461. doi: 10.1177/0022219412468161

Kadesjo, B., Janols, L. O., Korkman, M., Mickelsson, K., Strand, G., Trillingsgaard, A., \& Gillberg, C. (2004). The FTF (Five to Fifteen): the development of a parent questionnaire for the assessment of ADHD and comorbid conditions. Eur Child Adolesc Psychiatry, 13 Supp/ 3, 3-13. doi: 10.1007/s00787-004-3002-2

Kalff, A. C., Kroes, M., Vles, J. S., Bosma, H., Feron, F. J., Hendriksen, J. G., . . . Jolles, J. (2001). Factors affecting the relation between parental education as well as occupation and problem behaviour in Dutch 5- to 6-year-old children. Soc Psychiatry Psychiatr Epidemiol, 36(7), 324-331.

Meaux, J. B., \& Chelonis, J. J. (2003). Time perception differences in children with and without ADHD. J Pediatr Health Care, 17(2), 64-71. doi: 10.1067/mph.2003.26

Piaget, J. (1946). Le developpement de la notion de temps chez l'enfant. Paris: Presses Universitaires de France.

Rammsayer, T., \& Lustnauer, S. (1989). Sex differences in time perception. Percept Mot Skills, 68(1), 195198. doi: $10.2466 / p m s .1989 .68 .1 .195$

Shallice, T., \& Evans, M. E. (1978). The involvement of the frontal lobes in cognitive estimation. Cortex, 14(2), 294-303.

Sonuga-Barke, E., Bitsakou, P., \& Thompson, M. (2010). Beyond the dual pathway model: evidence for the dissociation of timing, inhibitory, and delay-related impairments in attention-deficit/hyperactivity disorder. J Am Acad Child Adolesc Psychiatry, 49(4), 345-355.

Van der Elst, W., Hurks, P., Wassenberg, R., Meijs, C., \& Jolles, J. (2011). Animal Verbal Fluency and Design Fluency in school-aged children: effects of age, sex, and mean level of parental education, and regression-based normative data. J Clin Exp Neuropsychol, 33(9), 1005-1015. doi: $10.1080 / 13803395.2011 .589509$

Walsh, V. (2003). A theory of magnitude: common cortical metrics of time, space and quantity. Trends Cogn Sci, 7(11), 483-488.

Wassenberg, R., Hendriksen, J. G. M., Hurks, P. P. M., Feron, F. J. M., Keulers, E. H. H., Vles, J. S. H., \& Jolles, J. (2007). Development of different aspects of sense of time. In R. Wassenberg (Ed.), Differential cognitive development: a neuropsychological approach (pp. 75-87). Maastricht: Neuropsych Publishers.

Wechsler, D. (2010). WPPSI-III-NL Nederlandse bewerking: Technische Handleiding (2nd ed.). Amsterdam: Netherlands: Pearson Assessment and Information BV.

White, J. L., Moffitt, T. E., Caspi, A., Bartusch, D. J., Needles, D. J., \& Stouthamer-Loeber, M. (1994). Measuring impulsivity and examining its relationship to delinquency. J Abnorm Psychol, 103(2), 192 205.

Wilson, B. A., Alderman, N., Burgess, P. W., Emslie, H., \& Evans, J. J. (2003). Behavioural assessment of the dysexecutive syndrome (BADS). J Occup Psychology Employment and Disability, 5(2), 33-37. 


\section{Chapter 4}

Can IQ predict parent-reported behavioral and emotional problems in children with neurological deficiencies?

JCAW Peijnenborgh, AM van Abeelen, PPM Hurks, AM Laridon, S Klinkenberg, AP Aldenkamp, JSH Vles, \& JGM Hendriksen Eur J Paediatr Neurol 2016 (in press) 


\section{Abstract}

\section{Objective}

The aim of the current study was to investigate whether total intelligence scores (FSIQ) and/or a discrepancy in intelligence can predict behavioral or emotional problems in children with neurological deficiencies.

\section{Method}

The population consists of children with neurological deficiencies ( $N=610$, ranging from 6 to 17 years), referred due to concerns on the (educational) development of the child to a tertiary outpatient clinic. All children were tested with the Dutch Wechsler Intelligence Scale for Children - third edition (WISC-III-NL). A VIQ-PIQ discrepancy score was calculated by subtracting the performance capacities of the verbal capacities. The effects of demographic variables, FSIQ, and the VIQ-PIQ discrepancy on two parent-rated questionnaires measuring behavior and emotions in children were analyzed with linear and logistic regression models.

\section{Results and conclusion}

The VIQ-PIQ discrepancy was not predictive of behavioral or emotional problems recorded on the above-mentioned parent-rated questionnaires. The FSIQ score, age, and sex were predictive to some extent: increases in age and FSIQ led to a decrease of reported problems, and boys showed more problems than girls. Children with neurological deficiencies had on average significantly higher verbal capacities than performance capacities, in line with the neuropsychological principle that language survives brain damage whereas performance capacities are more affected. 


\section{Introduction}

The Wechsler intelligence scales, such as the WISC for children aged 6 to 17 years (Wechsler, 2005) and the WAIS for adults (Wechsler, 2008), are the most frequently used assessment measurements of intellectual functioning for children worldwide (Reschly, 1997). Wechsler described intelligence as "the aggregate or global capacity of the individual to act purposefully, to think rationally, and to deal effectively with the environment" (Wechsler, 1939, p.3). These Wechsler scales can be used to estimate this aggregate or global capacity of intelligence (Full Scale IQ; hereafter FSIQ), but also provide data on more specific cognitive abilities, such as the verbal reasoning abilities (Verbal IQ, hereafter VIQ) and nonverbal reasoning (Performance IQ, hereafter PIQ) (Prifitera, Weiss, \& Saklofske, 1998; Wechsler, 2005). Factor analytic studies have repeatedly shown that VIQ and PIQ scores are two dissimilar functions with relatively low inter-correlations to one another (e.g., Kamphaus, 1993; Wechsler, 2005). When clinical psychologists use intelligence tests, such as the Wechsler's intelligence scales, they often aim to provide more insights in the capacities of the patient than just a general estimation of the FSIQ (Bishop \& Butterworth, 1980). When a discrepancy between VIQ and PIQ is found for instance, it is common practice to explain the significance of this finding in terms of dysfunctioning. This is not surprising, since even Wechsler himself stated that "a difference of 15 points or more calls for further investigation" (Wechsler, 1974, p. 34), and that this discrepancy is more commonly in pathological populations than in a healthy population (Wechsler, 1958).

Research has shown that a discrepancy between VIQ and PIQ has been associated with neurological disorders in children (e.g., Black, 1974, 1976; Blackburn et al., 2007). The idea that there might be a relationship between a VIQ-PIQ discrepancy and neurological deficiencies dates back to the 1950's, when Andersen (1951) observed a discrepancy between verbal and performance abilities in patients with lateralized brain lesions. The assumption was (and still is to some extent) that the verbal and performance scales of the Wechsler intelligence scales approximate measures of functions that are primarily lateralized in the two cerebral hemispheres. Lower VIQ compared to PIQ scores are assumed to be indicative of damage to the left hemisphere, whereas lower PIQ compared to VIQ scores are indicative of right hemisphere pathology (Ballantyne, Scarvie, \& Trauner, 1994; Blackburn et al., 2007). However, opposite relations (e.g., VIQ>PIQ when lesion is present in the left hemisphere) also occur (Teuber, 1975). This is explained by the developmental principle of the crowding hypothesis: after an early insult in the left hemisphere, language is taken over by the right hemisphere resulting in a sparing of verbal functions. This results in lower nonverbal skills due to crowding in the right hemisphere (Teuber, 1975).

Besides the levels of each IQ index, and independent of the other IQ indices, it is assumed in clinical care that a VIQ-PIQ discrepancy also has a significant impact on 
daily functioning (Black, Wallace, Sokoloff, \& Kenworthy, 2009). Children with a discrepancy in favor of performance capacities are hypothesized to have more difficulties in establishing social contacts or in explaining their feelings or worries, due to lower verbal capacities than performance capacities. Children with a contrary discrepancy might easily be overestimated on non-verbal cognitive functions since they are verbally strong(er). Therefore, the strength of the VIQ-PIQ discrepancy is believed to influence emotional and behavioral functioning. Overall, studies have found an inverse relationship between intelligence (i.e., FSIQ, VIQ, or PIQ) and emotional or behavioral problems in children (Teeter \& Korducki, 1998). When looking more specifically at the relation between VIQ-PIQ discrepancy and behavioral and emotional functioning, evidence showed that a VIQ-PIQ discrepancy in favor of the VIQ is related to depression in children with learning disabilities (Mokros, Poznanski, \& Merrick, 1989), whereas the opposite discrepancy is related to externalizing behavioral problems in juveniles (Cornell \& Wilson, 1992). To our knowledge, no studies have been done on this relation in a population of children with neurological deficiencies. We believe however that it is important to examine this relationship in children with neurological deficiencies, since neurological lesions might result in a VIQ-PIQ discrepancy (as mentioned above). In the current study, it was examined to which extent FSIQ and the VIQ-PIQ discrepancy have an influence on emotional and behavioral functioning and thus can predict behavioral or emotional problems in children with neurological deficiencies. We hypothesize that children with a VIQ $>$ PIQ discrepancy might have more internalizing problems, and children with a PIQ $>\mathrm{VIQ}$ discrepancy might experience more externalizing problems, in line with the studies mentioned above. It is important to examine this potential relationship, since it may give insights in treatment goals of the child and might be of influence on daily functioning.

\section{Method}

\section{Participants}

Charts of 1077 children referred to the outpatient clinic of the Center for Neurological Disabilities in the period 2010-2016 were reviewed. The Center for Neurological Disabilities is a tertiary center for children with developmental or learning problems due to a neurological condition. The parents of a total of 40 children did not want to participate in this research, and thus these children were not included. Informed consents of all other children were acquired prior to reviewing the charts. All patients were screened by a team of a child neurologist and neuropsychologist. All children $<6$ years and $>17$ years were excluded since they were assessed with different intelligence tests than the WISC-III-NL, due to age limits of the WISC-III-NL. This resulted in a group of 610 children with neurological deficiencies (386 boys, 224 girls) 
with a mean age of 10.09 years $(S D=2.75)$, ranging from 6 to 17 years. All children were referred with learning or developmental problems due to their neurological deficiencies. Neurological diagnoses varied. The following diagnosis were prevalent in 10 or more children: neurofibromatosis $(N=167)$, traumatic brain injury $(N=71)$, neurological complications due to prematurity $(N=43)$, meningitis $(N=23)$, congenital cerebral malformations $(N=22)$, genetic/chromosome abnormality $(N=19)$, Duchenne Muscular Dystrophy $(N=17)$, specific language impairment $(N=14)$, cerebral palsy $(N=13)$, epilepsy $(N=13)$, migraine $(N=11)$, brain tumor $(N=10)$.

An overview of the intelligence profiles in the largest diagnosis groups can be found in Table 4.1. A total of 66 children $(10.8 \%)$ had a discrepancy of more than 25 points: 56 children $(9.2 \% ; 67.8 \%$ of this sample was male) had a discrepancy in favor of verbal capacities, and 10 children (1.6\%; $70.0 \%$ of this sample was male) had a discrepancy in favor of performance capacities. Of the children with no discrepancy $>25$ points $(N=544), 61.8 \%$ was male.

Table 4.1 Prevalence of type of intelligence profile per diagnosis group (in percentages).

\begin{tabular}{|c|c|c|c|}
\hline Percentage of children with an IQ-discrepancy $>15$ points & Harmonic profile & $\mathrm{VIQ}>\mathrm{PIQ}$ & $\mathrm{PIQ}>\mathrm{VIQ}$ \\
\hline Neurofibromatosis $(N=167)$ & 67.1 & 22.8 & 10.1 \\
\hline Traumatic brain injury $(N=71)$ & 63.4 & 28.2 & 8.4 \\
\hline Prematurity $(N=43)$ & 67.4 & 27.9 & 4.7 \\
\hline Meningitis $(N=23)$ & 78.3 & 13,0 & 8.7 \\
\hline Congenital cerebral malformations ( $N=22)$ & 81.8 & 18.2 & 0 \\
\hline Genetic/chromosome abnormality $(N=19)$ & 79.0 & 10.5 & 10.5 \\
\hline Duchenne Muscular Dystrophy $(N=17)$ & 82.3 & 11.8 & 5.9 \\
\hline Cerebral palsy $(N=13)$ & 61.5 & 30.8 & 7.7 \\
\hline Epilepsy $(N=13)$ & 69.2 & 15.4 & 15.4 \\
\hline Specific Language Impairment $(N=14)$ & 50.0 & 7.1 & 42.9 \\
\hline Migraine $(N=11)$ & 54.5 & 36.4 & 9.1 \\
\hline Brain tumor $(N=10)$ & 50.0 & 40.0 & 10.0 \\
\hline Percentage of children with an IQ-discrepancy $>25$ points & Harmonic profile & $\mathrm{VIQ}>\mathrm{PIQ}$ & $\mathrm{PIQ}>\mathrm{VIQ}$ \\
\hline Neurofibromatosis $(N=167)$ & 87.4 & 10.2 & 2.4 \\
\hline Traumatic brain injury $(N=71)$ & 85.9 & 9.9 & 4.2 \\
\hline Prematurity $(N=43)$ & 81.4 & 16.3 & 2.3 \\
\hline Meningitis $(N=23)$ & 91.3 & 8.7 & 0 \\
\hline Congenital cerebral malformations ( $N=22)$ & 90.9 & 9.1 & 0 \\
\hline Genetic/chromosome abnormality $(N=19)$ & 94.7 & 5.3 & 0 \\
\hline Duchenne Muscular Dystrophy $(N=17)$ & 94.1 & 5.9 & 0 \\
\hline Cerebral palsy $(N=13)$ & 76.9 & 15.4 & 7.7 \\
\hline Epilepsy $(N=13)$ & 100 & 0 & 0 \\
\hline Specific Language Impairment $(N=14)$ & 92.9 & 0 & 7.1 \\
\hline Migraine $(N=11)$ & 72.7 & 27.3 & 0 \\
\hline Brain tumor $(N=10)$ & 90.0 & 10.0 & 0 \\
\hline
\end{tabular}

Note: $N=$ number of participants; $\mathrm{PIQ}>\mathrm{VIQ}=$ Discrepant profile in favor of performance capacities; $\mathrm{VIQ}>\mathrm{PIQ}$ $=$ Discrepant profile in favor of verbal capacities.

A total of 203 children (33.3\%) had a discrepancy of more than 15 points: 144 children (23.6\%; 69.4\% of this sample was male) had a discrepancy in favor of verbal capacities, and 59 children (9.7\%; $62.7 \%$ of this sample was male) had a discrepancy in 
favor of performance capacities. Of the children with a harmonic intelligence profile ( $N=407), 61.2 \%$ was male. Highest prevalence (>30\%) of a VIQ>PIQ discrepancy of more than 15 points was found in children with cerebral palsy, migraine, and/or a brain tumor. A contrary discrepancy (PIQ $>\mathrm{VIQ}$ ) was mostly found in children with specific language impairment.

\section{Materials}

\section{Intelligence test}

Wechsler Intelligence Scale for Children-III-NL (WISC-III-NL, Wechsler, 2005). Although the WISC-IV is used in other parts of the world, in the Netherlands this version is not issued. Currently, the WISC-V-NL is in development. The WISC-III-NL (3rd edition) is the most used intelligence test in The Netherlands at this moment. Aim of the WISCIII-NL is to measure the intelligence of children between 6 and 17 years of age. The test consists of 13 subtests. Performances on these subtests can be converted to three IQ-scores: Verbal IQ (VIQ), Performance IQ (PIQ), and Full Scale IQ (FSIQ). The VIQ consists of five subtests, measuring aspects of verbal knowledge, verbal reasoning, verbal comprehension, the application of verbal knowledge in daily life, and general knowledge. The PIQ consists of five subtests, measuring visual-spatial reasoning (both inductive as well as deductive), automation skills, and perception of visual details.

All IQ scores range from 45 to 145 , with 100 as the mean score $(S D=15)$. Cronbach's $\alpha$ of the FSIQ was 0.94, of the VIQ was 0.92, and of the PIQ was 0.87 (Wechsler, 2005).

\section{Questionnaires on behavioral and emotional functioning}

Child Behavior Check List (CBCL; Achenbach \& Rescorla, 2001). The CBCL is a questionnaire for parents of children between 6 and 18 years of age. It consists of 113 questions on behavior of the child (e.g., 'My child is impulsive or acts without thinking'), which can be answered on a three point scale, ranging from 'not at all' to 'often'. Used outcome measurements in the current study were the standardized scores of three scales: Internalizing problems (Cronbach's $\alpha$ : 0.90), Externalizing problems (Cronbach's $\alpha$ : 0.94), and a total score (Cronbach's $\alpha$ : 0.97) (Achenbach \& Rescorla, 2001). The higher these scores, the more problems parents reported.

Sociaal-Emotionele Vragenlijst [Social-Emotional Questionnaire] (SEV; Scholte \& Van der Ploeg, 2013). The SEV is a questionnaire for parents of children between 4 and 18 years of age. It consists of 72 questions on the social-emotional functioning of the child (e.g., 'My child is easily distracted'), which can be answered on a five point scale, ranging from 'barely' to 'very often'. The answers can be divided over four scales: Attention-deficit/Hyperactivity Disorder (ADHD; Cronbach's $\alpha$ : 0.94), Oppositional Defiant Disorder (ODD; Cronbach's $\alpha$ : 0.94), Anxious and mood disturbance behavior (Cronbach's $\alpha$ : 0.92), and Autism Spectrum Disorder (ASD; Cronbach's $\alpha$ : 0.83) 
(Scholte \& Van der Ploeg, 2013). The higher the scores on these scales, the more social-emotional functioning problems parents reported. For the present study, total raw score on each scale was converted to a standardized score. These standardized scores were converted to a clinical score $(=1)$ or a non-clinical score $(=0)$.

\section{Statistics}

Data were analyzed with IBM SPSS statistics version 21.0.0.0. All outliers (scores with z>3.29) were replaced by the mean + three times standard deviation as advised by Field (2009).

The VIQ-PIQ discrepancy was calculated by subtracting the PIQ-score of the VIQ-score. Positive results indicated better verbal capacities than performance capacities, and negative results indicated better performance capacities than verbal capacities. Prevalence of a discrepancy $>15$ points and $>25$ points was calculated. Since the prevalence of children with a discrepancy $>25$ points was low, it was decided to focus on a discrepancy $>15$ points (i.e., a 1 SD discrepancy). Based on this discrepancyrange, three profile subgroups were made: children with a harmonic profile, children with a VIQ (at least) 15 points higher than PIQ, and children with a PIQ (at least) 15 points higher than VIQ.

Descriptive statistics and frequencies of the IQ-scores (FSIQ, VIQ, and PIQ) and of the $\mathrm{CBCL}$ and SEV-scales were calculated for the total group and for the three profile subgroups separately. A paired-samples $t$-test was used to measure potential differences between VIQ and PIQ, again for the total group and for the three groups separately.

The Shapiro-Wilk test was used on the VIQ-PIQ discrepancy score and IQ-scores (FSIQ, $\mathrm{VIQ}$, and $\mathrm{PIQ}$ ) in the total group and across the three profile subgroups, to examine whether the distribution of the scores was different from normal distribution.

The effect of the VIQ-PIQ discrepancy score on the three scales of the CBCL was analyzed with multiple linear regression analyzes. The full regression models included age, sex, FSIQ, and the VIQ-PIQ discrepancy score as predictors. Age was centered (calendar age - mean age in the sample). Sex was dummy coded as $0=$ male, and $1=$ female.

Since the SEV consisted of two categories as outcome measurements, the effect of the VIQ-PIQ discrepancy score and FSIQ on each scale was analyzed with logistic regression analyzes. Predictors were similar to the predictors in the linear regression analyzes of the CBCL. 


\section{Results}

\section{Performance on the WISC-III-NL in a neurological group}

IQ-scores for the total group were calculated and for each group separately (see Table 4.2). A paired-samples $t$-test indicated that the difference between VIQ and PIQ was significant in the total group: $t(609)=8.51, p<.01$. In children with a harmonic profile, the difference between VIQ (mean=90.86, $S D=16.24$ ) and PIQ (mean=89.02, $S D=16.16$ ) was small, but significant: $t(406)=5.17, p<.01$. Analyzes on the distribution of the IQ-scores in the total group and in the three profile subgroups showed that all scores were normally distributed (see Table 4.3), with the exception of PIQ: $W(608)=.99, p<.05$.

A discrepancy score was calculated by subtracting the PIQ-score of the VIQ-score (see Table 4.3). The Shapiro-Wilks test indicated that this discrepancy score was normally distributed in the total group $(W(608)=1.00, p=.24)$. When looking at the three groups separately, this discrepancy was significantly non-normally distributed in all three groups: Harmonic profile: $W(407)=.97, p<.01$; VIQ>PIQ: $W(142)=.90, p<.01 ; \mathrm{PIQ}>\mathrm{VIQ}$ : $W(59)=.84, p<.01$.

\section{Regression models of the CBCL}

The multiple linear regression models are shown in Table 4.4. Although small, a significant proportion of variance in CBCL's Total Problems scores was explained by the model including four factors $\left(R^{2}=.02, F(4,556)=2.86, p<.05\right)$. However, only one of these factors significantly predicted the outcome on this scale: children with higher FSIQ-scores had significantly lower scores on the CBCL Total Problems.

The model of $\mathrm{CBCL}^{\prime} \mathrm{s}$ Internalizing Problems could not significantly predict the proportion of variance.

The model of CBCL's Externalizing Problems could predict a significant proportion of variance, but again this was only a small proportion $\left(R^{2}=.02, F(4,556)=2.48, p<.05\right)$. In this model, two factors were significant: the higher the FSIQ of the child, the lower the problem-score on this scale, and the older the child, the lower the reported problems. In all three models, sex and the IQ-discrepancy score could not significantly predict the outcome of the scales. 


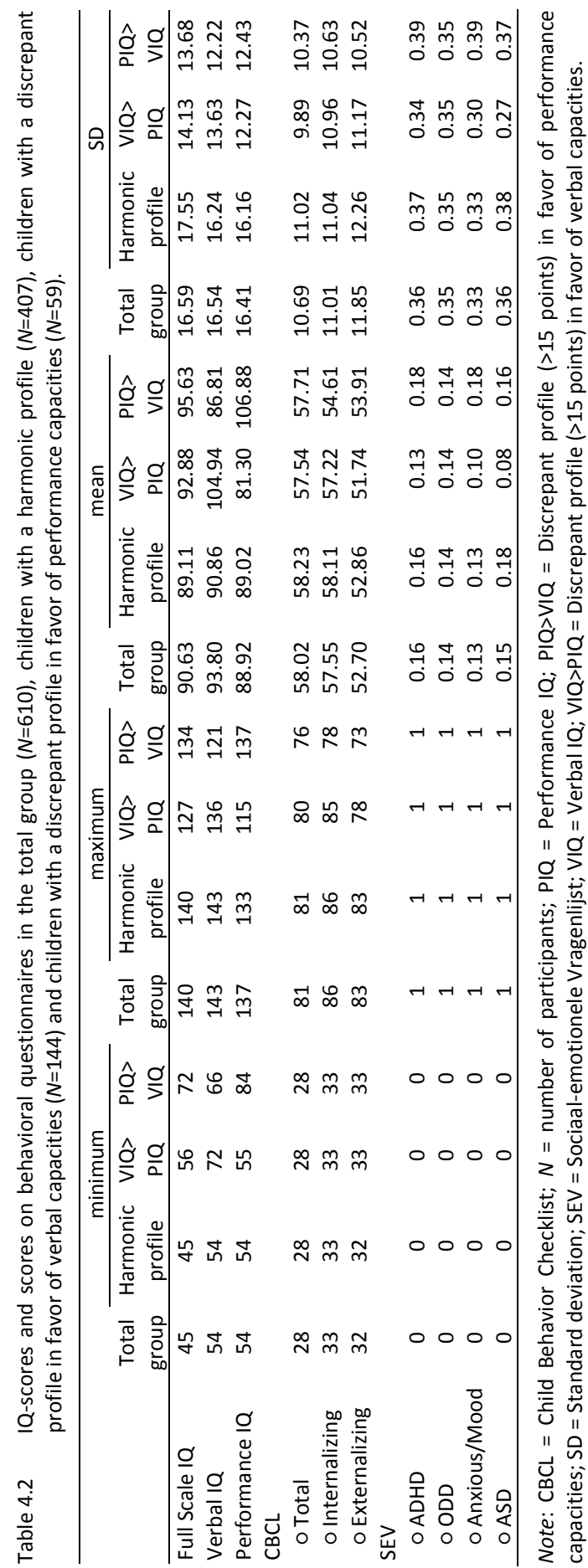


Table 4.3 Distribution of the IQ-scores.

\begin{tabular}{llccc}
\hline & & Shapiro-Wilk & & \\
& & Statistic & df & Sign. \\
\hline Full Scale IQ & Total group & 1.00 & 608 & .76 \\
& harmonic profile & 1.00 & 407 & .49 \\
& VIQ $>$ PIQ & .99 & 142 & .77 \\
VIQ & PIQ $>$ VIQ & .98 & 59 & .28 \\
& Total group & 1.00 & 608 & .08 \\
& harmonic profile & .99 & 407 & .08 \\
PIQ & VIQ $>$ PIQ & .99 & 142 & .60 \\
& PIQ $>$ VIQ & .97 & 59 & .12 \\
& Total group & .99 & .01 \\
& harmonic profile & .99 & .06 \\
Discrepancy score & VIQ $>$ PIQ & .99 & .29 \\
& PIQ $>$ VIQ & .98 & 142 & .47 \\
& Total group & 1.00 & 59 & .24 \\
& harmonic profile & .97 & 608 & .00 \\
& VIQ $>$ PIQ & .90 & 407 & .00 \\
& PIQ $>$ VIQ & .84 & 142 & .00 \\
\hline
\end{tabular}

Note: $\mathrm{df}=$ degrees of freedom; $\mathrm{PIQ}=$ Performance $\mathrm{IQ} ; \mathrm{PIQ}>\mathrm{VIQ}=$ Discrepant profile $(>15$ points) in favor of performance capacities; Sign = significance; $\mathrm{VIQ}=$ Verbal IQ; $\mathrm{VIQ}>\mathrm{PIQ}=$ Discrepant profile $(>15$ points $)$ in favor of verbal capacities.

Table 4.4 Regression models for behavioral problems in children with neurological deficiencies $(N=610)$.

\begin{tabular}{|c|c|c|c|c|c|c|}
\hline & $B$ & SE $B$ & $\beta$ & $R^{2}$ & $\Delta R^{2}$ & Sign \\
\hline CBCL Total problems & & & & 0.02 & 0.01 & 0.02 \\
\hline Constant & 66.30 & 2.55 & & & & \\
\hline FSIQ & -0.09 & 0.03 & $-.14^{*}$ & & & \\
\hline Age & -0.19 & 0.17 & -.05 & & & \\
\hline Sex & -0.24 & 0.93 & -.01 & & & \\
\hline IQ-discrepancy score & -0.02 & 0.03 & -.03 & & & \\
\hline $\mathrm{CBCL}$ Internalizing problems & & & & 0.01 & 0.00 & 0.21 \\
\hline Constant & 59.56 & 2.64 & & & & \\
\hline FSIQ & -0.03 & 0.03 & -.04 & & & \\
\hline Age & 0.25 & 0.17 & .06 & & & \\
\hline Sex & 1.18 & 0.96 & .05 & & & \\
\hline IQ-discrepancy score & 0.03 & 0.03 & .04 & & & \\
\hline CBCL Externalizing problems & & & & 0.02 & 0.01 & 0.04 \\
\hline Constant & 59.21 & 2.83 & & & & \\
\hline FSIQ & -0.07 & 0.03 & $-.10 *$ & & & \\
\hline Age & -0.44 & 0.19 & $-.10 *$ & & & \\
\hline Sex & -0.41 & 1.03 & -.02 & & & \\
\hline IQ-discrepancy score & -0.03 & 0.04 & -.03 & & & \\
\hline
\end{tabular}

Note: $B$ = regression coefficient; $\beta=$ standardized regression coefficient; $\mathrm{CBCL}=$ Child Behavior Checklist; FSIQ = Full scale IQ; $N=$ number of participants; $R^{2}=$ the coefficient of determination; $\Delta R^{2}=$ change of the coefficient of determination in the model; SE $B=$ Standard error of the regression coefficient; Sign = significance of the model. ${ }^{*}=p<.05$. 


\section{Logistic regression models of the SEV}

To predict whether a child had a clinical or non-clinical score on a subscale of the SEV, several logistic regression models were calculated. The logistic regression models are shown in Table 4.5.

Table 4.5 Regression models for emotional problems in children with neurological deficiencies $(N=610)$.

\begin{tabular}{llcccrr}
\hline & & \multicolumn{5}{c}{$95 \%$ CI for Odds Ratio } \\
SEV ADHD & $B$ & SE & Lower & Odds Ratio & Upper \\
\hline Constant & -0.26 & 0.69 & & & \\
& FSIQ & -0.01 & 0.01 & 0.94 & 0.99 & 1.00 \\
Age & $-0.13^{* *}$ & 0.05 & 0.80 & 0.88 & 0.97 \\
Sex & $-0.70^{* *}$ & 0.24 & 0.31 & 0.50 & 0.79 \\
& IQ-discrepancy score & 0.01 & 0.01 & 0.98 & 1.00 & 1.01 \\
\hline
\end{tabular}

$R^{2}=.79$ (Hosmer \& Lemeshow), .03 (Cox \& Snell), .05 (Nagelkerke). Model $X^{2}(4)=16.77, p<.01 .{ }^{* *}=p<.01$

95\% Cl for Odds Ratio

\begin{tabular}{llccccc} 
& & $B$ & SE & Lower & Odds Ratio & Upper \\
\hline Constant & -2.26 & 0.72 & & & \\
FSIQ & 0.01 & 0.01 & 0.99 & 1.01 & 1.02 \\
Age & $-.10^{*}$ & 0.05 & 0.82 & 0.90 & 0.99 \\
Sex & -.26 & 0.25 & 0.48 & 0.77 & 1.25 \\
& IQ-discrepancy score & -.00 & 0.01 & 0.98 & 1.00 & 1.01 \\
\hline
\end{tabular}

$R^{2}=.39$ (Hosmer \& Lemeshow), .01 (Cox \& Snell), .02 (Nagelkerke). Model $X^{2}(4)=7.33, p=.12{ }^{*}=p<.05$

$95 \% \mathrm{Cl}$ for Odds Ratio

\begin{tabular}{llccccc} 
SEV Anxious/Mood & & $B$ & SE & Lower & Odds Ratio & Upper \\
\hline & Constant & -1.56 & 0.75 & & & \\
& FSIQ & 0.00 & 1.00 & 0.99 & 1.00 & 1.02 \\
& Age & -.06 & 0.05 & 0.86 & 0.95 & 1.04 \\
& Sex & $-.62^{*}$ & 0.26 & 0.33 & 0.54 & 0.89 \\
& IQ-discrepancy score & -.01 & 0.01 & 0.97 & 0.99 & 1.01 \\
\hline
\end{tabular}

$R^{2}=.26$ (Hosmer \& Lemeshow), .02 (Cox \& Snell), .03 (Nagelkerke). Model $X^{2}(4)=8.59, p=.07 . *=p<.05$

$95 \% \mathrm{Cl}$ for Odds Ratio

\begin{tabular}{|c|c|c|c|c|c|c|}
\hline \multirow[t]{6}{*}{ SEV ASD } & & $B$ & SE & Lower & Odds Ratio & Upper \\
\hline & Constant & 0.12 & 0.70 & & & \\
\hline & FSIQ & $-.02 * *$ & 0.01 & 0.97 & 0.98 & 0.99 \\
\hline & Age & $-.11^{*}$ & 0.05 & 0.82 & 0.90 & 0.99 \\
\hline & Sex & -.31 & 0.24 & 0.45 & 0.73 & 1.18 \\
\hline & IQ-discrepancy score & -.02 & 0.01 & 0.97 & 0.98 & 1.00 \\
\hline
\end{tabular}

$R^{2}=.78$ (Hosmer \& Lemeshow), .03 (Cox \& Snell), .04 (Nagelkerke). Model $X^{2}(4)=14.22, p<.01 .^{*}=p<.05$

Note: $\mathrm{ADHD}=$ Attention-Deficit/Hyperactivity Disorder; $\mathrm{ASD}=$ Autism Spectrum Disorder; $B=$ regression coefficient; $X^{2}=$ Chi Square; $\mathrm{Cl}=$ Confidence Interval; $\mathrm{FSIQ}=$ Full scale IQ; $N=$ number of participants; ODD = Oppositional Defiant Disorder; $R^{2}=$ the coefficient of determination; SE = Standard error; SEV = SociaalEmotionele Vragenlijst; Sign = significance of the model. ${ }^{*}=p<.05 ;{ }^{* *}=p<.01$. 
The model of SEV's ADHD was significant $\left.\chi^{2}(4)=16.77, p<.01\right)$. Both age and sex were significant predictors: the older the child, the less likely $s /$ he is to receive a clinical score. Also, the chance of receiving a clinical score was higher in boys than in girls.

The models of SEV's ODD and Anxious/Mood were not significant.

The model of SEV's ASD was significant $\left(\chi^{2}(4)=14.22, p<.01\right)$. Two predictors were capable of predicting whether a child had a clinical score: the higher the FSIQ or the higher the age, the lower the chance of receiving a clinical score.

Again, the VIQ-PIQ discrepancy score could not significantly predict whether a child would receive a clinical or non-clinical score.

\section{Discussion}

To examine to which extent a Full-scale IQ (FSIQ) score and a discrepancy in IQ-profile can predict behavioral or emotional problems in children with neurological deficiencies, a group of 610 children with a large variation of neurological disorders ranging in age from 6 to 17 years was examined. We found that 33.3\% of the children in our population had a discrepancy in their VIQ-PIQ-profile of more than 15 points (23.6\% in favor of verbal capacities, $9.7 \%$ in favor of performance capacities). Prior research has indicated that this is $28 \%$ in normally developing children (Wechsler, 2005). The assumption is that performance capacities suffer specially from neurological problems, whereas verbal capacities are less negatively influenced by these (Eilander \& Hendriksen, 2011). Indeed, in this population we found that verbal capacities are significantly higher than performance capacities, although the difference between VIQ and PIQ was small. An explanation for this finding of VIQ>PIQ is that verbal capacities do an appeal on crystallized knowledge, whereas performance capacities do an appeal on motoric manipulation and speed, as well as new abilities: elements that are more affected by brain damage (Anderson, Northam, Hendy, \& Wrennall, 2001; Jaffe, Polissar, Fay, \& Liao, 1995).

Since several studies suggested that a VIQ-PIQ discrepancy correlates with behavioral problems, we wanted to study to which extent this discrepancy-score could predict behavioral and emotional problems. Previous research has shown that a discrepancy in favor of verbal capacities is related to depression (Mokros et al., 1989) or emotional dysregulation (Guenole et al., 2015), and a discrepancy in favor of performance capacities is found to be related to externalizing behavioral problems (e.g., Cornell \& Wilson, 1992). Contrary, Guenole and colleagues (2013) found that for gifted children, a VIQ>PIQ discrepancy was related to externalizing problems as opposed to a PIQ $>\mathrm{VIQ}$ discrepancy. Further studies' findings are often inconsistent and even contradictory. To our knowledge, no studies examined whether a VIQ-PIQ discrepancy can predict parent-reported behavioral or emotional problems in children with neurological deficiencies. Our findings suggest that we cannot accept this hypothesis. Analyzes of the regression models showed that a VIQ-PIQ discrepancy was not capable of 
predicting whether a child would have behavioral or emotional problems. Indeed, no significant relation was found between the VIQ-PIQ discrepancy and results of behavioral and emotional questionnaires. However, to some extent the FSIQ was a better predictor of behavioral of emotional functioning: the higher the FSIQ, the fewer problems are reported by parents. This is interesting, since clinicians often state that the FSIQ is less reliable when there is a discrepant VIQ-PIQ profile. These findings suggest that the FSIQ is a more robust measurement of the capacities of the child, even if there is a difference between verbal and performance capacities. This was also noted by Prifitera and colleagues (1998). Age was also of influence on reported behavioral and emotional problems. Less externalizing behavioral problems were reported for older children. This is in line with previous research that claims that ADHD-symptoms and externalizing behavior problems decrease with age (Ramtekkar, Reiersen, Todorov, \& Todd, 2010). A third factor that could to some extent predict parent-reported ADHD-problems, was sex. Boys were more likely to receive a clinical score than girls. Again, this is in line with previous research, which found that ADHD is more prevalent in boys than in girls (Gershon, 2002).

Several explanations might be given for the lack of a relationship between the VIQ-PIQ discrepancy and behavioral and emotional problems. It could indicate that in this population, no relationship exists between VIQ-PIQ discrepancies and behavioral or emotional problems. This is in line with Moffitt and Silva (1987), who found no relationship between a VIQ-PIQ discrepancy and behavior problems in healthy children, and Rispens and colleagues (1997) who found no relationship between VIQPIQ discrepancy and behavior in children with psychiatric disorders. Our results indicate that this low correlation also applies to children with neurological deficiencies. Another explanation might be found in the principle of "diagnostic overshadowing". Hendriksen, Peijnenborgh, Aldenkamp, and Vles (2015) found in the same population of children with neurological deficiencies that the diagnosis Attention-Deficit/Hyperactivity Disorder (ADHD) is often overshadowed by the neurological deficiencies. In diagnostic overshadowing, there is too much focus on the neurological deficiencies, which could result in a diagnosis such as ADHD to be overlooked. Perhaps the same principle applies when parents are asked to fill in behavioral questionnaires. Since the largest concern for parents might be the neurological deficiency itself, behavioral problems might be overshadowed or perceived as less worrisome. This could explain why parents did not report more behavioral or emotional problems. Further research is necessary to gain more insights in this field.

The current study had some limitations. The group of included children had a large variation of neurological disorders, causing a heterogeneous sample. The sample consisted of children with a congenital condition, but also children who acquired a neurological condition at a young age or later on in life. The level of experienced problems might be diverse in the children: some children experienced severe difficulties, while other children had recovered from the neurological condition (e.g., 
some children fully recovered from TBI). Although the group was heterogeneous in diagnosis, the age at which the neurological condition was experienced or started, and in the level of experienced difficulties due to the neurological condition, all children had in common that they experienced developmental and/or learning problems. Since this was not the aim of this study, we did not further examine these potentially different samples. It might be interesting to examine the prevalence of VIQ-PIQ discrepancies in subgroups of this sample (e.g., children with a lesion in the left hemisphere, or uni/bilateral lesions, children who suffer from a specific neurological condition, or timing of lesion in case of acquired neurological disorder) in future research.

To conclude, we believe that our findings indicate that a VIQ-PIQ-discrepancy in itself is not capable of predicting whether a child will have emotional or behavioral problems, but the FSIQ, age, and sex are better predictors. Future research is necessary to find out whether diagnostic overshadowing on behavioral or emotional problems is applicable for children with neurological deficiencies. 


\section{References}

Achenbach, T. M., \& Rescorla, L. A. (2001). Manual for the ASEBA School-Age Forms \& Profiles. Burlington: University of Vermont, Research Center for Children, Youth, \& Families.

Andersen, A. L. (1951). The effect of laterality localization of focal brain lesions on the Wechsler-Bellevue subtests. J Clin Psychol, 7(2), 149-153.

Anderson, V., Northam, E., Hendy, J., \& Wrennall, J. (2001). Developmental neuropsychology. A clinical approach. Hove: Psychology Press.

Ballantyne, A. O., Scarvie, K. M., \& Trauner, D. A. (1994). Verbal and performance IQ patterns in children after perinatal stroke. Dev Neuropsychol, 10(1), 39-50.

Bishop, D. V., \& Butterworth, G. E. (1980). Verbal-performance discrepancies: relationship to birth risk and specific reading retardation. Cortex, 16(3), 375-389.

Black, D. O., Wallace, G. L., Sokoloff, J. L., \& Kenworthy, L. (2009). Brief report: IQ split predicts social symptoms and communication abilities in high-functioning children with autism spectrum disorders. $J$ Autism Dev Disord, 39(11), 1613-1619. doi: 10.1007/s10803-009-0795-3

Black, F. W. (1974). WISC Verbal-Performance discrepancies as indicators of neurological dysfunction in pediatric patients. J Clin Psychol, 30(2), 165-167.

Black, F. W. (1976). Cognitive deficits in patients with unilateral war-related frontal lobe lesions. J Clin Psychol, 32(2), 366-372.

Blackburn, L. B., Lee, G. P., Westerveld, M., Hempel, A., Park, Y. D., \& Loring, D. W. (2007). The Verbal $\mathrm{IQ} /$ Performance IQ discrepancy as a sign of seizure focus laterality in pediatric patients with epilepsy. Epilepsy Behav, 10(1), 84-88. doi: 10.1016/j.yebeh.2006.10.001

Cornell, D. G., \& Wilson, L. A. (1992). The PIQ greater than VIQ discrepancy in violent and nonviolent delinquents. J Clin Psychol, 48(2), 256-261.

Eilander, H., \& Hendriksen, J. (2011). Traumatisch hersenletsel. In H. Swaab, A. Bouma, J. Hendriksen \& C. König (Eds.), Klinische Kinderneuropsychologie. Amsterdam: The Netherlands: Boom.

Field, A. (2009). Discovering statistics using IBM SPSS statistics (3rd ed.): Sage Publications Ltd.

Gershon, J. (2002). A meta-analytic review of gender differences in ADHD. J Atten Disord, 5(3), 143-154.

Guenole, F., Louis, J., Creveuil, C., Baleyte, J. M., Montlahuc, C., Fourneret, P., \& Revol, O. (2013). Behavioral profiles of clinically referred children with intellectual giftedness. Biomed Res Int, 2013, 540153. doi: $10.1155 / 2013 / 540153$

Guenole, F., Speranza, M., Louis, J., Fourneret, P., Revol, O., \& Baleyte, J. M. (2015). Wechsler profiles in referred children with intellectual giftedness: Associations with trait-anxiety, emotional dysregulation, and heterogeneity of Piaget-like reasoning processes. Eur J Paediatr Neurol, 19(4), 402410. doi: 10.1016/j.ejpn.2015.03.006

Hendriksen, J. G., Peijnenborgh, J. C., Aldenkamp, A. P., \& Vles, J. S. (2015). Diagnostic overshadowing in a population of children with neurological disabilities: A cross sectional descriptive study on acquired ADHD. Eur J Paediatr Neurol, 19(5), 521-524. doi: 10.1016/j.ejpn.2015.04.004

Jaffe, K. M., Polissar, N. L., Fay, G. C., \& Liao, S. (1995). Recovery trends over three years following pediatric traumatic brain injury. Arch Phys Med Rehabil, 76(1), 17-26.

Kamphaus, R. W. (1993). Clinical assessment of children's intelligence. Needham Heights: Allyn \& Bacon.

Moffitt, T. E., \& Silva, P. A. (1987). WISC-R verbal and performance IQ discrepancy in an unselected cohort: clinical significance and longitudinal stability. J Consult Clin Psychol, 55(5), 768-774.

Mokros, H. B., Poznanski, E. O., \& Merrick, W. A. (1989). Depression and learning disabilities in children: a test of an hypothesis. J Learn Disabil, 22(4), 230-233, 244.

Prifitera, A., Weiss, L. G., \& Saklofske, D. H. (1998). The WISC-III in context. In A. Prifitera \& D. H. Saklofske (Eds.), WISC-III Clinical use and interpretation: Scientist-practitioner perspectives (pp. 1-39). San Diego: Academic Press.

Ramtekkar, U. P., Reiersen, A. M., Todorov, A. A., \& Todd, R. D. (2010). Sex and age differences in attentiondeficit/hyperactivity disorder symptoms and diagnoses: implications for DSM-V and ICD-11. J Am Acad Child Adolesc Psychiatry, 49(3), 217-228 e211-213.

Reschly, D. J. (1997). Diagnostic and treatment utility of intelligence tests. In D. P. Flanagan, J. L. Genshaft \& P. L. harrison (Eds.), Contemporary intellectual assessment: Theories, tests, and issues (pp. 437-456). New York: Guilford. 
Rispens, J., Swaab, H., van den Oord, E. J., Cohen-Kettenis, P., van Engeland, H., \& van Yperen, T. (1997). WISC profiles in child psychiatric diagnosis: sense or nonsense? J Am Acad Child Adolesc Psychiatry, 36(11), 1587-1594. doi: 10.1016/S0890-8567(09)66569-2

Scholte, E., \& Van der Ploeg, J. (2013). Sociaal-Emotionele Vragenlijst (SEV) - Handleiding. Houten: The Netherlands: Bohn Stafleu Van Loghum.

Teeter, P. A., \& Korducki, R. (1998). Assessment of emotionally disturbed children with the WISC-III. In A. Prifitera \& D. H. Saklofske (Eds.), WISC-III Clinical use and interpretation: scientist-practioner perspectives. San Diego: Academic Press.

Teuber, H. L. (1975). Recovery of function after brain injury in man. Ciba Found Symp(34), 159-190.

Wechsler, D. (1939). The measurement of adult intelligence. Baltimore, MD: Williams \& Wilkins.

Wechsler, D. (1958). The Measurement and Appraisal of Adult Intelligence (4th ed.). Baltimore: Williams \& Wilkins Co.

Wechsler, D. (1974). Manual of the Wechsler Intelligence Scale for Children - Revised. New York: Psychological Corporation.

Wechsler, D. (2005). WISC-III-NL Handleiding. Amsterdam: The Netherlands: Harcourt Assessment.

Wechsler, D. (2008). Wechsler Adult Intelligence Scale (4th ed.). San Antonio: Pearson. 


\section{Chapter 5}

\section{Diagnostic overshadowing in a population of children with neurological learning disabilities:}

a cross sectional descriptive study on acquired ADHD

JGM Hendriksen, JCAW Peijnenborgh, AP Aldenkamp \& JSH Vles

Eur J Paediatr Neurol 2015;19, 521-524 


\section{Abstract}

\section{Aim}

Diagnostic overshadowing refers to the underdiagnosis of comorbid conditions in children with known neurological diagnoses. To demonstrate diagnostic overshadowing we determined the prevalence of Attention-Deficit/Hyperactivity Disorders (ADHD) in a cohort of children with a wide range of neurological disabilities.

\section{Method}

The study cohort consisted of 685 children (mean age 10.3 years, SD=3.1; 425 boys and 260 girls) who visited a tertiary outpatient multidisciplinary clinic for neurological learning disabilities. Patients with ADHD were identified by retrospective chart review using DSM-IV criteria.

\section{Results}

The prevalence of ADHD in this cohort was $38.8 \%$ (266 children); of these children only $28.2 \%$ (75 children) were diagnosed with ADHD before referral.

\section{Interpretation}

ADHD is a common problem in children with neurological disabilities and may be underdiagnosed due to overshadowing of somatic, physical or syndromal features of the disability. In our heterogeneous population ADHD was overshadowed in $71.8 \%$ of the cases. This finding may have important implications for diagnosis and treatment of mental health needs in children with neurological disabilities. 


\section{Introduction}

Attention-Deficit/Hyperactivity Disorder (ADHD) is the most common neurodevelopmental disorder in childhood with important implications for the child's functioning in the domain of learning, emotion, behavior, and social functioning. Polanczyk and colleagues estimated its prevalence in a systematic worldwide review to be $5.29 \%$ (Polanczyk, de Lima, Horta, Biederman, \& Rohde, 2007).

The aetiology of ADHD is heterogeneous. On the one hand it is a highly heritable disorder (estimated to be around $70-80 \%$ of the genetic variation), on the other hand it can be acquired due to lesions of the brain, other environmental factors such as deprivation, or a combination of factors (Spencer, Biederman, \& Mick, 2007). The presence of brain dysfunction is associated with a higher risk of neuropsychiatric problems. This was already described by Graham and Rutter in the classical Isle of Wight study (Graham \& Rutter, 1968). In a population of 11,826 school age children they found that in children with a neurological condition (epilepsy or cerebral palsy) $34.5 \%$ also manifested a psychiatric disorder. For children with lesions below the brainstem (like muscular dystrophy or poliomyelitis) the prevalence was $13.3 \%$. They furthermore reported that organic brain dysfunction was not associated with any specific type of psychiatric disorder such as hyperkinetic syndrome or neurotic disorders.

Literature on ADHD in neurological disabilities is fragmented and often restricted to small samples of children using different methodologies and lack of control groups. We reviewed the literature on the prevalence of ADHD in four different child neurological conditions. In children with severe traumatic brain injury, the incidence of ADHD is about one third of the children (Max et al., 2004). Max and colleagues introduced the term secondary attention deficit hyperactivity disorder (SADHD) to better characterize this condition of paediatric psychopathology. The term acquired ADHD has also been used for attention disorders in various neurodevelopmental disorders such as neurofibromatosis type 1 (NF1) where an incidence of ADHD has been reported of 53\% (Ewen \& Shapiro, 2005; Garg et al., 2013). In clinical practice only a small percentage of children with NF1 are diagnosed with ADHD (Johnson, Wiggs, Stores, \& Huson, 2005). For children with cerebral palsy (CP) there is to our knowledge only one population based study on psychiatric comorbidity (Bjorgaas, Hysing, \& Elgen, 2012). Bjorgaas and colleagues found in a Norwegian cohort of 67 children with CP that $50 \%$ of the children with mild to moderate motor function problems without intellectual disability, met the criteria of ADHD. Furthermore, in two thirds of children with CP meeting the criteria of ADHD, the attention problems had not been addressed prior to the study. Finally, in boys and young men with Duchenne muscular dystrophy (DMD) the involvement of the brain is now beyond any doubt (Snow, Anderson, \& Jakobson, 2013). Recently Pane and colleagues assessed ADHD in 103 boys with DMD. ADHD was found in $32 \%$ of the boys; 18 of them also had an 
intellectual disability. ADHD was not related to the level of motor ability, nor to the use of steroids (Pane et al., 2012).

There is a growing interest in the neurobehavioral aspects of child neurological conditions, but they may remain underdiagnosed. We hypothesize that the term diagnostic overshadowing applies for ADHD in children with neurological disabilities. Originally, Reiss, Levtan, and Szyszko introduced this term in 1982 to refer to the tendency to attribute behavior problems in individuals with intellectual disability to this underlying cognitive deficit and therefore underdiagnose a comorbid psychopathology (Reiss, Levitan, \& Szyszko, 1982). This clinical bias may result in underdiagnosis of attention deficit symptoms without further diagnosis and treatment. This may have important implications for the children's future academic and professional career, which is not only at risk because of physical impairments, but also because of the attention deficits if left untreated.

The aim of the present cohort study was to study the prevalence of ADHD in a clinical sample of school age children with a wide range of neurological disabilities in general and, more specific, in children with traumatic brain injury, cerebral palsy, neurofibromatosis type 1 , and Duchenne muscular dystrophy.

\section{Method}

Charts of children referred to a tertiary outpatient clinic of neurological learning disabilities in Heeze (Netherlands) for the period 2010-2014 were reviewed. A team of a child neurologist and a (child)neuropsychologist evaluated the children. A total of 863 children were referred with a neurological condition or suspicion of a neurological condition. Informed consent was given by all caregivers. One hundred children were five years or younger, and therefore were excluded because no formal diagnosis of ADHD can be made according to DSM-IV. Furthermore, data of 78 children were incomplete or there was no informed consent. The majority of the remaining 685 children was male $(N=425,62 \%)$. Mean age was 10.3 years $(S D=3.1)$. Most of the children referred to this clinic receive normal education: $68 \%$.

Medical diagnoses varied among the 685 children: severe traumatic brain injury $(N=13)$, Cerebral Palsy $(N=21)$, neurofibromatosis type $1(N=150)$, and Duchenne muscular dystrophy $(N=17)$. Data from referral were closely inspected to determine whether a diagnosis of ADHD had been made before referral. During medical history taking all parents were systematically asked whether there was a family history of ADHD, reflecting a possible heritability factor.

All children had a medical and psychological assessment. Intelligence testing with the Wechsler Intelligence scales for children (WISC-III-NL) was available in 446 of the children. The mean IQ of the total group was in the low average IQ zone: Total IQ 89.8 ( $S D=16.5)$; verbal IQ 92.9 ( $S D=16.2)$; performance IQ 88.6 ( $S D=17.6)$. The diagnosis of ADHD was made on the basis of a standard protocol (Goldman, Genel, Bezman, \& 
Slanetz, 1998) which includes 1) extensive history taking, 2) cognitive testing, 3) general physical and neurological examination of the child, as well as 4) systematic assessment of ADHD-characteristics by means of structured questions based on the DSM-IV criteria (American Psychiatric Association, 2000).

This research was conducted according to the rules of medical audit and good clinical care.

\section{Results}

In our patient population 266 children (38.8\%) were given the clinical diagnosis ADHD. Inspection of the medical files at referral showed that 75 of the children (28.2\%) had already received a diagnosis of ADHD before referral. Furthermore, the medical history revealed that for $6.1 \%$ of the children a previous family history of attention disorders was present. When looking at ADHD in the different medical diagnoses the following frequency distribution of $A D H D$ can be seen: traumatic brain injury $2 / 13$ (15\%); neurofibromatosis 60/150 (40\%), cerebral palsy 8/21 (38\%); Duchenne muscular dystrophy 5/17 (29\%). An overview of all results can be found in Table 5.1.

Table 5.1 ADHD diagnosis before and after assessment.

\begin{tabular}{lcr}
\hline & ADHD diagnosis before referral & ADHD diagnosis after assessment \\
\hline Total & $75 / 685(11 \%)$ & $266 / 685(39 \%)$ \\
Cerebral palsy & $1 / 21(5 \%)$ & $8 / 21(38 \%)$ \\
Duchenne & $0 / 17(0 \%)$ & $5 / 17(29 \%)$ \\
Neurofibromatosis & $16 / 150(11 \%)$ & $60 / 150(40 \%)$ \\
Traumatic brain injury & $1 / 13(8 \%)$ & $2 / 13(15 \%)$ \\
\hline
\end{tabular}

\section{Discussion}

The complexity and heterogeneity of child neurological disabilities constitutes a challenge to diagnose ADHD in this group of children. There is a growing scientific interest in the neurobehavioral comorbidities of these disabilities: terms as 'secondary ADHD' or 'acquired ADHD' are used in literature.

Our descriptive cohort study reports on the clinical data of a heterogeneous sample of children with a neurological disability, referred to a tertiary outpatient clinic. Overall the prevalence rate of ADHD is $38.8 \%$. A loaded family history for ADHD was reported in $6.1 \%$ of our cases, which corresponds with the general prevalence of ADHD in a normal population (Polanczyk et al., 2007). It can be concluded that acquired ADHD is an important comorbidity in our patient group as the prevalence rate is higher than in a normal population (Polanczyk et al., 2007). 
For neurofibromatosis type 1 and Duchenne muscular dystrophy our prevalence rates closely correspond with data reported in literature: $40 \%$ for neurofibromatosis and 29\% for Duchenne (Garg et al., 2013; Johnson et al., 2005; Pane et al., 2012). Prevalence numbers of ADHD in our sample of children with traumatic brain injury is lower (15\% in comparison to $33 \%$ in literature), as is also the case in cerebral palsy (38\% in comparison to $50 \%$ in literature) (Bjorgaas et al., 2012; Max et al., 2004). This could be related to the relatively small number of children with traumatic brain injury and cerebral palsy in our sample.

Several methodological difficulties may limit the conclusions that can be drawn from these data. First of all a clinical "convenience" sample of children was included without controlling for possible relevant variables such as functional level, different medical treatment regimens (e.g., steroids in Duchenne), other comorbid psychiatric and neurological conditions as well as the presence of other relevant problems e.g., communication problems, sleep problems, and fatigue. Intelligence data as presented, on the other hand, show that mental retardation is probably not a confounding factor in this study. Given the fact that these data are of only $65 \%$ of the sample, some caution however is necessary in the interpretation of these scores. Secondly this was a single center retrospective chart review study using the information that is available from clinical data i.e., information from parents, observation of the child during psychological testing and medical investigation. The fact that our data correspond with the recent literature in Duchenne and neurofibromatosis type 1 confirms that our data are representative.

These data emphasize the importance of a comprehensive and multidisciplinary approach to the assessment of attention disorders in the clinical practice of children with a variety of neurological disabilities. Diagnostic overshadowing is an important phenomenon in clinical practice that should not be overlooked. Adequate and early diagnosis may have important therapeutic implications for treating acquired ADHD and may improve quality of life in general and more specific learning and academics. Further research is needed especially on the effect of medication in treating acquired ADHD in these children (Lion-Francois et al., 2014; Tramontana, Cowan, Zald, Prokop, \& Guillamondegui, 2014). Especially for children with a neurological disability and a physical handicap this is important, as their future is highly dependent upon their academic performance and reading as for instance in Duchenne muscular dystrophy. Undiagnosed and untreated acquired ADHD is in our opinion undesirable and preventable. 


\section{References}

Bjorgaas, H. M., Hysing, M., \& Elgen, I. (2012). Psychiatric disorders among children with cerebral palsy at school starting age. Res Dev Disabil, 33(4), 1287-1293.

Ewen, J. B., \& Shapiro, B. K. (2005). Disorders of attention or learning in neurodevelopmental disorders. Semin Pediatr Neurol, 12(4), 229-241.

Garg, S., Lehtonen, A., Huson, S. M., Emsley, R., Trump, D., Evans, D. G., \& Green, J. (2013). Autism and other psychiatric comorbidity in neurofibromatosis type 1: evidence from a population-based study. Dev Med Child Neurol, 55(2), 139-145.

Goldman, L. S., Genel, M., Bezman, R. J., \& Slanetz, P. J. (1998). Diagnosis and treatment of attentiondeficit/hyperactivity disorder in children and adolescents. Council on Scientific Affairs, American Medical Association. JAMA, 279(14), 1100-1107.

Graham, P., \& Rutter, M. (1968). Organic brain dysfunction and child psychiatric disorder. Br Med J, 3(5620), 695-700.

Johnson, H., Wiggs, L., Stores, G., \& Huson, S. M. (2005). Psychological disturbance and sleep disorders in children with neurofibromatosis type 1. Dev Med Child Neurol, 47(4), 237-242.

Lion-Francois, L., Gueyffier, F., Mercier, C., Gerard, D., Herbillon, V., Kemlin, I., . . . Kassai, B. (2014). The effect of methylphenidate on neurofibromatosis type 1: a randomised, double-blind, placebocontrolled, crossover trial. Orphanet J Rare Dis, 9(1), 142.

Max, J. E., Lansing, A. E., Koele, S. L., Castillo, C. S., Bokura, H., Schachar, R., . . . Williams, K. E. (2004). Attention deficit hyperactivity disorder in children and adolescents following traumatic brain injury. Dev Neuropsychol, 25(1-2), 159-177.

Pane, M., Lombardo, M. E., Alfieri, P., D'Amico, A., Bianco, F., Vasco, G., . . . Mercuri, E. (2012). Attention deficit hyperactivity disorder and cognitive function in Duchenne muscular dystrophy: phenotypegenotype correlation. J Pediatr, 161(4), 705-709 e701.

Polanczyk, G., de Lima, M. S., Horta, B. L., Biederman, J., \& Rohde, L. A. (2007). The worldwide prevalence of ADHD: a systematic review and metaregression analysis. Am J Psychiatry, 164(6), 942-948.

Reiss, S., Levitan, G. W., \& Szyszko, J. (1982). Emotional disturbance and mental retardation: diagnostic overshadowing. Am J Ment Defic, 86(6), 567-574.

Snow, W. M., Anderson, J. E., \& Jakobson, L. S. (2013). Neuropsychological and neurobehavioral functioning in Duchenne muscular dystrophy: a review. Neurosci Biobehav Rev, 37(5), 743-752.

Spencer, T. J., Biederman, J., \& Mick, E. (2007). Attention-deficit/hyperactivity disorder: diagnosis, lifespan, comorbidities, and neurobiology. J Pediatr Psychol, 32(6), 631-642.

Tramontana, M. G., Cowan, R. L., Zald, D., Prokop, J. W., \& Guillamondegui, O. (2014). Traumatic brain injury-related attention deficits: treatment outcomes with lisdexamfetamine dimesylate (Vyvanse). Brain Inj, 28(11), 1461-1472. 


\section{Chapter \\ 6}

Efficacy of working memory training in children and adolescents with learning disabilities:

a review study and meta-analysis

JCAW Peijnenborgh, PPM Hurks, AP Aldenkamp, JSH Vles, \& JGM Hendriksen Neuropsychol Rehabil 2016;26, 645-672 


\section{Abstract}

The effectiveness of working memory (WM) training programs is still a subject of debate. Previous reviews were heterogeneous with regard to participant characteristics of the studies included. To examine whether these programs are of added value for children with learning disabilities (LDs), a systematic meta-analytic review was undertaken focusing specifically on LDs. Thirteen randomized controlled studies were included, with a total of 307 participants (age range $=5.5-17$, Mean age across studies $=10.61, S D=1.77$ ).

Potential moderator variables were examined, i.e., age, type of LD, training program, training dose, design type, and type of control group. The meta-analysis indicated reliable short-term improvements in verbal WM, visuo-spatial WM, and word decoding in children with LDs after training (effect sizes ranged between 0.36 and 0.63 ), when compared to the untrained control group. These improvements sustained over time for up to eight months. Furthermore, children $>10$ years seemed to benefit more in terms of verbal WM than younger children, both immediately after training as well as in the long-term. Other moderator variables did not have an effect on treatment efficacy. 


\section{Introduction}

Learning disabilities (LDs) are common among school-aged children. In short, the term "learning disabilities" refers to a set of problems interfering with learning of academic and/or social skills (Pennington, 2009) which can lead to major difficulties with adaptation to life and society (Wong \& Butler, 2012). Examples of LDs are verbal learning disabilities, such as dyslexia or reading disabilities, AttentionDeficit/Hyperactivity Disorder (ADHD), and non-verbal learning disabilities, such as dyscalculia or maths disabilities (Hendriksen et al., 2007). Children with LDs represent the largest single category of children receiving special education (Bender, 2004). Prevalence estimates attained from surveys of nonclinical samples worldwide indicate that $5-17 \%$ of school-aged children meet the criteria for LDs (Kar, in press). Furthermore, recent data indicate a significant increase in prevalence estimates in the past decade. For instance, Boyle et al. (2011) report a $17 \%$ increase in prevalence rates of LDs for children aged 3-17 years. Therefore, the recent expansion in commercially available, computer-based cognitive training programs, which promise to provide both significant and lasting improvements in performances of children with LDs, is an important treatment option.

The core symptoms and aetiology of LDs are believed to be neurobiological; they influence variations in brain development, and may be associated with multiple cognitive weaknesses-especially weaknesses in executive functioning (EF) (Pennington, 2009; Willcutt et al., 2011). EF is an umbrella term that refers to those top-down mental processes that enable goal-directed behavior and novel problem solving (Miyake, Emerson, \& Friedman, 2000) and are also associated with academic, occupational, and interpersonal performances (Diamond, 2013). Meta-analytic and factor analytic reviews consistently identified three core EFs-i.e., inhibition (or inhibitory control), working memory (WM), and cognitive flexibility (or set shifting) (Dickstein, Bannon, Castellanos, \& Milham, 2006; Miyake et al., 2000; Willcutt, Doyle, Nigg, Faraone, \& Pennington, 2005). Deficits in all three core EFs have been reported in children with a diversity of LDs, such as ADHD (Barkley, 1997), dyslexia (Wang \& Gathercole, 2013), and non-verbal LDs (Semrud-Clikeman, Fine, \& Bledsoe, 2013).

Of all the cognitive training studies to date, the fast majority focus on WM as the primary target for remediation (Rapport, Orban, Kofler, \& Friedman, 2013). WM is the cognitive system responsible for storing, integrating and manipulating information during complex and demanding activities (Baddeley, 2000; Baddeley \& Hitch, 1974). Consequently, WM is believed to be one of the more fundamental cognitive functions. From WM, higher order EFs are built, such as reasoning, problem solving abilities, and planning (Diamond, 2013; Klingberg et al., 2005). In literature, two approaches have been described to alleviate children's difficulties resulting from poor WM. The first approach is indirect, minimising failures in the classroom via effective classroom management of WM loads, i.e., a so-called bypass strategy in which teachers are instructed to give simple task instructions or the time to fulfil a task is modified (e.g., 
Alloway, Gathercole, \& Elliott, 2010; St Clair-Thompson, Stevens, Hunt, \& Bolder, 2010). A negative consequence of this approach is that children do not learn to internalise the WM strategies. The second approach is aimed to stimulate WM more directly. Although WM has been viewed in the past as a constant trait, that cannot be influenced by training, recent studies suggest that this direct approach can indeed improve WM capacity as a consequence of adaptive and extended training, at least in healthy individuals (e.g., Klingberg, 2010). Ericcson, Chase, and Faloon (1980) found for one that an individual's digit span can significantly improve by repeating this WM task several times. Many current cognitive training programs (e.g., Klingberg's CogMed or Prins' Braingame Brian) are based on the assumption that, by repeatedly performing WM tasks, participants themselves will elaborate on the different strategies that could improve their performance. These training programs are adaptive: after successful performances, the difficulty of the tasks increases. In literature, these programs are labelled as so-called "implicit WM programs". Alternatively, some authors claim that participants need explicit help in elaborating on different strategies to improve their performance. In, for example, Diamond's Tools of the Mind and St Clair Thompson's Memory Booster, participants are not only asked to repeat the WM tasks, but are also instructed in different memory strategies. These cognitive training methods are known as so-called "explicit WM training".

The effectiveness of these (implicit and explicit) WM training methods is still under debate. Recently, in a review study, Melby-Lervag and Hulme (2013) found that over a course of four to five weeks of WM training, participants typically advanced in their performances on trained WM tasks, however, these positive effects were no longer found six months post-training. Also, these training effects seem to be specific for the to-be-trained WM tasks (so-called near transfer effects) and do not generalise to other skills (so-called far transfer effects), such as verbal ability, word decoding, and arithmetic (Melby-Lervag \& Hulme, 2013). Melby-Lervag and Hulme (2013), as well as two other reviews, claim that it is too early to draw conclusions on the potential efficacy of WM training (Jaeggi, Buschkuehl, Jonides, \& Shah, 2011; Melby-Lervag \& Hulme, 2013; Shipstead, Redick, \& Engle, 2012). However, these reviews included a broad range of participants: both adults and children, healthy or with a broad range of disabilities. None of these authors specifically reviewed the effectiveness of WM training methods in children with LDs. It may be that children with LDs benefit more from these programs, since LDs may arise from WM constraints operating at the point of learning new skills (Gathercole, Alloway, Willis, \& Adams, 2006; St Clair-Thompson et al., 2010). Furthermore, age may be of influence: maybe younger children benefit more from WM training than older children (Jolles \& Crone, 2012). WM appears to undergo considerable changes during childhood (Korkman, Lahti-Nuuttila, Laasonen, Kemp, \& Holdnack, 2013). Spurts in this developmental trajectory seem to parallel a structural and functional maturation of frontoparietal areas and their connectivity with other brain regions (Cartwright, 2012). In their review paper, Melby-Lervag and Hulme (2013) found larger gains after WM training programs in studies that included 
only children younger than 10 years than in studies that included older children (i.e., 11-18 years) or adults. The authors opted to include age as a categorical variable in their meta-analyzes, that is, young children aged $\leq 10$ years, older children aged 11-18 years, young adults aged 19-50, and older adults aged 51 and older, due to the non-normal distribution of age in the studies that were included in these metaanalyzes. However, as mentioned above, these authors included both healthy participants and those with a broad range of disabilities in their analyzes.

Therefore, the aim of this study is to provide a systematic review and meta-analysis of experimental studies examining the effectiveness of WM training programs for children and adolescents with LDs. More specifically, the current review and metaanalysis investigates whether the claims are valid that WM training programs improve WM, and as a consequence higher order EFs, in children with LDs, and thus lead to a decrease of the suffering of individuals with LDs. Also, the potential moderating factor "age" was studied in this context.

\section{Method}

The PRISMA (Preferred Reporting Items for Systematic Reviews and Meta-Analyses) statement (www.prisma-statement.org) was used as a guideline in the design and report of the meta-analysis. This statement was developed as a consensus for the conduct and reporting of systematic reviews and meta-analyzes.

\section{Literature search}

Figure 6.1 shows details of the method of literature search and the inclusion and exclusion criteria for the studies. Studies were identified by searching electronic databases (ERIC, PubMed, Summon, APA PsycNet) with keywords "Working Memory Training", and by scanning reference lists of articles and reviews. This resulted in 203 articles, which were screened for specific inclusion criteria. To be included, a study had to include children or adolescents with LDs. These participants had to receive an adaptive computerized training program that aimed to improve WM skills. The study had to include a training group and a control group, which received no training or a different (non-WM) type of training. To examine treatment efficacy, all participants had to be tested before the start of the training and again afterwards. Thirteen studies met the inclusion criteria.

The different measures used in the studies to measure WM treatment efficacy were categorized as verbal WM, visuo-spatial WM, (non) verbal ability, inhibition, decoding and arithmetic, or none of the above. The first two are near transfer categories, the others are far transfer categories. 


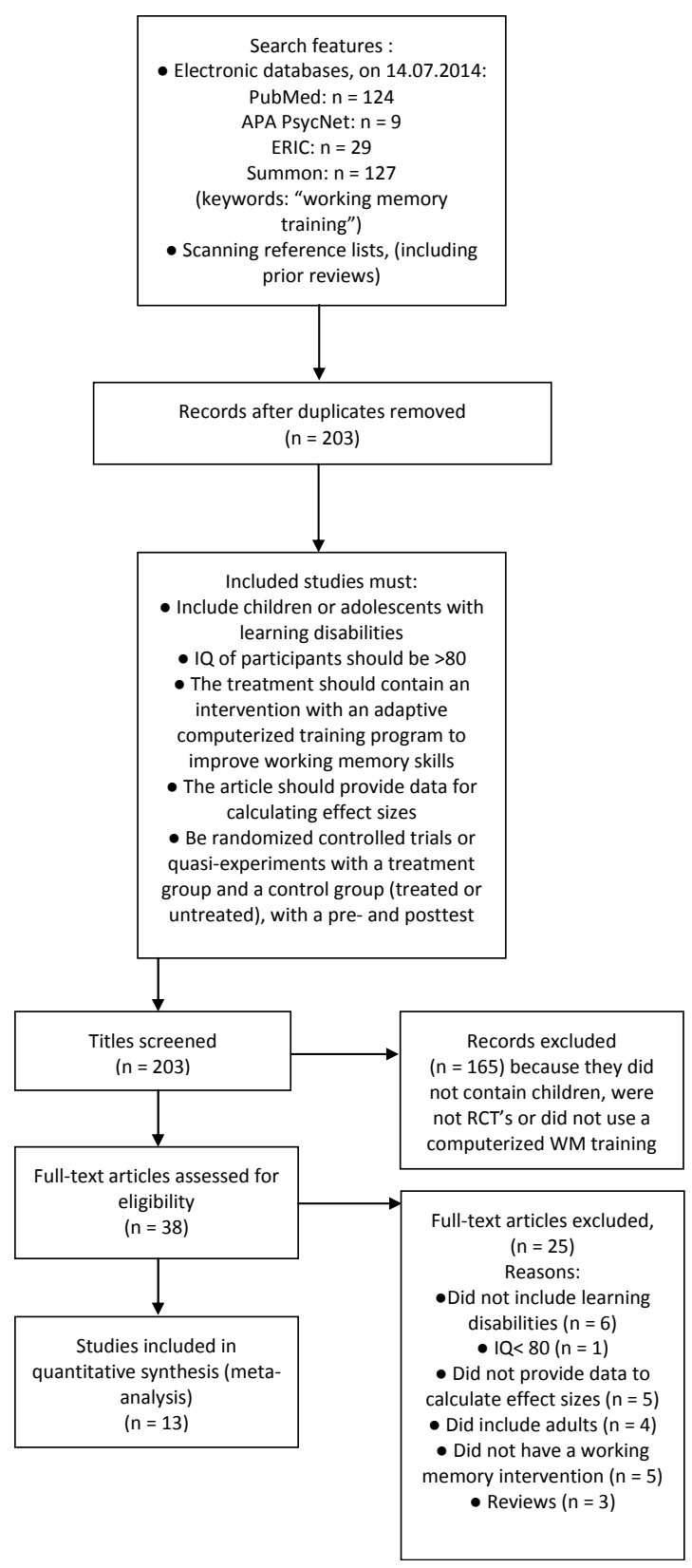

Figure 6.1 Flow diagram for the search and inclusion criteria for studies in this review. WM: Working Memory; ERIC: Education Resources Information Center; APA: American Psychological Association. Adapted from "Preferred Reporting Items for Systematic Reviews and MetaAnalyses: The PRISMA Statement," by D. Moher, A. Liberati, J. Tetzlaff, D. G. Altman, and The PRISMA Group, 2009, PLoS Med 6(6). Copyright 2009 by the Public Library of Science. 


\section{Meta-analytic procedure}

All analyzes were conducted with the use of the computer program Comprehensive Meta-Analysis (Borenstein, Hedges, Higgins, \& Rothstein, 2009). The effect size difference was calculated as the standardized mean difference of the pre-test and post-test scores for the control and treatment group, by using Hedges' g, corrected for small sample size bias, and the unbiased least squares estimate of the pooled standard deviation. In the case that a study provided multiple measurements (e.g., several similar measurements in one category), a weighted average of the means (based on population size) and the pooled standard deviation of those measurements were used to calculate Hedges' $g$. The variation in effect sizes between studies was examined by using the $Q$-test of homogeneity (Hedges \& Olkin, 1985), and $I^{2}$ was calculated as an estimate of between trial heterogeneity in standardized mean difference. However, the power to detect heterogeneity is relatively low because of the small number of included trials. Random effects models were used to test whether lower quality trials had larger effect sizes. Forest plots were created to determine the distributions of effect sizes.

\section{Moderator variables}

To examine the variability in effect sizes between studies, the following moderator variables per study were coded by two authors (JP and $\mathrm{PH}$ ) independently: age, design type, duration of training sessions, type of control group, type of LD and training program. The mean age of the participants as reported in the study was separated into two groups: $\leq 10$ and $>10$, to examine whether age does have an influence on the effectiveness of the training. For design type, it was coded whether the participants were randomized or non-randomized into the treatment or control group. The total duration of training sessions was coded as intensive training (nine hours or more) or less intensive training (less than nine hours). The type of control group was coded, with a distinction between treated controls, e.g., a different (non-WM) training, or a non-adaptive WM training, and untreated controls, being made. The type of LD of the participants was coded as ADHD, verbal LD, non-verbal LD, combined or not specified. Finally, the training program which was used was coded as CogMed, Jungle Memory, or Braingame Brian. Inter-rater reliability for the categorical moderators was measured using Cohen's (1960) kappa, $=.937,95 \% \mathrm{Cl}(0.85,1.02), p<.001$. In the case of a disagreement between raters, the original article was consulted and discussed until consensus was reached.

\section{Results}

An overview of studies included $(N=13)$, the measurements used, and the associated moderators can be found in Table S6.1 in the Appendix. Two studies (Beck, Hanson, 
Puffenberger, Benniger, \& Benniger, 2010; Van der Oord, Ponsioen, Geurts, Ten Brink, $\&$ Prins, 2012) fulfilled all inclusion criteria, but used questionnaires as measurements for WM; care should be taken in comparing the results of these studies including only so-called performance-based cognitive tests. Three different training programs were used, namely, CogMed $(N=10)$, Braingame Brian $(N=1)$, and Jungle Memory $(N=2)$. Three age groups were defined, namely, $\leq 10$ years $(N=3),>10$ years $(N=7)$, and age not specified or blank $(N=1)$. After assessing the different moderator variables for all studies, it became clear that only limited variability was found for the moderator variables type of $L D$, design type, and duration of training sessions across studies. For example, almost all studies included children with ADHD. Other LDs were hardly ever the subject of research (10 studies included only children with ADHD, one study included children with LDs not specified and those with ADHD, and two studies included children with LDs not specified). In all but three studies the children were divided randomly to the treatment or control group. Furthermore, in all studies (except for Prins, Dovis, Ponsioen, Ten Brink, \& Van der Oord, 2011; and Van DongenBoomsma, Vollebregt, Buitelaar,\& Slaats-Willemse, 2014), the children used the WM training program for more than nine hours. Due to this limited variability across studies, no analyzes were performed on these moderator variables (type of LD, design type and duration of training sessions).

Furthermore, Table 6.1 shows large variations in the number of studies included for each category of measures used. The majority of the studies investigated the near transfer effects on WM (Verbal WM: $N=9$ and Visuo-Spatial: $N=9$ ). Only a few studies investigated far transfer effects (three to four studies investigated the different far effect categories, again see Table 6.1).

Of the seven categories of measures that we defined, we found that the treatment groups benefited significantly from WM training on near transfer measurements, measured immediately after training (immediate training effect): all the near transfer categories showed that the effect sizes were significant (Verbal WM: Hedges' $g=0.64$, $p<.01$ and Visuo-Spatial WM: Hedges' $g=0.63, p<.01)$. In the far transfer category "Decoding", a significant effect was found immediately after training (Hedges' $g=0.36$, $p<.05)$. None of the other far transfer categories showed significant effects.

Of the 13 studies included, seven had a follow-up measurement (long-term training effect). An overview can be found in Table S6.2 (refer to Appendix). In Table 6.1, an overview of the results of the long-term training analysis can be found. We found that in the long term, children in the treatment group benefited significantly from WM training compared to the control group, for the same categories (Decoding, Verbal WM, and Visuo-Spatial WM) in which the treatment group benefited immediately after training. All the near transfer categories showed that the effect sizes were significant (Verbal WM: Hedges' $g=0.54, p<.01$ and Visuo-Spatial WM: Hedges' $g=0.39$, $p<.01)$. In the far transfer category "Decoding" a significant effect was found (Hedges' $g=0.48, p<.01$ ). Verbal Ability also revealed a significant effect (Hedges' $g=1.47, p<.01$ ), 
but only one study was found that investigated long-term training effects in this category. For an overview of all the long-term training outcomes, refer to Table 6.1.

Table 6.1 Overview of meta-analysis on training effects per category.

\begin{tabular}{|c|c|c|c|c|c|c|c|c|c|c|}
\hline \multirow[b]{2}{*}{ Category } & \multirow[b]{2}{*}{$n$} & \multirow[b]{2}{*}{ Hedges' $g$} & \multicolumn{3}{|c|}{$95 \% \mathrm{Cl}$} & \multirow[b]{2}{*}{$z$-value } & \multirow[b]{2}{*}{$p$-value } & \multicolumn{2}{|c|}{ Cochran's $Q$ test } & \multirow[b]{2}{*}{$P^{2}$} \\
\hline & & & SD & LL & UL & & & $Q$ & $\overline{p \text {-value }}$ & \\
\hline \multicolumn{11}{|c|}{ Immediate training effects: } \\
\hline \multicolumn{11}{|l|}{ Near transfer effects: } \\
\hline Verbal WM & 9 & 0.64 & 0.13 & 0.38 & 0.90 & 4.77 & 0.00 & 11.05 & 0.20 & 42.51 \\
\hline Visuo-Spatial WM & 9 & 0.63 & 0.12 & 0.40 & 0.85 & 5.43 & 0.00 & 11.05 & 0.20 & 27.63 \\
\hline \multicolumn{11}{|l|}{ Far transfer effects: } \\
\hline Arithmetic & 3 & 0.25 & 0.16 & -0.06 & 0.56 & 1.58 & 0.11 & 0.39 & 0.82 & 0.00 \\
\hline Inhibition & 4 & 0.19 & 0.16 & -0.13 & 0.51 & 1.14 & 0.26 & 0.35 & 0.95 & 0.00 \\
\hline Decoding & 4 & 0.36 & 0.16 & 0.04 & 0.68 & 2.20 & 0.03 & 1.52 & 0.68 & 0.00 \\
\hline Non-Verbal Ability & 4 & 0.34 & 0.28 & -0.21 & 0.88 & 1.22 & 0.22 & 7.71 & 0.05 & 61.10 \\
\hline Verbal Ability & 3 & 0.36 & 0.28 & -0.18 & 0.90 & 1.30 & 0.19 & 4.06 & 0.13 & 50.70 \\
\hline \multicolumn{11}{|c|}{ Long term training effects } \\
\hline \multicolumn{11}{|c|}{ Near transfer measurement } \\
\hline Verbal WM & 5 & 0.54 & 0.20 & 0.16 & 0.91 & 2.81 & 0.01 & 10.20 & 0.04 & 60.79 \\
\hline Visuo-Spatial WM & 5 & 0.39 & 0.20 & 0.00 & 0.78 & 1.98 & 0.05 & 10.92 & 0.03 & 63.35 \\
\hline \multicolumn{11}{|c|}{ Far transfer measurement } \\
\hline Arithmetic & 2 & 0.29 & 0.18 & -0.06 & 0.64 & 1.613 & 0.11 & 0.17 & 0.68 & 0.00 \\
\hline Inhibition & 2 & 0.74 & 0.42 & -0.09 & 1.57 & 1.746 & 0.08 & 3.99 & 0.05 & 74.92 \\
\hline Decoding & 3 & 0.48 & 0.18 & 0.12 & 0.84 & 2.641 & 0.01 & 2.47 & 0.29 & 19.00 \\
\hline Non-Verbal Ability & 2 & 0.02 & 0.20 & -0.42 & 0.38 & -0.097 & 0.92 & 0.10 & 0.76 & 0.00 \\
\hline Verbal Ability & 1 & 1.47 & 0.29 & 0.90 & 2.04 & 5.067 & 0.00 & 0.00 & 1.00 & 0.00 \\
\hline
\end{tabular}

Note: $\mathrm{Cl}=$ Confidence Interval; $I^{2}=$ heterogeneity; $\mathrm{LL}=$ lower limit; $Q$ test = Cochran's $Q$ test; UL = upper limit; $\mathrm{WM}=$ Working Memory.

\section{Influence of moderators on near transfer effects}

Measurements in these categories can be seen as near transfer effects, because they measure skills that were trained (or were similar to the trained tasks).

\section{Verbal working memory}

Immediate training effects. Nine studies $(k=9)$ were included in the analysis of verbal WM, comparing pre-test and post-test gains between children who used a WM training program and the control group, as shown in Table 6.1 (children in training groups: $N=229, M_{\text {sample size }}=25.44$; control group: $N=204, M_{\text {sample size }}=22.67$ ). The $M_{\text {effect }}$ size was medium, $g=0.64,95 \% \mathrm{Cl}(0.38,0.90), p<.01$. The heterogeneity between the included studies was not significant, $Q(8)=11.05, p=.20$, and $l^{2}=43 \%$, indicating low to medium heterogeneity between the included studies. The forest plot with the overall average effect size, the confidence interval, and individual effect sizes can be found in Figure 6.2. Pairwise comparison of the moderators showed no significant effects for use of active or non-active controls and type of training program. However, a significant effect was found on age: older children have higher effect sizes and 
therefore benefit more from WM training than children who are aged 10 years or younger, $Q(6)=13.78, p=.03$, as can be seen in Table 6.2.

Long-term training effects. Five studies $(k=5)$ were included in the analysis of effect sizes of measurements of verbal WM, comparing pre-test and post-test gains between children who used a WM training program and the control group, as shown in Table 6.1 (children in training groups: $N=150, \mathrm{M}_{\text {sample size }}=30$; control group: $N=156, \mathrm{M}_{\text {sample }}$ size=31.2). The $M_{\text {effect size }}$ was medium, $g=0.54,95 \% \mathrm{Cl}(0.16,0.91), p=.01$. The heterogeneity between the included studies was significant, $Q(4)=10.20, p=.04$, and $I^{2}=60.8 \%$, indicating moderate homogeneity between the included studies. The forest plot with the overall average effect size, the confidence interval, and individual effect sizes can be found in Figure 6.3. Pairwise comparison of the moderators showed no significant effects for use of active or non-active controls and type of training program. However, a significant effect was found for age: children older than 10 years have a slightly higher mean effect size from WM training than children who are aged 10 years or younger, $Q(2)=9.91, p<.01$, as can be seen in Table 6.2.

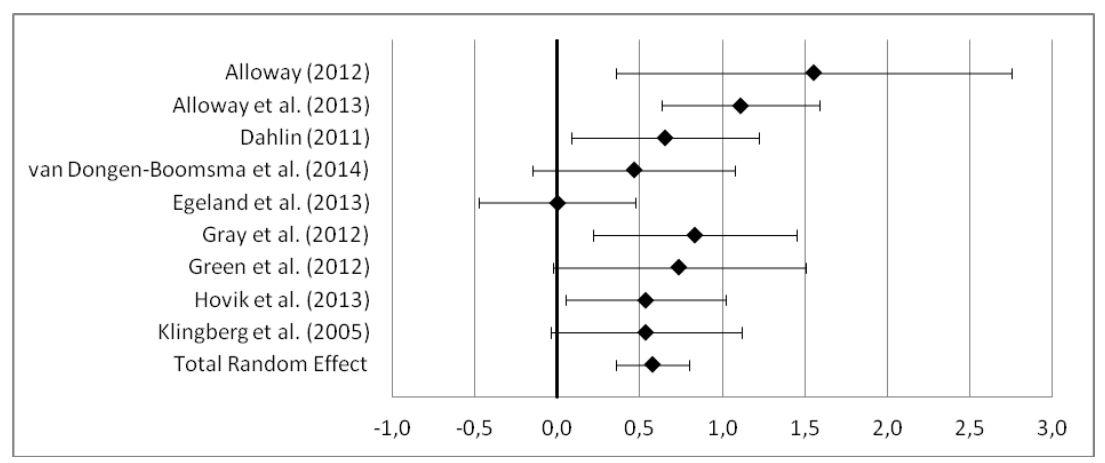

Figure 6.2 Forest plot of immediate training effects on verbal working memory.

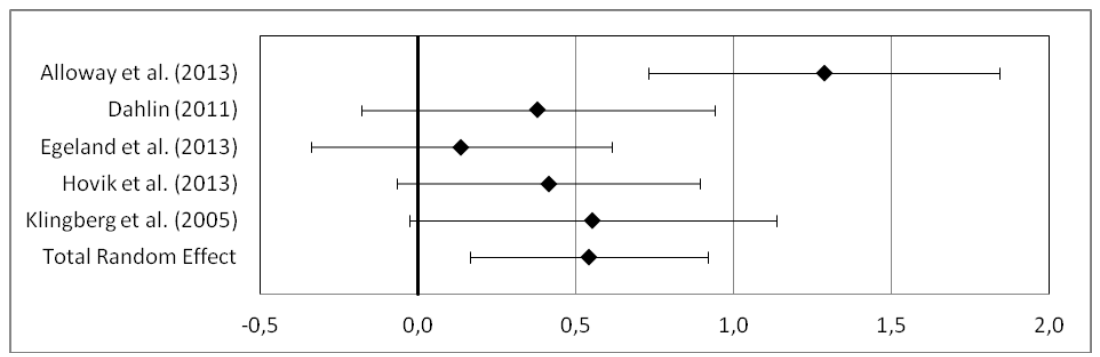

Figure 6.3 Forest plot of long-term training effects on verbal working memory. 
In summary, WM training leads to significant improvements on verbal WM measurements in children with LDs compared to children who were not trained with an adaptive computerized WM training. This holds especially true for older children. This improvement (increased mean effect size) is sustained over several months. Although almost all studies included measurements on verbal WM, there was little consensus on which measurement was used.

Table 6.2 Analysis of moderators on training effects on verbal working memory.

\begin{tabular}{|c|c|c|c|c|c|c|}
\hline \multirow[b]{2}{*}{ Moderator variable } & \multirow[b]{2}{*}{$k$} & \multirow[b]{2}{*}{ Hedges' $g$} & \multirow[b]{2}{*}{ SD } & \multicolumn{2}{|c|}{ Cochran's $Q$ test } & \multirow[b]{2}{*}{$P^{2}$} \\
\hline & & & & $Q$ & $p$-value & \\
\hline \multicolumn{7}{|c|}{ Immediate training effects } \\
\hline \multicolumn{7}{|l|}{ Age } \\
\hline$\leq 10$ & 3 & 0.56 & 0.16 & 0.31 & 0.86 & 0.00 \\
\hline$>10$ & 5 & 0.71 & 0.20 & 13.47 & 0.01 & 70.30 \\
\hline Blank & 1 & 0.65 & 0.29 & 0.00 & 1.00 & 0.00 \\
\hline \multicolumn{7}{|l|}{ Treatment } \\
\hline Treated & 6 & 0.81 & 0.13 & 5.11 & 0.40 & 2.22 \\
\hline Untreated & 3 & 0.38 & 0.12 & 3.72 & 0.16 & 46.17 \\
\hline \multicolumn{7}{|l|}{ Intervention program } \\
\hline CogMed & 7 & 0.49 & 0.10 & 6.10 & 0.42 & 0.83 \\
\hline Jungle Memory & 2 & 1.17 & 0.23 & 0.46 & 0.50 & 0.00 \\
\hline \multicolumn{7}{|c|}{ Long term training effects } \\
\hline \multicolumn{7}{|l|}{ Age } \\
\hline$\leq 10$ & 1 & 0.55 & 0.30 & 0.00 & 1.00 & 0.00 \\
\hline$>10$ & 3 & 0.60 & 0.33 & 9.91 & 0.01 & 79.82 \\
\hline Blank & 1 & 0.38 & 0.29 & 0.00 & 1.00 & 0.00 \\
\hline \multicolumn{7}{|l|}{ Treatment } \\
\hline Treated & 2 & 0.92 & 0.37 & 3.17 & 0.08 & 68.48 \\
\hline Untreated & 3 & 0.30 & 0.15 & 0.74 & 0.69 & 0.00 \\
\hline \multicolumn{7}{|l|}{ Intervention program } \\
\hline CogMed & 4 & 0.35 & 0.13 & 1.32 & 0.73 & 0.00 \\
\hline Jungle Memory & 1 & 1.29 & 0.28 & 0.00 & 1.00 & 0.00 \\
\hline
\end{tabular}

Note: $I^{2}=$ heterogeneity; $k=$ number of studies; SD = Standard deviation; $Q=$ Cochran's $Q$ test.

\section{Visuo-spatial working memory}

Immediate training effects. Nine studies $(k=9)$ were included in the analysis of visuospatial WM - measured by use of performance-based testing - comparing pre-test and post-test gains between children who used a WM training program and the control group, as shown in Table 6.1 (children in training groups: $N=246, M_{\text {sample size }}=$ 27.33; control group: $N=230, M_{\text {sample size }}$ size $\left.=25.56\right)$. The forest plot can be found in Figure 6.4. The mean effect size was medium, $g=0.63,95 \% \mathrm{Cl}(0.40,0.85), p<.01$. The heterogeneity between the included studies was low and not significant, $Q(8)=11.05$, $p=.20$ and $l^{2}=27$. Analysis of the moderators showed no significant moderator variable effects, as can be seen in Table 6.3. 


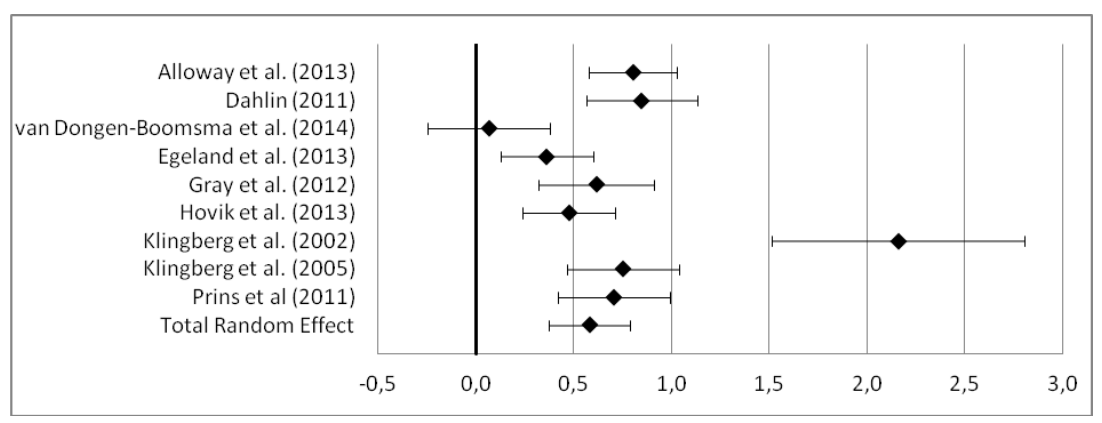

Figure 6.4 Forest plot of immediate training effects on visuo-spatial working memory.

Long-term training effects. Five studies $(k=5)$ were included in the analysis of effect sizes of measurements of visuo-spatial WM - measured by use of performancebased testing - comparing pre-test and post-test gains between children who used a WM training program and the control group, as shown in Table 6.1 (children in training groups: $N=150, M_{\text {sample size }}$ size=30; control group: $N=156, M_{\text {sample size }}=31.2$ ). The forest plot can be found in Figure 6.5. The mean effect size was small, $g=0.39,95 \% \mathrm{Cl}$ $(0.00,0.78), p<.05$. The heterogeneity between the included studies was moderate and significant, $Q(4)=10.92, p=.03$, and $l^{2}=63 \%$. Analysis of the moderators showed a medium to high significant difference between the different training programs, $Q(3)=10.90, p=.01$, indicating that Jungle Memory had more effect than CogMed. Other moderator variables had no significant effects on the heterogeneity. An overview of all moderator effects can be found in Table 6.3.

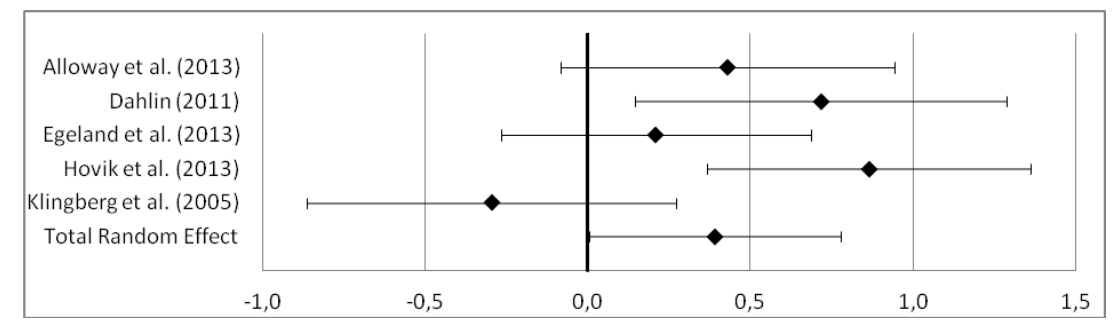

Figure 6.5 Forest plot of long-term training effects on visuo-spatial working memory.

It can be concluded, with respect to visuo-spatial WM, that children with LDs who followed an adaptive WM training have a higher mean effect size in the long term compared to children who did not follow an adaptive WM training. These effects can be seen as near transfer effects, because the measurements resemble the trained tasks. As with Verbal WM, there is moderate to large heterogeneity between the results and increased heterogeneity compared to the immediate training effects. 
Table 6.3 Analysis of Moderators on Visuo-Spatial Working Memory.

\begin{tabular}{|c|c|c|c|c|c|c|}
\hline \multirow[b]{2}{*}{ Moderator variable } & \multirow[b]{2}{*}{$k$} & \multirow[b]{2}{*}{ Hedges' $g$} & \multirow[b]{2}{*}{ SD } & \multicolumn{2}{|c|}{ Cochran's $Q$ test } & \multirow[b]{2}{*}{$P^{2}$} \\
\hline & & & & $Q$ & $p$-value & \\
\hline \multicolumn{7}{|c|}{ Immediate training effects: } \\
\hline \multicolumn{7}{|l|}{ Age } \\
\hline$\leq 10$ & 3 & 0.53 & 0.22 & 2.94 & 0.23 & 32.02 \\
\hline$>10$ & 5 & 0.66 & 0.18 & 7.28 & 0.12 & 45.07 \\
\hline Blank & 1 & 0.85 & 0.30 & 0.00 & 1.00 & 0.00 \\
\hline \multicolumn{7}{|l|}{ Treatment } \\
\hline Treated & 6 & 0.70 & 0.17 & 8.79 & 0.12 & 43.13 \\
\hline Untreated & 3 & 0.53 & 0.15 & 1.66 & 0.44 & 0.00 \\
\hline \multicolumn{7}{|l|}{ Intervention program } \\
\hline CogMed & 8 & 0.60 & 0.13 & 10.11 & 0.17 & 32.16 \\
\hline Jungle Memory & 1 & 0.80 & 0.24 & 0.00 & 1.00 & 0.00 \\
\hline \multicolumn{7}{|c|}{ Long term training effects } \\
\hline \multicolumn{7}{|l|}{ Age } \\
\hline$\leq 10$ & 1 & -0.30 & 0.29 & 0.00 & 1.00 & 0.00 \\
\hline$>10$ & 3 & 0.50 & 0.20 & 3.56 & 0.17 & 43.78 \\
\hline Blank & 1 & 0.72 & 0.29 & 0.00 & 1.00 & 0.00 \\
\hline \multicolumn{7}{|l|}{ Treatment } \\
\hline Treated & 2 & 0.08 & 0.36 & 3.46 & 0.06 & 71.10 \\
\hline Untreated & 3 & 0.59 & 0.21 & 3.80 & 0.15 & 47.32 \\
\hline \multicolumn{7}{|l|}{ Intervention program } \\
\hline CogMed & 4 & 0.38 & 0.26 & 10.90 & 0.01 & 72.47 \\
\hline Jungle Memory & 1 & 0.43 & 0.26 & 0.00 & 1.00 & 0.00 \\
\hline
\end{tabular}

Note: $I^{2}=$ heterogeneity; $k=$ number of studies; SD = Standard deviation; $Q=$ Cochran's $Q$ test.

\section{Influence of moderators on far transfer effects}

This category comprises measurements that measure skills which were not trained in the different computerized WM programs.

\section{Decoding}

Immediate training effects. Four studies $(k=4)$ were included in the analysis of effect sizes of measurements of decoding - measured by use of performance-based testing - comparing pre-test and post-test gains between children who used a WM training program and the control group, as shown in Table 6.1 (children in training groups: $N=105, M_{\text {sample size }}=26.25$; control group: $N=95, M_{\text {sample size }}=23.75$ ). The forest plot can be found in Figure 6.6. The mean effect size was small, $g=0.36,95 \% \mathrm{Cl}(0.04,0.68)$, $p=.00$. The heterogeneity between the included studies was low, but not significant, $Q(3)=1.52, p=.68$, and $I^{2}=0$. The outcome of the moderator analysis indicated that moderator variables have no significant effects on the heterogeneity as can be seen in Table 6.4. This indicates that age and type of training program does not make a difference on the overall effects of WM training. 


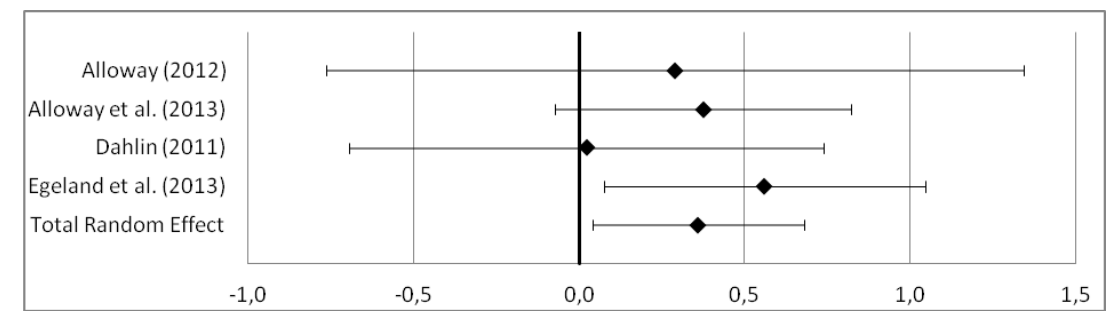

Figure 6.6 Forest plot of immediate training effects on decoding.

Table 6.4 Analysis of Moderators on Decoding.

\begin{tabular}{|c|c|c|c|c|c|c|}
\hline \multirow[b]{2}{*}{ Moderator variable } & \multirow[b]{2}{*}{$k$} & \multirow[b]{2}{*}{ Hedges' $g$} & \multirow[b]{2}{*}{ SD } & \multicolumn{2}{|c|}{ Cochran's $Q$ test } & \multirow[b]{2}{*}{$l^{2}$} \\
\hline & & & & $Q$ & $p$-value & \\
\hline \multicolumn{7}{|c|}{ Immediate training effects: } \\
\hline \multicolumn{7}{|l|}{ Age } \\
\hline$\leq 10$ & 3 & 0.45 & 0.16 & 0.40 & 0.82 & 0.00 \\
\hline Blank & 1 & 0.02 & 0.37 & 0.00 & 1.00 & 0.00 \\
\hline \multicolumn{7}{|l|}{ Treatment } \\
\hline Treated & 2 & 0.36 & 0.21 & 0.02 & 0.89 & 0.00 \\
\hline Untreated & 2 & 0.36 & 0.26 & 1.49 & 0.22 & 32.80 \\
\hline \multicolumn{7}{|l|}{ Intervention program } \\
\hline CogMed & 2 & 0.36 & 0.26 & 1.49 & 0.22 & 32.80 \\
\hline Jungle Memory & 2 & 0.36 & 0.21 & 0.02 & 0.89 & 0.00 \\
\hline \multicolumn{7}{|c|}{ Long term training effects: } \\
\hline \multicolumn{7}{|l|}{ Age } \\
\hline$\leq 10$ & 2 & 0.61 & 0.18 & 0.59 & 0.44 & 0.00 \\
\hline Blank & 1 & 0.05 & 0.37 & 0.00 & 1.00 & 0.00 \\
\hline \multicolumn{7}{|l|}{ Treatment } \\
\hline Treated & 1 & 0.46 & 0.26 & 0.00 & 1.00 & 0.00 \\
\hline Untreated & 2 & 0.44 & 0.34 & 2.44 & 0.12 & 59.01 \\
\hline \multicolumn{7}{|l|}{ Intervention program } \\
\hline CogMed & 2 & 0.44 & 0.34 & 2.44 & 0.12 & 59.01 \\
\hline Jungle Memory & 1 & 0.46 & 0.26 & 0.00 & 1.00 & 0.00 \\
\hline
\end{tabular}

Note: $I^{2}=$ heterogeneity; $k$ = number of studies; SD = Standard deviation; $Q=$ Cochran's $Q$ test.

Long-term training effects. Three studies $(k=3)$ were included in the analysis of effect sizes of measurements of decoding - measured by use of performance-based testing - comparing pre-test and post-test gains between children who used a WM training program and the control group, as shown in Table 6.1 (children in training groups: $N=97, M_{\text {sample size }}=32.3$; control group: $\left.N=98, M_{\text {sample size }}=32.7\right)$. The forest plot can be found in Figure 6.7. The mean effect size was small to medium, $g=0.48,95 \% \mathrm{Cl}(0.12$, $0.84), p=.01$. The heterogeneity between the included studies was low, but not significant, $Q(2)=2.47, p=.29$, and $I^{2}=19 \%$. The outcome of the moderator analysis indicated that moderator variables have no significant effects on the heterogeneity as can be seen in Table 6.4 . 
Most studies did not include decoding measures. However, the studies that included decoding measurements showed a small but promising effect on decoding in children with LDs that followed a WM training when compared to children who did not follow a WM training. This can be promising because decoding skills are not part of WM training and can be seen as far transfer effects.

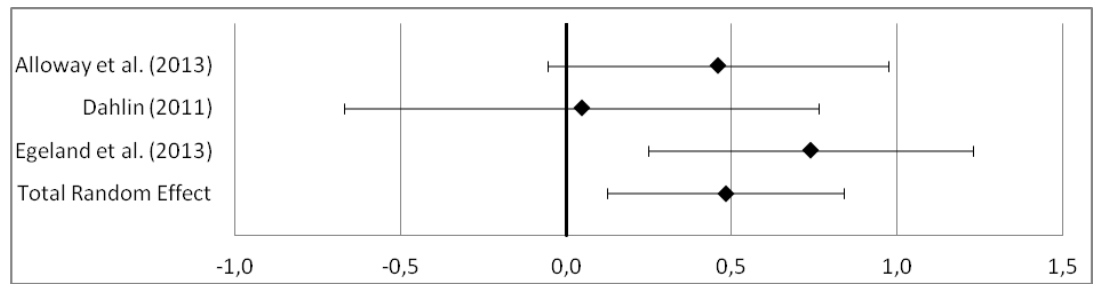

Figure 6.7 Forest plot of long-term training effects on decoding.

\section{Discussion}

Working memory (WM) training programs promise to provide both significant and lasting improvements in performances of children and adolescents with learning disabilities (LDs). This paper reviewed whether these claims regarding the efficacy of these programs are empirically sound. In an extensive literature search we found only 13 studies which focused on training WM in children and adolescents with LDs, encompassing three different WM training programs. These 13 randomized controlled trials included a total of 307 children who completed a WM training (age range: 5.5-17, $M_{\text {age across studies }}=10.61, S D=1.77$ ). The majority of studies (10 of the 13 ) included children with ADHD $(N=244)$, whereas one study included both children with ADHD and LDs not specified $(N=32)$. Two studies included children with LDs not specified $(N=31)$. No study until now focused on the effectiveness of WM training of children with non-verbal LDs, such as dyscalculia or maths disabilities, or verbal LDs, such as dyslexia, or reading disabilities.

Over a course of 4-5 weeks of WM training, children with LDs included in the studies typically showed improved performances in trained (verbal and visuospatial) WM tasks measured immediately after training: so-called near transfer effects. These results on near transfer effects are in line with Melby-Lervag and Hulme (2013) who included both healthy individuals and individuals with LDs. However, our results are contrary to those of Shipstead et al. (2012), who found only near transfer effects for short-term memory (STM) tasks and not for WM tasks. However, Shipstead et al. (2012) included only healthy children and adults, whereas our review showed that WM tasks have significant near transfer effects in children with LDs. Our data seemed to confirm the hypothesis that the effectiveness of WM training should be evaluated 
in different populations. Also, age is an important moderator variable showing that children above 10 years benefit more on Verbal WM than children who are 10 years or younger.

In our study, far transfer effects revealed a small but still significant positive effect on tasks involving decoding immediately after training. This is an important finding, indicating that children with LDs benefit from WM training on tasks other than the trained tasks, at least immediately after training. This is in line with the larger effects on Verbal WM. Speed and accuracy of decoding may be a more fluid skill than, for example, verbal ability and thus benefit more from training.

Long-term effects on near and far transfer variables were only assessed in seven studies (six for CogMed and one for Jungle Memory) and revealed significant effect sizes on Verbal WM (medium effect), Visuo-Spatial WM (small effect), and Decoding (small to medium effect) in children with LDs. Analysis of the moderator variables showed again that children above the age of 10 years benefit more than younger children on Verbal WM. König and Kievit (2011) state that cognitive treatment is more effective when children are old enough to have insight into their neurocognitive deficits and the need to use training, which might explain why the older children in our study benefit more from WM training than the children who are 10 years or younger. In terms of Visuo-Spatial WM, we found larger improvements when the child was trained with Jungle Memory compared to CogMed, but there was only one study which used Jungle Memory and measured Visuo-Spatial WM, so results need to be replicated before firm conclusions can be drawn.

To summarize, the results revealed positive and sustaining effects in the three training programs under review using both near and far transfer variables in children with LDs immediately after the training and sustained over several months. This indicates that it is possible to train WM, which may lead to a decrease of problems from LDs. Research focused especially on children with LDs such as ADHD, which is a shortcoming of the current studies because children with other LDs (both verbal and non-verbal) are also known to suffer from deficits in WM.

\section{Limitations and recommendations}

Our review revealed a number of limitations in the reviewed studies and therefore provides several recommendations for future research. An important methodological drawback in the studies under review was the diverse methodologies being used, e.g., limited numbers of participants and varying times of evaluation. Also, different outcome measures were used. The methods used to measure WM varied significantly among studies: five different verbal WM tests were used in 11 studies and eight different visuo-spatial WM tests in nine studies. Also, most studies included performance-based tests administered to the subjects. For instance, far transfer measures often included were Raven's Progressive Matrices (Raven, 1990, 1995), a measure of non-verbal reasoning, and the Stroop Color Word task, a measure of 
attention and inhibition. Interestingly, except for Van der Oord et al. (2012) and Beck et al. (2010), no other studies involved parents. These authors used questionnaires for parents claiming to measure, for example, WM or other executive functions (EFs), such as inhibition, attention, or non-verbal reasoning. Both found small effects on the WM scale of the BRIEF. We believe these measures should be considered in future research, because these behaviors are related to deficits in EFs (Huizinga \& Smidts, 2011) and parents could provide important information about far transfer effects in the daily life of children. However, very low correlations were found between questionnaires (i.e., the BRIEF) and experimental EF tasks (Bodnar, Prahme, Cutting, Denckla, \& Mahone, 2007). We can only speculate on why these correlations are so low (e.g., different concepts are being measured). Therefore, we strongly advise analysis of the efficacy studies focusing on only questionnaires measuring cognition or those on performance-based cognitive tests separately.

Secondly, six studies did not include long-term measurements, therefore a solid conclusion on the sustainability of training effects is not possible. Of those studies investigating the long-term effects of WM training programs, the interval of follow-up varied significantly, ranging from nine weeks to eight months post-intervention. The actual goal of intervention is achievement of long-term effects, i.e., positive effect on educational career for which we believe that at least a 12-month follow up is required. This could give information on effects after the completion of an entire grade. All these factors made it difficult unequivocally to compare results. Furthermore, it is not possible to draw conclusions on the effects from WM training on the difficulties of the LD itself, because research only focused on underlying mechanisms of WM.

Thirdly, when reviewing the different studies, we noticed an interesting evolution of training programs being used. Historically, paper-and-pencil training programs (e.g., self-instructional training) were used, evolving into a computer-based training at the beginning of the 21st century (CogMed) giving rise more recently to a gaming environment (Braingame Brian) in order to improve motivation in children. The use of a virtual gaming environment has not yet been researched, but looks promising. A virtual gaming environment offers the possibility of objectively measuring behavior in a challenging but safe and ecologically valid environment while maintaining control over stimulus delivery and measurement (Schultheis, Himelstein, \& Rizzo, 2002).

Fourthly, all studies in our review used implicit training programs, therefore, conclusions on the effectiveness of explicit versus implicit training programs cannot be made here. Overall, we concluded that there is only little systematic randomized controlled research in WM training programs for children with LDs. Reported results mainly concern CogMed in children with ADHD, but results are promising and show both short-term and long-term benefits. Future studies are needed on different populations of LDs, using different training programs, e.g., gaming environment and virtual reality training, due to the increased prevalence rates in LDs (Boyle et al., 2011). 


\section{Towards a triple pathway model in cognitive intervention}

So far, most of the studies on WM training efficacy include children with ADHD. These studies do not control for or examine the moderating effects of "subtypes of ADHD". We believe that the "one size fits all" approach often used in studies on WM training and ADHD fails to recognise the diversity of symptom expressions in children with ADHD. Therefore, WM should not be the only focus of training programs. To illustrate this point, we refer to the triple pathway model of ADHD, as described by SonugaBarke, Bitsakou, and Thompson (2010). These authors stated that WM deficits, as well as other cognitive deficits such as disinhibition, are only one cluster of core problems seen in some children with ADHD. According to the model, motivational problems (e.g., an aversion towards delay), and timing deficits are two other important and unique characteristics of ADHD. These three clusters of deficits have their own unique neural substrate: respectively, dorsal fronto-stratial circuits for cognitive functions, ventral fronto-stratial circuits for motivation, and the cerebellum and the basal ganglia for timing (Sonuga-Barke et al., 2010). As such, each neural substrate can be disturbed, leading to diverse expressions of ADHD, but also emphasising the need for different approaches to "deal" with these diverse expressions. Sonuga-Barke et al. indicated that only $20.7 \%$ of all children with ADHD have a cognitive deficit, that is, with or without another problem in timing and/or motivation. This indicates that only one-fifth of all children with ADHD would benefit from a cognitive training method, such as the WM training. Based on this, one can conclude that at least four out of five of all children with ADHD would benefit (more) from another training, e.g., focusing on motivation or timing or a combination of motivation, timing, and/or WM elements. None of the existing training programs in our review takes all three into consideration and matches results on WM training efficacy to "ADHD subtypes".

Currently, some limited research on training the "motivational pathway" is available, including research into the inclusion of context in training programs. For instance, Prins et al. (2011) developed a game in which elements from CogMed were intertwined in a storyline that may be motivating to the child. Prins et al. (2011) compared both games to evaluate the effect of a storyline and context on motivation. Children with ADHD are known to be highly motivated to play computer games and are less hampered by their ADHD problems during the playing of such games (Shaw, Grayson, \& Lewis, 2005). Prins, Dovis, Ponsioen, and Ten Brink (2007) suggested that a training tool (for example, to train EFs) would be more effective if this training is disguised as a computer game with a storyline. Future studies should investigate whether children with specific "subtypes" of ADHD benefit more from the addition of a gaming element and/or giving specific instructions on motivational strategies. If our hypotheses are correct, children with ADHD-motivation deficits (with or without deficits in timing or WM) would benefit most from a training including motivation elements.

Accurate time perception, as representing Sonuga Barke's timing mechanism, helps to predict, anticipate, and respond competently to everyday situations and/or future 
events and is therefore an elementary aspect of our human adaptive system (e.g., Booth \& Siegler, 2006; Gonzalez-Garrido et al., 2008). Increasing empirical evidence suggests that timing, along with other broad constructs, such as motor planning and sequencing, is relevant to attentional problems (Hurks \& Hendriksen, 2011). Only a few studies have addressed the efficacy of techniques focusing on timing using an Interactive Metronome ${ }^{\circledR}$, that provides accurate real-time guide sounds to indicate users' temporal accuracy as they perform a series of prescribed movements (Cosper, Lee, Peters, \& Bishop, 2009; Shaffer et al., 2001). These studies found improvements on aspects of attention, motor, and perceptual-motor functioning, and academic performance in children with severe attentional problems. Again, future studies should investigate whether children with specific "subtypes" of ADHD benefit more from the addition of a timing element and/or giving them specific instructions on temporal processing strategies. If our hypotheses are correct, children with ADHDtiming deficits (with or without deficits in motivation or WM) would benefit most from training that included timing elements.

At present, no study has investigated correlations between WM training efficacy and subtypes of ADHD, therefore no conclusions can be made (a) whether only specific children with ADHD benefit from WM training programs and (b) whether a training combining timing, WM and/or rewards that suits the symptoms of the individual child with ADHD would result in larger near and far transfer effects. This warrants further research.

\section{Conclusions}

This review and meta-analysis is the first to analyse effect sizes on both near and far transfer effects, as a result of WM training programs for children with LDs. Results are limited (mainly ADHD and CogMed) but promising (both significant near and far transfer effects). Based on theoretical considerations we argue that WM training needs to be supplemented by modules focusing on motivation and timing. 


\section{References}

Alloway, T. (2012). Can interactive working memory training improve learning? Journal of Interactive Learning Research, 23(3), 197-207.

Alloway, T. P., Bibile, V., \& Lau, G. (2013). Computerized working memory training: Can it lead to gains in cognitive skills in students. Comput Hum Behav, 29, 632-638.

Alloway, T. P., Gathercole, S. E., \& Elliott, J. (2010). Examining the link between working memory behaviour and academic attainment in children with ADHD. Dev Med Child Neurol, 52(7), 632-636. doi:10.1111/j.14698749.2009.03603.x

Baddeley, A. (2000). The episodic buffer: A new component of working memory? Trends Cogn Sci, 4(11), 417-423.

Baddeley, A. D., \& Hitch, G. (1974). Working memory. In G. H. Bower, (Ed.), The psychology of learning and motivation: Advances in research and theory (Vol. 8, pp. 47-89). New York: Academic press.

Barkley, R. A. (1997). Behavioral inhibition, sustained attention, and executive functions: constructing a unifying theory of ADHD. Psychol Bull, 121(1), 65-94.

Beck, S. J., Hanson, C. A., Puffenberger, S. S., Benninger, K. L., \& Benninger, W. B. (2010). A controlled trial of working memory training for children and adolescents with ADHD. J Clin Child Adolesc Psychol, 39(6), 825836. doi:10.1080/15374416.2010.517162

Bender, W. N. (2004). Learning disabilities: Characteristics, identification and teaching strategies (5th ed.). Boston: Pearson.

Bodnar, L. E., Prahme, M. C., Cutting, L. E., Denckla, M. B., \& Mahone, E. M. (2007). Construct validity of parent ratings of inhibitory control. Child Neuropsychol, 13(4),345-362. doi:10.1080/09297040600899867

Booth, J. L., \& Siegler, R. S. (2006). Developmental and individual differences in pure numerical estimation. Developmental psychology, 42(1), 189-201. doi:10.1037/0012-1649.41.6.189

Borenstein, M., Hedges, L., Higgins, J., \& Rothstein, H. (2009). Introduction to meta-analysis. Chichester, England: Wiley.

Boyle, C. A., Boulet, S., Schieve, L. A., Cohen, R. A., Blumberg, S. J., Yeargin-Allsopp, M., ... Kogan, M. D. (2011). Trends in the prevalence of developmental disabilities in US children, 1997-2008. Pediatrics, 127(6), 1034-1042. doi:10.1542/peds.2010-2989

Cartwright, K. B. (2012). Insights from cognitive neuroscience: The importance of executive function for early reading development and education. Early Educ Dev, 23(1), 24-36. doi:10.1080/10409289.2011.615025

Cohen, J. (1960). A coefficient of agreement for nominal scales. Educ Psychol Meas, 20, 37-46.

Cosper, S. M., Lee, G. P., Peters, S. B., \& Bishop, E. (2009). Interactive Metronome training in children with attention deficit and developmental coordination disorders. Int J Rehab Res, 32(4), 331-336. doi:10.1097/MRR.0b013e328325a8cf

Dahlin, K. I. E. (2011). Effects of working memory training on reading in children with special needs. Read Writ, 24, 479-491. doi:10.1007/s11145-010-9238-y

Diamond, A. (2013). Executive functions. Annu Rev Psychol, 64, 135-168. doi:10. 1146/annurev-psych113011-143750

Dickstein, S. G., Bannon, K., Castellanos, F. X., \& Milham, M. P. (2006). The neural correlates of attention deficit hyperactivity disorder: an ALE meta-analysis. J Child Psychol Psyc, 47(10), 1051-1062. doi:10.1111/j.14697610.2006.01671.x

van Dongen-Boomsma, M., Vollebregt, M. A., Buitelaar, J. K., \& Slaats-Willemse, D. (2014). Working memory training in young children with ADHD: a randomized placebo-controlled trial. J Child Psychol Psyc, 55(8), 886-896. doi:10.1111/jcpp.12218

Egeland, J., Aarlien, A. K., \& Saunes, B. K. (2013). Few effects of far transfer of working memory training in ADHD: a randomized controlled trial. PLoS One, 8(10), e75660. doi:10.1371/journal.pone.0075660

Ericcson, K. A., Chase, W. G., \& Faloon, S. (1980). Acquisition of a memory skill. Science, 208(4448), 11811182.

Gathercole, S. E., Alloway, T. P., Willis, C., \& Adams, A. M. (2006). Working memory in children with reading disabilities. J Exp Child Psychol, 93(3), 265-281. doi:10.1016/j.jecp.2005.08.003 
Gonzalez-Garrido, A. A., Gomez-Velazquez, F. R., Zarabozo, D., Lopez-Elizalde, R., Ontiveros, A., Madera-Carrillo, H., ... Tuya, J. M. (2008). Time reproduction disturbances in ADHD children: an ERP study. Int J Neurosci, 118(1), 119- 135. doi:10.1080/00207450601042177

Gray, S. A., Chaban, P., Martinussen, R., Goldberg, R., Gotlieb, H., Kronitz, R., ... Tannock, R. (2012). Effects of a computerized working memory training program on working memory, attention, and academics in adolescents with severe LD and comorbid ADHD: a randomized controlled trial. J Child Psychol Psyc, 53(12), 1277-1284. doi:10. 1111/j.1469-7610.2012.02592.x

Green, C. T., Long, D. L., Green, D., Iosif, A. M., Dixon, J. F., Miller, M. R., ... Schweitzer, J. B. (2012). Will working memory training generalize to improve off-task behavior in children with attentiondeficit/hyperactivity disorder? Neurotherapeutics, 9(3), 639-648. doi:10.1007/s13311-012-0124-y

Hedges, L. V., \& Olkin, I. (1985). Statistical methods for meta-analysis. Orlando, FL: Academic Press.

Hendriksen, J. G., Keulers, E. H., Feron, F. J., Wassenberg, R., Jolles, J., \& Vles, J. S. (2007). Subtypes of learning disabilities: Neuropsychological and behavioural functioning of 495 children referred for multidisciplinary assessment. Europ Child Adol Psyc, 16(8), 517-524. doi:10.1007/s00787-007-0630-3

Hovik, K. T., Saunes, B. K., Aarlien, A. K., \& Egeland, J. (2013). RCT of working memory training in ADHD: Long-term near-transfer effects. PLoS One, 8(12), e80561. doi:10.1371/journal.pone.0080561

Huizinga, M., \& Smidts, D. P. (2011). Age-related changes in executive function: A normative study with the Dutch version of the Behavior Rating Inventory of Executive Function (BRIEF). Child Neuropsychol, 17(1), 51-66. doi:10.1080/09297049.2010.509715

Hurks, P. P., \& Hendriksen, J. G. (2011). Retrospective and prospective time deficits in childhood ADHD: The effects of task modality, duration, and symptom dimensions.Child Neuropsychol, 17(1), 34-50. doi:10.1080/09297049.2010.514403

Jaeggi, S. M., Buschkuehl, M., Jonides, J., \& Shah, P. (2011). Short- and long-term benefits of cognitive training. P Natl Acad Sci USA, 108(25), 10081-10086. doi:10.1073/pnas.1103228108

Jolles, D. D., \& Crone, E. A. (2012). Training the developing brain: a neurocognitive perspective. Front Hum Neurosci, 6, 76. doi:10.3389/fnhum.2012.00076

Kar, B. (in press). Learning disability: Issues and concerns with implications for social policy. In R. C. T. a. Y. Sinha (Ed.), Social policy in India: Searching for psychological coordinates. New York, NY: Springer.

Klingberg, T. (2010). Training and plasticity of working memory. Trends Cogn Sci, 14(7), 317-324. doi:10.1016/j.tics.2010.05.002

Klingberg, T., Fernell, E., Olesen, P. J., Johnson, M., Gustafsson, P., Dahlstrom, K., ...Westerberg, H. (2005). Computerized training of working memory in children with ADHD-a randomized, controlled trial. J Am Acad Child Psy, 44(2), 177-186. doi:10.1097/00004583-200502000-00010

Klingberg, T., Forssberg, H., \& Westerberg, H. (2002). Training of working memory in children with ADHD. J Clin Exp Neuropsyc, 24(6),781-791. doi:10.1076/jcen.24.6.781.8395

König, C., \& Kievit, A. (2011). Behandeling. In H. Swaab, A. Bouma, J. Hendriksen, \& C. König (Eds.), Klinische Kinderneuropsychologie (pp. 297-325). Amsterdam: Boom.

Korkman, M., Lahti-Nuuttila, P., Laasonen, M., Kemp, S. L., \& Holdnack, J. (2013). Neurocognitive development in 5to 16-year-old North American children: a cross-sectional study. Child Neuropsychol, 19(5), 516-539. doi:10.1080/09297049.2012.705822

Melby-Lervag, M., \& Hulme, C. (2013). Is working memory training effective? A meta-analytic review. Dev psych, 49(2), 270-291. doi:10.1037/a0028228

Miyake, A., Emerson, M. J., \& Friedman, N. P. (2000). Assessment of executive functions in clinical settings: problems and recommendations. Seminars in Speech and Language, 21(2), 169-183.

Pennington, B. F. (2009). Diagnosing learning disorders: A neuropsychological framework (2nd ed.). New York, NY: Guilford Publications Inc.

Prins, P., Dovis, S., Ponsioen, A., Ten Brink, E., \& Van der Oord, S. (2011). Does computerized working memory training with game elements enhance motivation and training efficacy in children with ADHD? Cyberpsychology, Behavior, and Social Networking, 14(3), 115-122.

Prins, P. J., Dovis, S., Ponsioen, A. J., \& Ten Brink, E. (2007). Nieuwe generaties, nieuwe media: ADHD behandelen met een computergame. Kind en Adolescent Praktijk, 06, 148-155.

Rapport, M. D., Orban, S. A., Kofler, M. J., \& Friedman, L. M. (2013). Do programs designed to train working memory, other executive functions, and attention benefit children with ADHD? A meta-analytic review of cognitive, academic, and behavioral outcomes. Clin psychol rev, 33(8), 1237-1252. doi:10.1016/j.cpr.2013.08.005 
Raven, J. C. (1990). Advanced Progressive Matrices. Set II. Oxford, United Kingdom: Oxford Psychologists Press.

Raven, J. C. (1995). Coloured Progressive Matrices. Oxford, United Kingdom: Oxford Psychologists Press.

Schultheis, M. T., Himelstein, J., \& Rizzo, A. A. (2002). Virtual reality and neuropsychology: upgrading the current tools. J Head Trauma Rehab, 17(5), 378-394.

Semrud-Clikeman, M., Fine, J. G., \& Bledsoe, J. (2013). Comparison among children with children with autism spectrum disorder, nonverbal learning disorder and typically developing children on measures of executive functioning. J Autism Dev Disord, doi:10.1007/s10803-013-1871-2

Shaffer, R. J., Jacokes, L. E., Cassily, J. F., Greenspan, S. I., Tuchman, R. F., \& Stemmer, P. J., Jr. (2001). Effect of interactive metronome training on children with ADHD. [I]. Am J Occup Ther, 55(2), 155-162.

Shaw, R., Grayson, A., \& Lewis, V. (2005). Inhibition, ADHD, and computer games: the inhibitory performance of children with ADHD on computerized tasks and games. J Attent Disord, 8(4), 160-168. doi:10.1177/1087054705278771

Shipstead, Z., Redick, T. S., \& Engle, R. W. (2012). Is working memory training effective? Psychol Bull, 138(4), 628-654. doi:10.1037/a0027473

Sonuga-Barke, E., Bitsakou, P., \& Thompson, M. (2010). Beyond the dual pathway model: evidence for the dissociation of timing, inhibitory, and delay-related impairments in attention-deficit/hyperactivity disorder. J Am Acad Child Psy, 49(4), 345-355.

St Clair-Thompson, H. L., Stevens, R., Hunt, A., \& Bolder, E. (2010). Improving children's working memory and classroom performance. Educ Psychol, 30(2), 203-219.

Van der Oord, S., Ponsioen, A. J., Geurts, H. M., Brink, E. L., \& Prins, P. J. (2012). A pilot study of the efficacy of a computerized executive functioning remediation training with game elements for children with ADHD in an outpatient setting: Outcome on parent- and teacher-rated executive functioning and ADHD behavior. $J$ Attent Disord. doi:10.1177/1087054712453167

Wang, S., \& Gathercole, S. E. (2013). Working memory deficits in children with reading difficulties: memory span and dual task coordination. J Exp Child Psychol, 115(1), 188-197. doi:10.1016/j.jecp.2012.11.015

Willcutt, E. G., Boada, R., Riddle, M. W., Chhabildas, N., Defries, J. C., \& Pennington, B. F. (2011). Colorado learning difficulties questionnaire: Validation of a parent-report screening measure. Psychol Assessment, 23(3), 778-791. doi:10.1037/a0023290

Willcutt, E. G., Doyle, A. E., Nigg, J. T., Faraone, S. V., \& Pennington, B. F. (2005). Validity of the executive function theory of attention-deficit/hyperactivity disorder: A meta-analytic review. Biol Psychiat, 57(11), 1336-1346. doi:10.1016/j.biopsych.2005.02.006

Wong, B., \& Butler, D. L. (2012). Learning about learning disabilities (4th ed.). Waltham,Massachusetts: Academic Press. 


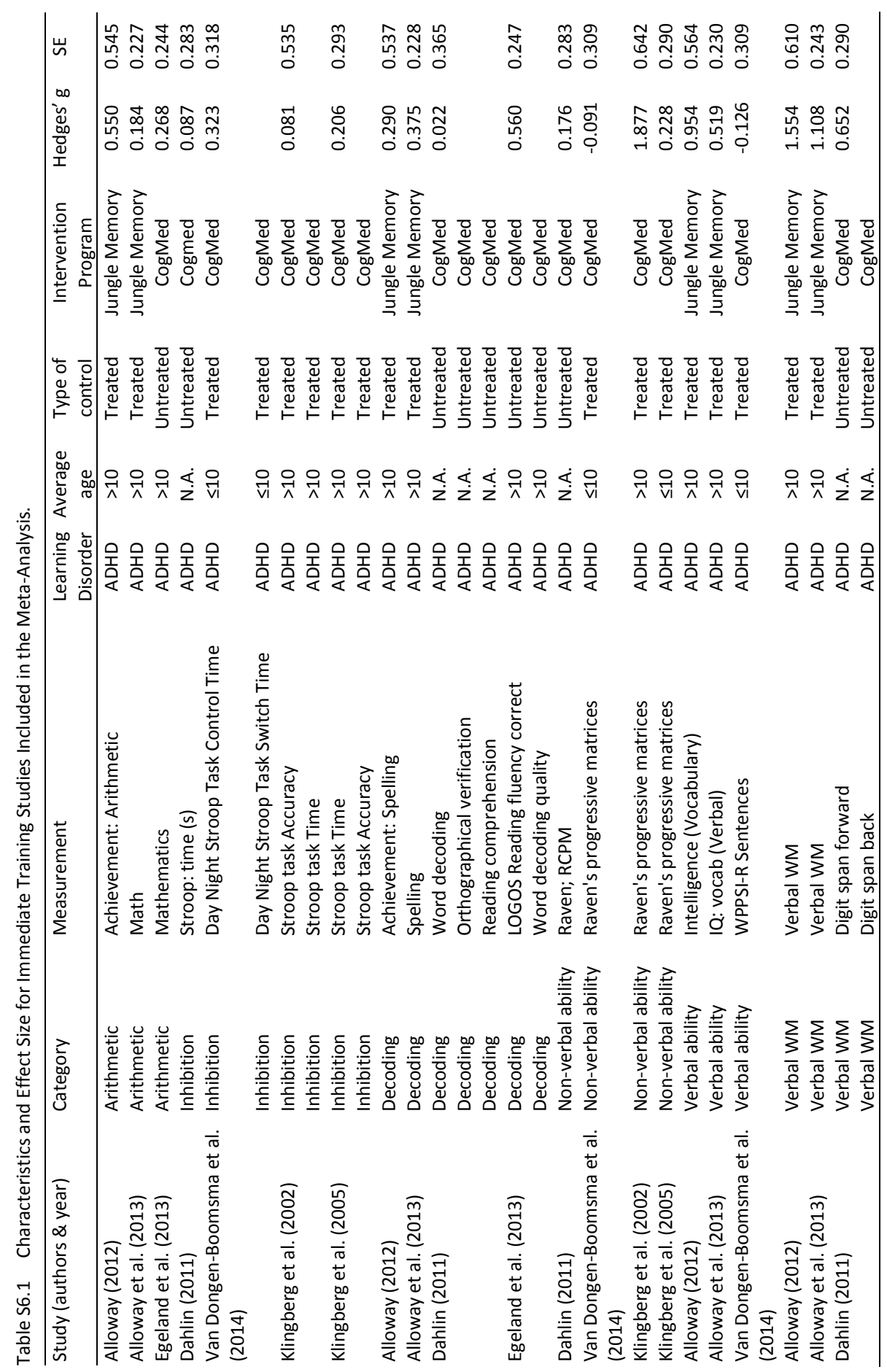




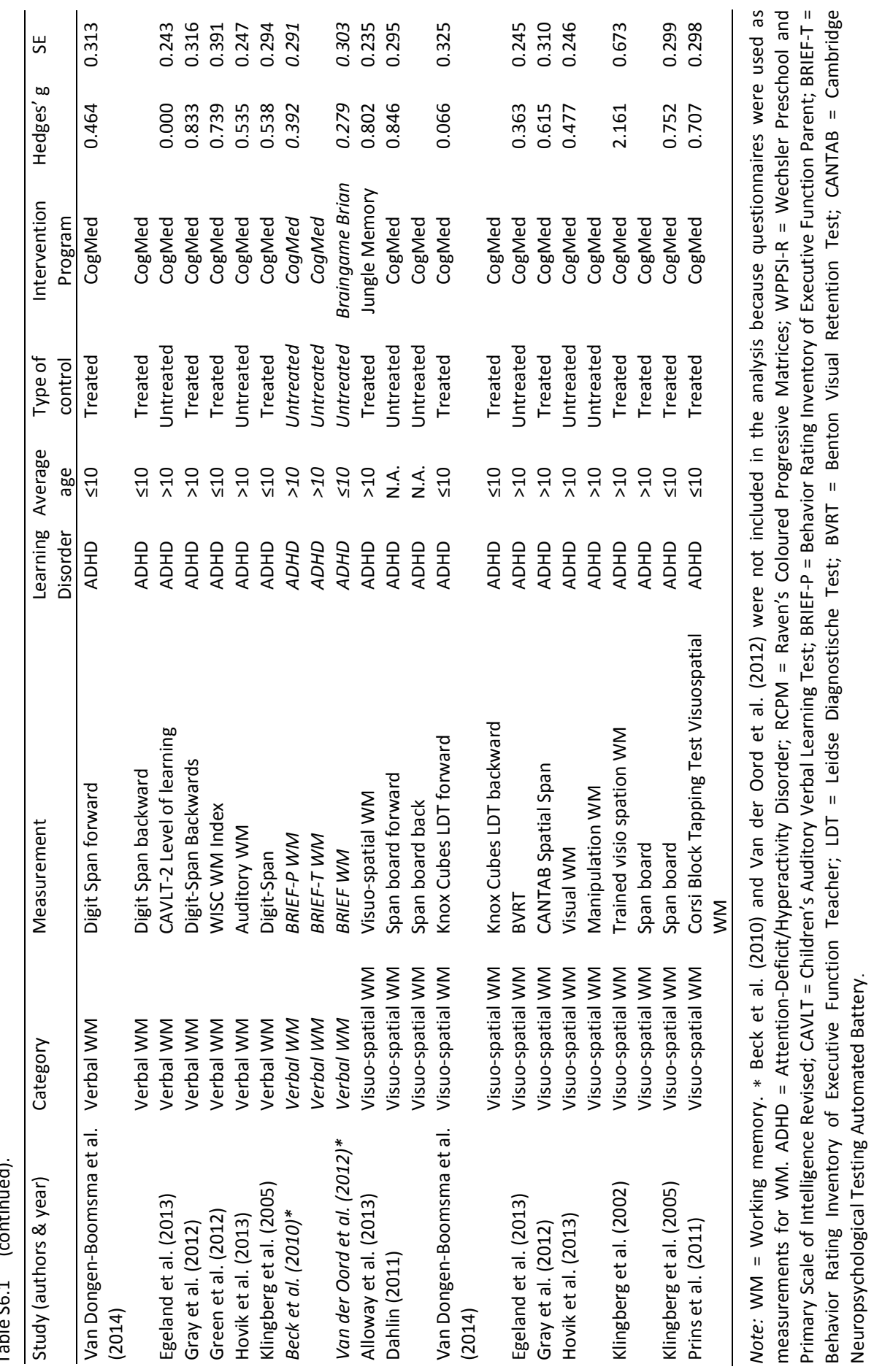




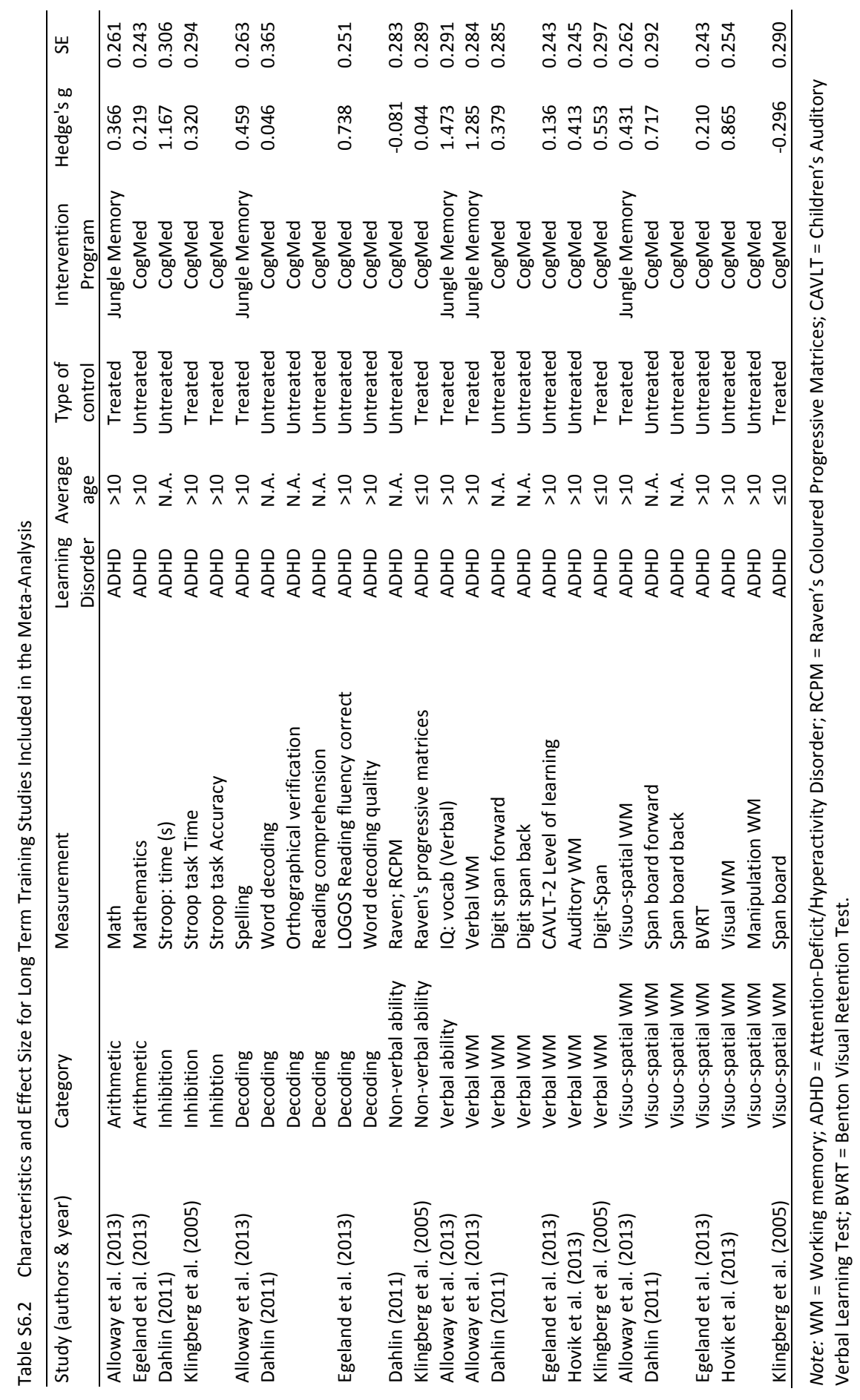


Chapter 7

General discussion 
Chapter 7 


\section{General discussion}

The aim of this thesis was threefold. Firstly, we studied whether it is possible to examine cognition, time perception, and motivation in young children aged 4 to 8 years in a valid and reliable way. These behaviors (and in particular the role of attention) were examined in both healthy individuals and children with neurological learning disorders. Secondly, we examined the prevalence of ADHD in children with neurological deficiencies, and examined the role of IQ in the prediction of behavioral and emotional problems in this population. Finally, we examined whether cognitive functions can be trained in children with learning disorders.

First we will summarize the main findings as reported in this thesis. Subsequently these findings will be discussed in the light of existing literature, theoretical considerations, and the aim of this thesis.

\section{A summary of the main findings}

- The computerized diagnostic game Timo's Adventure and the Children's Time Awareness Questionnaire (CTAQ) can be useful in clinical practice to map out possible cognitive, motivation, or time perception deficits in children (Chapter 2 and 3)

- Time perception skills develop with age: Older children have better knowledge of time perception and produce more precise time intervals (Chapter 2 and 3 )

- Children with ADHD have significantly fewer time perception skills than typically developing peers (Chapter 3)

- Reward mechanisms are significantly different in children with ADHD compared to typically developing peers: children with ADHD more often prefer small but immediate rewards over large but delayed rewards, whereas typically developing children inhibit their response to gain a large, delayed reward (Chapter 2)

- Children with neurological learning disorders have significantly higher verbal capacities than performance capacities (Chapter 4)

- A discrepancy between verbal and performance capacities cannot predict behavioral or emotional problems in children with neurological deficiencies. The Full Scale IQ is a slightly better predictor: the higher the IQ, the lower the parentreported behavioral or emotional problems (Chapter 4)

- The diagnosis of ADHD is more prevalent in children with neurological deficiencies than in the normal population (Chapter 5 )

- The diagnosis of ADHD in children with neurological deficiencies is often missed by medical specialists, due to overshadowing by somatic, physical, or syndromal features of the neurological condition (Chapter 5) 
- Working memory training programs especially have influence on the working memory itself in children with learning disorders, but also on non-trained functions such as word decoding (Chapter 6)

- Children above 10 years of age benefit more from working memory training than younger children (Chapter 6 )

\section{Discussion of the results}

\section{Is it possible to examine cognition, time perception, and motivation in young children in a valid and reliable way?}

Current neuropsychological assessments usually consist of memory tasks, attention tasks, visual-spatial tasks, tasks on executive functions, and tasks on informationprocessing abilities, and is preceded by an intelligence assessment (Baron, 2004). Based on the model by Sonuga-Barke, Bitsakou, and Thompson (2010) we developed two assessment tools on cognitive functions, motivation, and time perception, which can be used to examine these functions in young children (aged 4 to 8). Assessment instruments on motivation and time perception for young children are scarce. Most neuropsychological assessment instruments in the Netherlands are designed for children above the age of 6 , the age that children in the Netherlands start in first grade (in Dutch: groep 3). The assumption is that assessment tools for children $<6$ years are less useful, since the cognitive functions are still in development at that age (Anderson, 2002). However, the lack of existing assessment tools for the kindergarten age is a shortcoming. Although several cognitive functions (such as information processing abilities) develop above the age of 6 , other cognitive functions (such as attention control) develop rapidly in early childhood, the so-called 4-to-7 attention shift (Diamond, 2002). It is important to identify potential attentional and cognitive problems at a young age (i.e., in kindergarten), since they predict later academic achievement (Wassenberg et al., 2007), and early cognitive training at kindergarten age is found to be effective on achievements in later grades (Diamond \& Lee, 2011). For the purpose of assessing cognitive functions in young children, we developed two assessment tools.

Theoretical framework on which these assessment tools were based, was the triple pathway by Sonuga-Barke and colleagues (2010), which explains the three pathways of patterns of deficits in cognition in children with ADHD, namely executive dysfunctioning, motivation, and time perception. Executive dysfunctioning relates cognitive deficits to a dysregulation of thought and action. Motivation describes that children with ADHD prefer small but immediate rewards, over large but delayed rewards. Time perception consists of knowledge on time related concepts (such as knowledge on time units, patterns on days and months, and a distinction between past, present, and future [Friedman, 1978, 2003; Friedman \& Laycock, 1989] and the 
ability to estimate, produce, and reproduce time intervals [Block, Zakay, \& Hancock, 1999]). Two separate tools were developed and used in this thesis: a computerized diagnostic tool on all three pathways, and a questionnaire focusing on time perception.

The computerized diagnostic tool, named Timo's Adventure, aims to assess cognitive functions (e.g., executive functions such as inhibition or planning), time production, and motivation. In chapter 2 of this thesis, the validity of this instrument was examined. In the development of the game, we introduced the context of a story line (Gongsook, 2015), to improve the feeling of being part of a gaming environment (Gorini, Capideville, De Leo, Mantovani, \& Riva, 2011). Also, the use of intrinsic fantasy elements has been found to improve motivation to conduct a specific task (Habgood \& Ainsworth, 2011; Van der Spek, Sidorenkova, Porskamp, \& Rauterberg, 2014). Indeed, we found that children liked the game very much. Proof for the validity of Timo's Adventure was found in terms of developmental differences in normal developing children. We compared children from 4 to 8 years of age and found that the older the child, the fewer inhibition mistakes were made and the faster the reaction times, which is in line with previous research (Davidson, Amso, Anderson, \& Diamond, 2006; Gathercole, Pickering, Ambridge, \& Wearing, 2004). Furthermore, we found that older children were more accurate in producing time intervals than younger children. This is in line with prior research by e.g., Friedman and Laycock (1989), and Pouthas and Jacquet (1987), who found that development of time perception skills start to develop before the age of 7 and is further refined in the last grades of elementary school. Second proof for validity was found in the comparison of children (aged 6-8 years) who were diagnosed with ADHD and their normally developing peers. As expected, planning skills were better in the control group than in children with ADHD. This is in line with the research by Gau and colleagues (2013), who found that planning skills are affected in children in ADHD. Also, we found that children with ADHD more often prefer a small, but immediate reward, than typically developing children (who were better able to wait for the large, but delayed reward). Previous research on this topic found this difference too, but focused mainly on older children (Mischel, Shoda, \& Rodriguez, 1989). Our results suggest that this difference can also be found in children aged 6-8. Besides these two proofs for the validity of the assessment tool, we found satisfactory results on the sensitivity and specificity of the instrument, in the differentiation between children with and without ADHD.

The second measurement instrument that we developed was the Children's Time Awareness Questionnaire (CTAQ), a questionnaire on time perception. The questionnaire consists of 20 questions on time related topics. To improve the ecological validity of the test the questions were designed to be familiar to the child. The questionnaire includes two types of questions: close-ended questions (e.g., 'What takes longer: a week or a month?') and open-ended questions in which the child needs to give an estimation of how long (in seconds, minutes, weeks, or years) an event would take (e.g., 'how long does the summer holiday take?'). Answers on these 
open-ended questions that were between the $5^{\text {th }}$ and $9^{\text {th }}$ percentile (based on the normative sample of 248 adults by Wassenberg and colleagues [2007]) were scored as 1 , whereas scores outside this range were scored as 0 ; answers on the close-ended questions were scored as 0 (incorrect) or 1 (correct). The higher the score, the better the child's performance. We examined whether this test could be reliably used for children. Internal consistency of the questionnaire was satisfactory. Validity was examined by investigating age related differences in a group of normally developing children (between 4 and 12 years of age). Previous studies found developmental differences in time perception: children first develop knowledge on time aspects related to daily activities around the age of 4 to 6 , and subsequently develop knowledge on more abstract concepts (such as the order of the days of the weeks) around the age of 8 (Friedman, 1986, 1990, 2000). In the normative data of the CTAQ results, we found that the age of the child had the largest influence. The older the child, the better the time perception skills as measured on the CTAQ. Second proof for validity was found when comparing group differences between children with and without ADHD. Based on previous research (e.g., Hurks \& Hendriksen, 2011; SonugaBarke et al., 2010), we expected children with ADHD to have lower scores on the CTAQ than their normally developing peers. This is consistent with our results, in which significant differences were found between both groups in the expected direction. As last proof for validity, we compared results of the CTAQ with different measurements (i.e., parent-rated questionnaires) of time perception. We found significant correlations between those outcomes, thereby supporting the validity of the CTAQ. Again, we found satisfactory results on sensitivity and specificity, in the differentiation between children with and without ADHD.

Since both assessment tools showed promising psychometric properties (i.e., both instruments showed promising results on sensitivity and specificity, and satisfactory results on reliability and validity), we concluded that they can be of added value in neuropsychological assessments in terms of indicating strengths and weaknesses of the behavioral and cognitive profile of the child. Timo's Adventure can be used for young children (between 4 and 8 ) to identify potential problems in terms of attention, motivation, and time perception at a young age. The CTAQ can be used in children above 4 years of age and norm data are available (Chapter 3 ).

\section{What is the role of attention problems in children with neurological deficiencies?}

One group of children that have an elevated risk for a deviant development in terms of behavior (i.e., cognitive functioning, motivation, and/or time perception) is the group of children with a neurological condition. This is due to the fact that the mediating structure that is responsible for the development of deviant behaviors is the brain (Lenroot \& Giedd, 2006). Several studies in this thesis took place at the 
Center of Neurological Learning Disabilities, a tertiary outpatient clinic in Heeze, The Netherlands.

In the fifth chapter of this thesis, we found that a large proportion of the patient population of the center suffered from ADHD: $38.8 \%$ of the children were diagnosed with ADHD. This is a significantly higher percentage than the prevalence of ADHD in the normal population, which is estimated at 5.3\% (Polanczyk, de Lima, Horta, Biederman, \& Rohde, 2007). Remarkably, only a quarter of these children were diagnosed with ADHD before referral to the center, although all children were referred by a medical specialist. We therefore state that a warning for "diagnostic overshadowing" is necessary. When children suffer from a medical condition or neurological deficiency, usually the focus is on the medical aspects of the condition. We state however that it is necessary to focus also on the cognitive and behavioral effects of the condition. In focusing on the cognitive and behavioral effects of a (neurological) condition, more children who are at risk for a developmental problem can be distinguished. By underestimating the prevalence of ADHD in this group of children, a large group of children does not get the help or interventions they need.

We also examined the role of the intelligence profile on daily life of these children with acquired and congenital brain damage (Chapter 4). Traditionally, clinicians are alarmed when a discrepant intelligence profile (i.e., significantly stronger verbal capacities than performance capacities, or vice versa) is found. Such a discrepancy is linked to neurological conditions (Black, 1974, 1976; Blackburn et al., 2007) and is interpreted as indicator of potential brain lesions (Ballantyne, Scarvie, \& Trauner, 1994; Blackburn, et al., 2007). Recently, the distinction between aspects of intelligence has been questioned: in newer versions of the WISC (the most used intelligence test for children worldwide [Reschly, 1997]) the verbal and performance capacities are no longer measured as separate scales (Wechsler, 2014). These newer versions are not available in the Netherlands at this moment (the WISC-V is currently in development). The most used instrument in the Netherlands (the WISC-III-NL) does make a distinction between verbal and performance capacities. We were interested whether a discrepant profile was more common in children with neurological learning disorders. We found that $33 \%$ of the children with neurological learning disorders had an IQ-discrepancy. In the normal population, $28 \%$ of the children have an IQdiscrepancy (Wechsler, 2005). We also found that verbal capacities were significantly stronger than performance capacities. This can be explained by the neuropsychological principle that language survives brain damage, whereas performance capacities are more affected (Eilander \& Hendriksen, 2011). An explanation for this is that verbal capacities do an appeal on crystallized knowledge, whereas performance capacities do an appeal on motoric manipulation and speed, as well as new abilities: elements that are more affected by brain damage (Anderson, Northam, Hendy, \& Wrennall, 2001; Jaffe, Polissar, Fay, \& Liao, 1995).

Furthermore, we examined whether the IQ-discrepancy is related to behavioral or emotional problems. The assumption was that children who experience a discrepancy 
might suffer from more problems in daily life (Black, Wallace, Sokoloff, \& Kenworthy, 2009). The idea is that when verbal capacities are significantly lower than performance capacities, the child might have problems in explaining him/herself verbally or, when a contrary discrepancy is found, the child might easily be overestimated since $s /$ he is verbally strong(er). We hypothesized that if this assumption was true, more emotional and behavioral problems might be reported by the parents (Teeter \& Korducki, 1998). This was not the case: the IQ-discrepancy could not predict whether the parents would report such problems. A better predictor to distinguish children who are at risk for emotional and behavioral problems is the Full Scale IQ, the sex and age of the child. However, these predictors combined can only explain a small proportion of behavioral and emotional problems, indicating that other factors are of influence on these problems. Future research is necessary to identify these potential predictors for behavioral or emotional problems.

\section{Can cognitive functions be trained in children with learning disorders?}

In chapter 6, we focused on treatment of cognitive functions. The training of cognitive functions is an area that gains increasing interest in the current literature on the treatment of children with learning disorders. The effectiveness of these training programs however is still topic of debate. Several reviews found that the treatment effects of working memory training are only limited and extinguish over time (Jaeggi, Buschkuehl, Jonides, \& Shah, 2011; Melby-Lervag \& Hulme, 2013; Shipstead, Redick, \& Engle, 2012). These reviews did not specifically focus on children with learning disorders, but included a broad range of participants of both adults and children and of both healthy participants and participants with a broad range of disabilities (Jaeggi et al., 2011; Melby-Lervag \& Hulme, 2013; Shipstead et al., 2012). In this thesis we focused on working memory training in children with learning disabilities. We reviewed and analyzed results of thirteen studies on the efficacy of working memory training in children with learning disabilities. We found some promising, positive results on the efficacy of working memory training programs in the studies (published up to 2014) which we investigated. Working memory training especially resulted in both short-term and long-term improvements on the trained working memory tasks, the so-called near transfer effects. Improvements in functions that are known to be influenced by working memory but are not explicitly trained (the so-called far transfer effects) were found on tasks involving word decoding. Both near and far transfer effects sustained over time. This indicates that children with learning disorders benefit from working memory training, even on other tasks than the trained tasks. Furthermore, we found that children above the age of 10 benefit more from cognitive training programs than younger children, possibly due to the fact that older children have better insights in their neurocognitive deficits and are better motivated for the training (König \& Kievit, 2011). 
Although we found positive results in this specific target group of children with learning disorders, only a small number of studies $(N=7)$ investigated the sustainability of these effects of the training in the long term. These long term effect studies investigated these effects over only a time for up to (a maximum of) eight months. This is surprising, since the actual goal of the intervention is to achieve long-term effects to help the child in daily life. Further research on the long-term effects is necessary.

\section{What does this thesis contribute?}

\section{Implications for clinical practice}

- In neuropsychological assessments, it is useful to add measurements on time perception and motivation. When children show potential problems on these measurements, it could indicate that they might be at risk for learning problems. Early signaling of these problems might help in determining the right interventions for the child and preventing possible further problems (Diamond \& Lee, 2011). For this purpose, we developed two assessment tools that can be used to facilitate this early signaling.

- The emphasis on a discrepant IQ-profile as a predictor of problems in daily life (such as emotional or behavioral problems) in children with neurological deficiencies is not justified.

- In children with neurological deficiencies it is important to screen for potential attention problems, since the diagnosis of ADHD is more prevalent in this target group, but is often overlooked due to the medical condition.

- Training of cognitive functions is empirically effective although the precise mechanism has to be identified. Combining a diagnostic game with a therapeutic game is in our opinion the challenge for the future.

\section{Implications for future research}

- In the studies that included children with ADHD, we excluded children who used medication. It would be interesting to examine the influence of medication on the outcome of the assessment tools (Timo's Adventure and the CTAQ). Potential future research could compare the outcome of the assessment tools of the children before and after the start of medication.

- Sonuga-Barke and colleagues (2010) found that there are children with ADHD who suffer from deficits in one or more of the pathways and not necessarily in all pathways. In the current studies, we did not specify these separate groups, but instead looked at children who were diagnosed with ADHD without a subdivision in type of problems. Future research would be useful to examine the profiles of 
the separate groups on the CTAQ and Timo's Adventure. Possibly, these distinct profiles can benefit from a distinct treatment fitting the profile.

- It would be interesting to examine which variables can be identified that can predict which children with neurological deficiencies are at risk for behavioral or emotional problems.

- There is only a limited amount of research into the long-term benefits from working memory trainings in children with learning disabilities. Future research to examine these effects would be useful. 


\section{References}

Anderson, P. (2002). Assessment and development of executive function (EF) during childhood. Child Neuropsychol, 8(2), 71-82. doi: 10.1076/chin.8.2.71.8724

Anderson, V., Northam, E., Hendy, J., \& Wrennall, J. (2001). Developmental neuropsychology. A clinical approach. Hove: Psychology Press.

Ballantyne, A. O., Scarvie, K. M., \& Trauner, D. A. (1994). Verbal and performance IQ patterns in children after perinatal stroke. Dev Neuropsychol, 10(1), 39-50.

Baron, I. S. (2004). Neuropsychological evaluation of the child. New York: Oxford University Press.

Black, D. O., Wallace, G. L., Sokoloff, J. L., \& Kenworthy, L. (2009). Brief report: IQ split predicts social symptoms and communication abilities in high-functioning children with autism spectrum disorders. $J$ Autism Dev Disord, 39(11), 1613-1619. doi: 10.1007/s10803-009-0795-3

Black, F. W. (1974). WISC Verbal-Performance discrepancies as indicators of neurological dysfunction in pediatric patients. J Clin Psychol, 30(2), 165-167.

Black, F. W. (1976). Cognitive deficits in patients with unilateral war-related frontal lobe lesions. J Clin Psychol, 32(2), 366-372.

Blackburn, L. B., Lee, G. P., Westerveld, M., Hempel, A., Park, Y. D., \& Loring, D. W. (2007). The Verbal $\mathrm{IQ} /$ Performance IQ discrepancy as a sign of seizure focus laterality in pediatric patients with epilepsy. Epilepsy Behav, 10(1), 84-88. doi: 10.1016/j.yebeh.2006.10.001

Block, R. A., Zakay, D., \& Hancock, P. A. (1999). Developmental changes in human duration judgments: a meta-analytic review. Dev Rev, 19, 183-211.

Davidson, M. C., Amso, D., Anderson, L. C., \& Diamond, A. (2006). Development of cognitive control and executive functions from 4 to 13 years: evidence from manipulations of memory, inhibition, and task switching. Neuropsychologia, 44(11), 2037-2078. doi: 10.1016/j.neuropsychologia.2006.02.006

Diamond, A. (2002). Normal development of prefrontal cortex from birth to young adulthood: cognitive functions, anatomy, and biochemistry. In D. Stuss \& R. Knight (Eds.), Principles of frontal lobe function. New York: Oxford University Press.

Diamond, A., \& Lee, K. (2011). Interventions shown to aid executive function development in children 4 to 12 years old. Science, 333(6045), 959-964. doi: 10.1126/science.1204529

Eilander, H., \& Hendriksen, J. (2011). Traumatisch hersenletsel. In H. Swaab, A. Bouma, J. Hendriksen \& C. König (Eds.), Klinische Kinderneuropsychologie. Amsterdam: The Netherlands: Boom.

Friedman, W. J. (1978). Development of time concepts in children. Adv Child Dev Behav, 12, 267-298.

Friedman, W. J. (1986). The development of children's knowledge of temporal structure. Child Dev, 57(6), 1386-1400.

Friedman, W. J. (1990). Children's representations of the pattern of daily activities. Child Dev, 61(5), 13991412.

Friedman, W. J. (2000). The development of children's knowledge of the times of future events. Child Dev, 71(4), 913-932.

Friedman, W. J. (2003). The development of a differentiated sense of the past and the future. Adv Child Dev Behav, 31, 229-269.

Friedman, W. J., \& Laycock, F. (1989). Children's analog and digital clock knowledge. Child Dev, 60(2), 357371. doi: $10.2307 / 1130982$

Gathercole, S. E., Pickering, S. J., Ambridge, B., \& Wearing, H. (2004). The structure of working memory from 4 to 15 years of age. Dev Psychol, 40(2), 177-190. doi: 10.1037/0012-1649.40.2.177

Gau, S. S., \& Chiang, H. L. (2013). Association between early attention-deficit/hyperactivity symptoms and current verbal and visuo-spatial short-term memory. Res Dev Disabil, 34(1), 710-720. doi: 10.1016/j.ridd.2012.10.005

Gongsook, P. (2015). Interactive diagnostic game for time perception. Eindhoven: Technische Universiteit.

Gorini, A., Capideville, C. S., De Leo, G., Mantovani, F., \& Riva, G. (2011). The role of immersion and narrative in mediated presence: the virtual hospital experience. Cyberpsychol Behav Soc Netw, 14(3), 99-105. doi: 10.1089/cyber.2010.0100

Habgood, M. J., \& Ainsworth, S. E. (2011). Motivating children to learn effectively: Exploring the value of intrinsic integration in educational games. J Learn Sci, 20(2), 169-206. 
Hurks, P. P., \& Hendriksen, J. G. (2011). Retrospective and prospective time deficits in childhood ADHD: The effects of task modality, duration, and symptom dimensions. Child neuropsychol, 17(1), 34-50. doi: 10.1080/09297049.2010.514403

Jaeggi, S. M., Buschkuehl, M., Jonides, J., \& Shah, P. (2011). Short- and long-term benefits of cognitive training. P Natl Acad Sci USA, 108(25), 10081-10086. doi: 10.1073/pnas.1103228108

Jaffe, K. M., Polissar, N. L., Fay, G. C., \& Liao, S. (1995). Recovery trends over three years following pediatric traumatic brain injury. Arch Phys Med Rehabil, 76(1), 17-26.

König, C., \& Kievit, A. (2011). Behandeling. In H. Swaab, A. Bouma, J. Hendriksen \& C. König (Eds.), Klinische kinderneuropsychologie. Amsterdam: Boom.

Lenroot, R. K., \& Giedd, J. N. (2006). Brain development in children and adolescents: insights from anatomical magnetic resonance imaging. Neurosci Biobehav Rev, 30(6), 718-729. doi: 10.1016/j.neubiorev.2006.06.001

Melby-Lervag, M., \& Hulme, C. (2013). Is working memory training effective? A meta-analytic review. Dev psychol, 49(2), 270-291. doi: 10.1037/a0028228

Mischel, W., Shoda, Y., \& Rodriguez, M. I. (1989). Delay of gratification in children. Science, 244(4907), 933938.

Polanczyk, G., de Lima, M. S., Horta, B. L., Biederman, J., \& Rohde, L. A. (2007). The worldwide prevalence of ADHD: a systematic review and metaregression analysis. Am J Psychiatry, 164(6), 942-948.

Pouthas, V., \& Jacquet, A. Y. (1987). A developmental study of timing behavior in 4 1/2- and 7-year-old children. J Exp Child Psychol, 43(2), 282-299.

Reschly, D. J. (1997). Diagnostic and treatment utility of intelligence tests. In D. P. Flanagan, J. L. Genshaft \& P. L. harrison (Eds.), Contemporary intellectual assessment: Theories, tests, and issues (pp. 437-456). New York: Guilford.

Shipstead, Z., Redick, T. S., \& Engle, R. W. (2012). Is working memory training effective? Psychol bull, 138(4), 628-654. doi: 10.1037/a0027473

Sonuga-Barke, E., Bitsakou, P., \& Thompson, M. (2010). Beyond the dual pathway model: evidence for the dissociation of timing, inhibitory, and delay-related impairments in attention-deficit/hyperactivity disorder. J Am Acad Child Adolesc Psychiatry, 49(4), 345-355.

Teeter, P. A., \& Korducki, R. (1998). Assessment of emotionally disturbed children with the WISC-III. In A. Prifitera \& D. H. Saklofske (Eds.), WISC-III Clinical use and interpretation: scientist-practioner perspectives. San Diego: Academic Press.

Van der Spek, E. D., Sidorenkova, T., Porskamp, P., \& Rauterberg, M. (2014). The effect of familiar and fantasy aesthetics on learning and experience of serious games Entertainment Computing-ICEC 2014 Berlin Heidelberg: Springer.

Wassenberg, R., Hendriksen, J. G. M., Hurks, P. P. M., Feron, F. J. M., Keulers, E. H. H., Vles, J. S. H., \& Jolles, J. (2007). Development of different aspects of sense of time. In R. Wassenberg (Ed.), Differential cognitive development: a neuropsychological approach (pp. 75-87). Maastricht: Neuropsych Publishers.

Wassenberg, R., Hurks, P. P. M., Hendriksen, J. G. M., Feron, F. J. M., Kessels, A. G. H., \& Vles, J. S. H. (2007). Attention in kindergarten and the first grade predicts academic outcome in the sixth grade. In R. Wassenberg (Ed.), Differential cognitive development: a neuropsychological approach (pp. 59-74). Maastricht: Neuropsych Publishers.

Wechsler, D. (2005). WISC-III-NL Handleiding. Amsterdam: The Netherlands: Harcourt Assessment.

Wechsler, D. (2014). Wechsler Intelligence Scale for Children (5th ed.). San Antonio: Harcourt Assessment. 


\section{Chapter 8}

Summary 
Chapter 8 


\section{Summary}

If there are concerns about the cognitive development of the child, a professional can advise to do a (clinical) neuropsychological assessment with the child. Lezak, Howieson, Bigler, and Tranel (2012) defined the discipline "clinical neuropsychology" as an applied science concerned with the behavioral expression of brain dysfunction. Although there are different conceptualizations of the term "behavior", in this thesis we chose to differentiate three aspects, based on the description by Lezak and colleagues, as well as the triple pathway model by Sonuga-Barke, Bitsakou, and Thompson (2010): cognition, emotionality and time perception. Cognition includes the information handling aspect of behavior and how behavior is expressed. Emotionality concerns feelings and motivation (Lezak et al., 2012). Time perception, also known as temporal processing, consists of knowledge on time related concepts and the ability to estimate, produce, and reproduce time intervals (Block, Zakay, \& Hancock, 1999). By studying these three aspects of behavior, professionals aim at acquiring insights into daily functioning by assessing cognitive functions of the child.

The aim of this thesis was threefold, as described in Chapter 1. Firstly, we examined whether it is possible to examine cognition, time perception, and motivation in young children aged 4 to 8 years in a valid and reliable way. These behaviors (and in particular the role of attention) were examined in both healthy individuals and children with neurological learning disorders. Secondly, we examined the prevalence of ADHD in children with neurological learning disabilities, and examined the role of $\mathrm{IQ}$ in the prediction of behavioral and emotional problems in this population. Finally, we examined whether cognitive functions can be trained in children with learning disorders.

Two assessment tools were developed by our team to measure cognition, motivation, and time perception. The first assessment tool is an interactive computer game, named Timo's Adventure and is described in Chapter 2. Timo's Adventure is developed to assess specific cognitive functions (e.g., attention, planning, and working memory), time perception and motivation in children aged 4 to 8 . The game consists of six interactive mini-games, embedded in a storyline and including fairytale figures to enhance motivation. We investigated the validity of Timo's Adventure, by examining the effects of age on performances within normally developing children, as well as the performance differences between normally developing children and children with ADHD. Proof for validity was found for developmental differences. Older children made fewer inhibition mistakes, had faster (and therefore better) reaction times and were able to produce time intervals more accurately than younger children. For the group differences between children with and without ADHD we found significant differences on motivation and cognition. Discriminant analysis showed that Timo's Adventure was accurate in the majority of the classifications on whether a child belonged to the ADHD-group or the normally developing group: $78 \%$ of the 
children were correctly classified as having ADHD or as being in the normally developing group.

The second assessment tool which we developed was the Children's Time Awareness Questionnaire (CTAQ). The CTAQ is a 20-item questionnaire designed to assess childrens' time perception in an ecological valid way. Normative data is provided and the psychometric properties of the questionnaire are described in Chapter 3. A multiple regression model on the normative date showed that the demographic variables age and sex contributed significantly to CTAQ performance, whereas the level of parental education did not. The internal consistency examined in a population of normally developing children between 4 and 12 years of age, as a measure of reliability, was found to be satisfactory. The results showed positive correlations between CTAQ scores and parent-reports and performance tests measuring time perception in children. In line with temporal processing deficits reported in prior studies (Hurks \& Hendriksen, 2011; Sonuga-Barke et al., 2010), children with ADHD scored significantly lower on the CTAQ in comparison to normally developing children. Sensitivity of the CTAQ was 0.67 and specificity was 0.73 .

In Chapter 4, we investigated whether total intelligence scores and/or a discrepancy in intelligence can predict behavioral or emotional problems in children with neurological deficiencies. The effects of demographic variables, IQ and the IQdiscrepancy in two parent-rated questionnaires on behavioral and emotional functioning were analyzed with linear and logistic regression models. We found that the IQ-discrepancy was not predictive of behavioral or emotional problems recorded on parent-rated questionnaires. The total intelligence score, age, and sex were to some extent predictive of behavioral or emotional problems. Furthermore, we found that verbal capacities were significantly higher than performance capacities in children with neurological learning deficiencies. This result is in line with the neuropsychological principle that language survives brain damage, whereas performance capacities are more affected (Anderson, Northam, Hendy, \& Wrennall, 2001; Eilander \& Hendriksen, 2011).

In Chapter 5, we investigated the prevalence of ADHD and found that this is much higher in children with neurological disabilities, than in normally developing children (38.8\% vs $5.3 \%$ ). Of these children with a diagnosis of ADHD and a neurological disability, only $28.2 \%$ were diagnosed with ADHD before referral. We concluded that ADHD is a common problem in children with neurological disabilities and may be underdiagnosed due to overshadowing of somatic, physical or syndromal features of the disability. In our heterogeneous population of children with neurological learning disorders, ADHD was overshadowed in $71.8 \%$ of the cases. It is important to prevent this underdiagnosis, since it has important implications for diagnosis and treatment of mental health needs in children with neurological disabilities. 
In Chapter 6, we examined whether cognitive functions can be trained in children with learning disorders. For this purpose, we reviewed and analyzed studies on working memory training programs. The effectiveness of these working memory training programs is still subject of debate. This was the first time that a review focused on this specific target group of children with learning disorders. Previous reviews were heterogeneous with regard to participant characteristics of the studies included. Thirteen randomized controlled studies were included in chapter 6. Potential moderator variables were examined, being age, type of learning disorder, training program, training dose, design type, and type of control group. The meta-analytical results indicated reliable short-term improvements in working memory and word decoding in children with learning disorders immediately after training compared to the untrained control group. Only few studies also measured the long-term effects, but they found that the improvements sustained over time for up to eight months. Furthermore, children $>10$ years seemed to benefit more in terms of verbal working than younger children, immediately after training but also on the long-term.

Finally, in Chapter 7, a general discussion on the studies described in this thesis is included. The discussion is started with a short summary of our main findings. Subsequently the main research questions are discussed in the light of existing literatures and theoretical considerations. Finally, implications for clinical practice are discussed, as well as implications for future research. 


\section{Chapter 9}

Samenvatting 
Chapter 9 


\section{Samenvatting}

Wanneer er zorgen zijn over de cognitieve ontwikkeling van een kind, kan een professional adviseren om een (klinisch) neuropsychologisch onderzoek te doen. Lezak, Howieson, Bigler, en Tranel (2012) definiëren de discipline "klinische neuropsychologie" als een toegepaste wetenschap die zich bezighoudt met de gedragsuitingen van disfunctioneren van het brein. Hoewel er meerdere conceptualisaties zijn van de term "gedrag", kiezen we er in deze thesis voor om drie aspecten te differentiëren, gebaseerd op zowel de omschrijving van Lezak en collega's, als op het 'triple pathway model' van Sonuga-Barke, Bitsakou, en Thompson (2010): cognitie, emotionaliteit, en tijdsperceptie. Cognitie omvat het informatieverwerkingsaspect van het gedrag en hoe het gedrag wordt uitgedrukt. Emotionaliteit omvat gevoelens en motivatie (Lezak et al., 2012). Tijdsperceptie, ook wel bekend als temporele verwerking, omvat kennis over tijdsgerelateerde concepten, en de mogelijkheid tot het schatten, produceren en reproduceren van tijdsintervallen (Block, Zakay, \& Hancock, 1999). Door het bestuderen van deze drie aspecten van gedrag proberen professionals om inzichten te krijgen over het dagelijks functioneren, door middel van het meten van cognitieve functies van een kind.

Het doel van deze thesis was drievoudig, en wordt omschreven in hoofdstuk 1. Allereerst onderzochten we of het mogelijk is om cognitie, tijdsperceptie en motivatie betrouwbaar en valide te meten in jonge kinderen (tussen 4 en 8 jaar). Deze gedragingen (en in het bijzonder de rol van aandacht) werden onderzocht in zowel gezonde kinderen, als in kinderen met een neurologisch bepaalde leerstoornis. Ten tweede onderzochten we de prevalentie van ADHD in kinderen met een neurologisch bepaalde leerstoornis, en onderzochten we de rol van IQ als voorspeller van gedragsen emotionele problemen van kinderen in deze populatie. Ten slotte onderzochten we of het mogelijk is om cognitieve functies te trainen in kinderen met een leerstoornis.

Twee meetinstrumenten voor het meten van cognities, motivatie en tijdsperceptie werden door ons team ontwikkeld. Het eerste meetinstrument is een interactief computerspel, genaamd Timo's Avontuur, en wordt beschreven in hoofdstuk 2. Timo's Avontuur is ontwikkeld voor het meten van specifieke cognitieve functies (zoals aandacht, planning en werkgeheugen), tijdsperceptie en motivatie in kinderen tussen de 4 en 8 jaar. Het spel bestaat uit zes interactieve mini-spellen, ingebed in een verhaallijn en met sprookjesfiguren om de motivatie te verbeteren. We onderzochten de validiteit van Timo's Avontuur door leeftijdseffecten te onderzoeken in gezonde kinderen, en door de prestatie-verschillen te onderzoeken tussen normaal ontwikkelende kinderen en kinderen met ADHD. Bewijs voor de validiteit werd gevonden in ontwikkelingsverschillen. Oudere kinderen maakten minder inhibitiefouten, hadden snellere (en dus betere) reactietijden en waren beter in staat om precieze tijdsintervallen te produceren dan jongere kinderen. Ook vonden we 
groepsverschillen tussen kinderen met en zonder ADHD op zowel maten voor motivatie als cognitie. Een discriminantenanalyse toonde dat Timo's Avontuur accuraat was in de meerderheid van de classificaties op de vraag of een kind tot de ADHD-groep behoorde of tot de normaal ontwikkelende kinderen. $78 \%$ van de kinderen werd correct geclassificeerd als hebbende ADHD of als zijnde in de normaal ontwikkelende groep.

Het tweede meetinstrument dat we ontwikkelden, was de Children's Time Awareness Questionnaire (CTAQ). De CTAQ is een vragenlijst bestaande uit 20 vragen, en ontworpen om de tijdsperceptie van kinderen te meten op een ecologisch valide manier. In hoofdstuk 3 worden normdata gegeven en worden de psychometrische eigenschappen beschreven. Een meervoudig regressiemodel voor de normdata liet zien dat de demografische variabelen leeftijd en geslacht een significante bijdrage hadden aan de prestatie op de CTAQ, terwijl het opleidingsniveau van ouders geen invloed had. De interne consistentie van de vragenlijst, als maat voor betrouwbaarheid, werd gemeten in een groep normaal ontwikkelende kinderen tussen 4 en 12 jaar. Interne betrouwbaarheid was naar tevredenheid. De resultaten toonden positieve correlaties tussen resultaten op de CTAQ en resultaten van vragenlijsten voor ouders en prestatietesten op het gebied van tijdsperceptie voor kinderen. Overeenkomstig met eerder onderzoek dat tijdsperceptieproblemen vond in kinderen met ADHD (Hurks \& Hendriksen, 2011; Sonuga-Barke et al., 2010) vonden we dat kinderen met ADHD significant lager scoorden op de CTAQ in vergelijking met normaal ontwikkelende kinderen. Sensitiviteit van de CTAQ was 0.67 en specificiteit was 0.73 .

In hoofdstuk 4 onderzochten we of de totale intelligentie score en/of een discrepantie in intelligentie gedrags- en emotionele problemen kan voorspellen in kinderen met neurologische afwijkingen. De effecten van demografische variabelen, IQ en de IQ-discrepantie op twee oudervragenlijsten op het gebied van gedragsmatig en emotioneel functioneren werden onderzocht door middel van lineaire en logistische regressiemodellen. We vonden dat de IQ-discrepantie geen goede voorspeller was voor gedrags- en emotionele problemen zoals vastgesteld met oudervragenlijsten. De totale intelligentie score, leeftijd en geslacht konden tot een bepaald niveau gedragsen emotionele problemen voorspellen. Verder vonden we dat verbale capaciteiten significant hoger zijn dan performale capaciteiten in kinderen met neurologische leerstoornissen. Dit resultaat komt overeen met het neuropsychologische principe dat taal hersenschade overleeft, terwijl performale capaciteiten meer aangedaan zijn (Anderson, Northam, Hendy, \& Wrennall, 2001; Eilander \& Hendriksen, 2011).

In hoofdstuk 5 onderzochten we de prevalentie van ADHD, en vonden dat deze veel hoger is in kinderen met neurologische afwijkingen dan in normaal ontwikkelende kinderen (38.8\% vs 5.3\%). Van deze kinderen met een diagnose ADHD en een neurologisch probleem was slechts $28.2 \%$ gediagnosticeerd met ADHD voordat ze 
verwezen werden naar ons centrum. We concludeerden dat ADHD een vaak voorkomend probleem is in kinderen met neurologische afwijkingen en mogelijk ondergediagnosticeerd wordt doordat de somatische, fysieke of syndromale eigenschappen van het neurologisch probleem zorgen voor overschaduwing. In onze heterogene populatie van kinderen met neurologische leerstoornissen bleek de diagnose ADHD overschaduwd te zijn in $71.8 \%$ van de gevallen. Het is van belang om onderdiagnosticering te voorkomen, omdat het belangrijke implicaties heeft voor de diagnose en behandeling van psychische behoeften van kinderen met neurologische afwijkingen.

In hoofdstuk 6 onderzochten we of cognitieve functies getraind kunnen worden in kinderen met leerproblemen. Voor dit doel beoordeelden en analyseerden we studies over werkgeheugentrainingprogramma's. De effectiviteit van deze werkgeheugentrainingprogramma's is nog steeds onderwerp van discussie. Dit was de eerste keer dat een review zich richtte op deze specifieke doelgroep van kinderen met leerstoornissen. Eerdere reviews waren heterogeen op het gebied van karakteristieken van deelnemers van de geïncludeerde studies. Dertien gerandomiseerd gecontroleerde studies werden geïncludeerd in hoofdstuk 6 . Mogelijke moderator variabelen werden onderzocht, namelijk leeftijd, type leerstoornis, training programma, duur van de training, soort onderzoek en soort controle groep. De meta-analytische resultaten lieten betrouwbare korte termijn verbeteringen zien in werkgeheugen en woord decoderen direct na de training, wanneer kinderen die de training hadden gevolgd werden vergeleken met kinderen die geen training volgden. Slechts enkele studies onderzochten ook de lange termijn effecten, maar zij vonden dat deze verbeteringen ook na acht maanden terug werden gevonden. Verder vonden we dat kinderen ouder dan 10 jaar meer profiteerden van de training dan jongere kinderen, zowel direct na de training als op de lange termijn.

Ten slotte wordt in hoofdstuk $\mathbf{7}$ een algemene discussie van de studies uit deze thesis beschreven. De discussie start met een korte samenvatting van de belangrijkste bevindingen. Vervolgens worden de belangrijkste onderzoeksvragen bediscussieerd in het licht van bestaande literatuur en theoretische overwegingen. Ten slotte wordt gediscussieerd over de implicaties voor klinische praktijk en toekomstig onderzoek. 


\section{Chapter 10}

Valorisation 
Chapter 10 


\section{Valorisation}

\section{Relevance}

Attentional problems are common in children. Although the worldwide point prevalence of Attention-Deficit/Hyperactivity Disorder (ADHD) is estimated at $5.3 \%$ (Polanczyk, de Lima, Horta, Biederman, \& Rohde, 2007), we found in this thesis that this percentage is much higher in children with neurological deficiencies. In our population of 685 children with a neurological condition, we found that 266 children (38.8\%) also fulfilled the criteria for the diagnosis of ADHD. Previous research found that, in young children, early detection of potential attentional problems can predict later academic achievements (Wassenberg et al., 2007). Even more importantly, research indicates that early treatment of symptoms can diminish academic failure (Diamond \& Lee, 2011). It therefore is surprising that hardly any neuropsychological assessment instruments exist for preschoolers (under the age of 8). Furthermore, the existing neuropsychological assessment instruments for children usually focus on (one of the) cognitive functions. We found, however, based on the triple pathway model by Sonuga-Barke, Bitsakou and Thompson (2010) and the description of neuropsychology by Lezak, Howieson, Bigler, and Tranel (2012), that it is a shortcoming to focus on only cognitive functions. Sonuga-Barke and colleagues, as well as Lezak and colleagues, also described two elements that are usually not part of neuropsychological assessments: motivation and time perception. Previous research indicates that a subgroup of children with ADHD might suffer from cognitive deficits, whereas subgroups of children with ADHD suffer more from time perception deficits and/or motivation problems (Sonuga-Barke et al., 2010). By focusing on only potential cognitive deficits, problems of a large group of children with ADHD might be misunderstood.

This thesis is relevant in several ways. The first is the fact that two assessment instruments are described that were developed by our team with the aim of signalizing early symptoms of potential time perception, motivation, or attention problems. One instrument is a questionnaire on time perception (named the Children's Time Awareness Questionnaire, described in chapter 3), which can be used in children of four years and older. The second instrument is a computerized diagnostic tool (named Timo's Adventure, described in chapter 2), which includes tasks for time perception, motivation, as well as (aspects of) cognition and can be used in children between four and at least eight years. The use of these instruments can help in mapping out early signs of potential attentional problems. This can help professionals in adjusting the right treatment options to the child, and thus possibly prevent further problems. This thesis aims at finding support for both assessment instruments, by examining the psychometric properties. We found that both instruments can be used in a reliable and valid way in young children, in a way that is non-invasive and even entertaining for the child. The results of this thesis therefore 
contributed in improving diagnostic options in young children. After this first step (i.e., the development of the assessment instruments and examining the psychometric properties), the next step is the translation to the use of the instruments in healthcare (e.g., by health care professionals such as psychologists). For this purpose, in this thesis normative models are made by which the results of an individual child can be compared to the results of a large group of children; the so-called normative data. This is based on the method by Van der Elst, Hurks, Wassenberg, Meijs, and Jolles (2011) who describe that it is necessary to "identify the demographic variables that are associated with test performance (e.g., age, sex, and parental education), so that the normative data can be appropriately corrected for the relevant demographic influences". By using these normative models, it is possible to give an answer to the question whether a child has a deviant result on the assessment instrument and thus is at risk for developmental problems.

The second reason why this thesis is relevant, is that this thesis contributed in the knowledge on children with neurological deficiencies (chapters 4 and 5). First of all, we found that it is necessary to pay attention to cognitive and attentional problems in children with a neurological condition. We found that the prevalence of ADHD is much higher in this specific target group than in the general population. The relevance of this finding is significant. By underdiagnosing ADHD, a large group of children do not get the treatment that they need, which might result in large problems for the children themselves, but also for the society in general. This finding therefore might influence the children who are at risk for attentional problems, because it might lead to an increase of awareness on these problems. Furthermore, this might influence the environment of the concerning children, such as parents and teachers. By reporting these findings, this thesis aims at presenting a warning for medical professionals to pay attention to potential neuropsychological difficulties of the child. Although it is understandable that the focus of assessment and treatment is the neurological condition in the first place, it is necessary to also examine and screen for potential attentional problems. Also, besides the knowledge about the prevalence of ADHD in children with neurological deficiencies, we provide more insights in the IQ-profiles of this specific group of children. Our analyzes indicate that children with a neurological condition have in average significantly better verbal capacities, than performance capacities. This finding is interesting, since it stipulates the neuropsychological principle that language survives brain damage, whereas performance capacities are more affected (Eilander \& Hendriksen, 2011). The level of discrepancy however did not influence the level of emotional and behavioral problems of the child, as this thesis describes. This finding is relevant, since it is often hypothesized by psychologists that children with a discrepant IQ-profile might be at risk for developing emotional or behavioral problems, but we could not confirm this hypothesis. It is however necessary to pay attention to a discrepant IQ-profile, since it might influence treatment options, and children who have a discrepant IQ-profile are at risk of being overestimated. 
The third subject, that we investigated and which provides relevant information, was a review of scientific literature on specific treatment options for children with learning disorders, such as ADHD and learning difficulties: the computerized working memory training programs (chapter 6). Since previous research reviews (Jaeggi, Buschkuehl, Jonides, \& Shah, 2011; Melby-Lervag \& Hulme, 2013; Shipstead, Redick, \& Engle, 2012) were inconsistent in their findings on whether these treatment protocols are effective, we decided to focus on research studies that only included children with learning disorders. Interestingly, we found that results are more positive for this specific target group than when including a broad range of other diagnoses or problems. This finding is relevant, since it might improve treatment options for children with learning disorders.

\section{Target groups}

Three main groups can be distinguished as target groups in this thesis. First of all, children can benefit from the use of the described assessment instruments and knowledge on potential neuropsychological deficits that are related to neurological deficiencies, since potential developmental problems or weaknesses can be identified at an early age, and treatment options can be tailored to the needs of the child. This might diminish the effects of potential problems.

Secondly, parents and teachers of the child can benefit from the results in this thesis, since it helps parents and teachers in mapping out potential problems and thus give them the possibility to help the child and therefore prevent potential problems.

Healthcare professionals, such as psychologists, are the third group that can benefit from the use of the developed assessment instruments and the reported results on intelligence profiles. As stated earlier: for professionals these results might lead to a warning to prevent underdiagnosing. Also, the described results might lead to a nuance on the current focus on discrepant IQ-profiles, since the hypothesis that a discrepant IQ-profile leads to emotional or behavioral problems was not correct.

\section{Innovation}

In neuropsychological assessments, the aim is to gain information on specific cognitive domains and underlying cognitive functions that might exhibit problems. Based on the three aspects of the model by Sonuga-Barke and colleagues (2010) and the description of neuropsychology by Lezak and colleagues (2012), it is necessary to focus on cognition, motivation, and time perception. Interestingly, most neuropsychological assessment instruments measure only aspects of cognition, thereby underexposing the aspects of motivation and time perception. The results of this thesis contributed to the development of assessment instruments on motivation and time perception. As stated earlier: for this purpose we developed two assessment instruments. The first, a computerized diagnostic tool named Timo's Adventure, was developed in collaboration with a team from the University of Technology in 
Eindhoven. To our knowledge, this game is the first diagnostic tool on cognition, time perception, and motivation, that is suitable for young children. The second assessment instrument that we developed was the questionnaire on time perception (CTAQ), which can be used in children above the age of four. Again, to our knowledge, this is the first assessment instrument of this kind that we know of.

The innovation of these two assessment instruments led to positive reactions from both users (i.e., psychologists) as well as the children. Furthermore, our research indicates that these assessment instruments have satisfying psychometric properties, which led us to the conclusion that time perception, cognition, and motivation can be reliably measured in young children.

\section{Implementation}

The results of this thesis can be used to improve the current neuropsychological assessment options in young children. The two described instruments (Timo's Adventure and the (TAQ) are of added value next to the already existing assessment instruments, since they are the first instruments for children focusing on time perception, motivation, and cognition. In the current thesis, we found that both instruments can be used in a reliable and valid way in young children. A benefit of the instruments is that they can be used in non-invasive way: information is collected in a short amount of time, in an entertaining manner for the child. When looking at the bigger picture, both instruments might play a small role in the early signalizing of ADHD and thus prevent later academic problems: a benefit of which the entire society can benefit. 


\section{References}

Diamond, A., \& Lee, K. (2011). Interventions shown to aid executive function development in children 4 to 12 years old. Science, 333(6045), 959-964. doi: 10.1126/science.1204529

Eilander, H., \& Hendriksen, J. (2011). Traumatisch hersenletsel. In H. Swaab, A. Bouma, J. Hendriksen \& C. König (Eds.), Klinische Kinderneuropsychologie. Amsterdam: The Netherlands: Boom.

Jaeggi, S. M., Buschkuehl, M., Jonides, J., \& Shah, P. (2011). Short- and long-term benefits of cognitive training. P Natl Acad Sci USA, 108(25), 10081-10086. doi: 10.1073/pnas.1103228108

Lezak, M. D., Howieson, D. B., Bigler, E. D., \& Tranel, D. (2012). Neuropsychological Assessment (5th ed.). New York: Oxford University Press.

Melby-Lervag, M., \& Hulme, C. (2013). Is working memory training effective? A meta-analytic review. Dev psychol, 49(2), 270-291. doi: 10.1037/a0028228

Polanczyk, G., de Lima, M. S., Horta, B. L., Biederman, J., \& Rohde, L. A. (2007). The worldwide prevalence of ADHD: a systematic review and metaregression analysis. Am J Psychiatry, 164(6), 942-948. doi: 10.1176/ajp.2007.164.6.942

Shipstead, Z., Redick, T. S., \& Engle, R. W. (2012). Is working memory training effective? Psychol bull, 138(4), 628-654. doi: 10.1037/a0027473

Sonuga-Barke, E., Bitsakou, P., \& Thompson, M. (2010). Beyond the dual pathway model: evidence for the dissociation of timing, inhibitory, and delay-related impairments in attention-deficit/hyperactivity disorder. J Am Acad Child Adolesc Psychiatry, 49(4), 345-355. doi:10.1016/j.jaac.2009.12.018

Van der Elst, W., Hurks, P., Wassenberg, R., Meijs, C., \& Jolles, J. (2011). Animal Verbal Fluency and Design Fluency in school-aged children: effects of age, sex, and mean level of parental education, and regression-based normative data. J Clin Exp Neuropsychol, 33(9), 1005-1015. doi: 10.1080/13803395.2011.589509

Wassenberg, R., Hurks, P. P. M., Hendriksen, J. G. M., Feron, F. J. M., Kessels, A. G. H., \& Vles, J. S. H. (2007). Attention in kindergarten and the first grade predicts academic outcome in the sixth grade. In R. Wassenberg (Ed.), Differential cognitive development: a neuropsychological approach (pp. 59-74). Maastricht: Neuropsych Publishers. 
Dankwoord 


\section{Dankwoord}

En dan is het toch ineens zo ver: tijd om mijn dankwoord te gaan schrijven! Dit proefschrift was niet mogelijk geweest zonder de hulp, het enthousiasme en de inzet van veel mensen. Om te beginnen wil ik alle kinderen en ouders bedanken die aan de studies deel wilden nemen. Zonder jullie was dit proefschrift niet mogelijk geweest!

Prof. dr. J.S.H. Vles, beste Hans, u heeft er een talent voor om altijd precies de vinger te leggen op de zere plek van een artikel (en dat terwijl u altijd zegt: "Ik ben maar een neuroloog, geen psycholoog!"). Uw rake opmerkingen (vaak gepaard gaand met de nodige humor) hebben me keer op keer aan het denken doen zetten, maar daarnaast kreeg ik ook de ruimte om mijn eigen plan te trekken. Dank ook voor de zeer snelle reacties die ik altijd van $u$ kan verwachten en het feit dat ik $u$ altijd mocht bellen voor overleg. Dank voor uw grote betrokkenheid en inzet om tot dit proefschrift te komen.

Prof. dr. A.P. Aldenkamp, beste Bert, jij ziet soms mogelijkheden waar anderen die nog niet ontdekt hebben. Hoe groot het probleem soms ook in mijn ogen lijkt, jij weet het altijd met een paar opmerkingen op te lossen. Hoe druk je het ook hebt, je maakt altijd tijd voor overleg of voor het lezen van mijn stukken. Daarnaast kon ik er op rekenen dat jij op de achtergrond altijd mijn planning in de gaten hield.

Dr. J.G.M. Hendriksen, beste Jos, dit project was natuurlijk 'jouw kindje'. Wat ben ik blij dat ik daar mee aan de slag mocht gaan! Je drive om dit project te laten slagen, en ook in je klinische werk, is inspirerend. Het maakt niet uit wanneer ik je mail, ik heb altijd zo een reactie. Dankjewel voor alle kansen en alle mogelijkheden tot leren (zowel professioneel als op persoonlijk vlak) die ik van je gehad heb. Dank ook voor het overnemen van mijn patiënten als er echt weer eens meters gemaakt moesten worden met mijn boekje. Zonder jou was dit boekje er nooit in deze vorm geweest.

Dr. P.P.M. Hurks, beste Petra, ik heb veel geleerd van je kennis, inzet en enthousiasme. Ik kon er altijd op vertrouwen dat je meer dan grondig naar mijn stukken keek, en met allerlei suggesties kwam waar ik zelf nog niet op gekomen was (en waar je dan ook nog eens, totaal onnodig, je excuses voor aanbood: "Sorry dat ik nog meer feedback heb, ik kan het niet laten!"). Dank ook voor je luisterend oor als ik even vast zat. Fijn dat jij na een jaar aansloot bij mijn promotieteam, door jouw ideeën zijn mijn stukken absoluut naar een hoger niveau getild.

Ook wil ik de leden van de beoordelingscommissie van dit proefschrift hartelijk danken voor het lezen en beoordelen van mijn thesis: Prof. dr. S.A. Kotz, Prof. dr. W.C.M. Resing, Prof. dr. L.M.E. Smit, Prof. dr. L.J.I. Zimmermann, onder voorzitterschap van Prof. dr. R.J. van Oostenbrugge. 
Een groot deel van mijn promotie betreft de ontwikkeling van het spel Timo's Avontuur, wat niet mogelijk was geweest zonder het team van de TU/e: I would like to thank Prof. dr. G.W.M. Rauterberg, dr. J. Hu, dr. E.D. van der Spek, Pongpanote Gongsook and Christian Sallustro. Pong and Christian, thanks so much for all the fun we had in discussing and development of the game. Pong, thank you for answering my endless stream of questions on all the difficult technical stuff.

Irene Gijselhart, bedankt voor het maken van zoekopdrachten en het opsporen van artikelen. Zonder jouw hulp had ik heel vaak misgegrepen op artikelen die ik wilde gebruiken voor mijn onderzoek. Ik weet niet hoe je het doet, maar je hebt er een talent voor om zelfs de meest oude, obscure artikelen met een razend tempo op te duiken.

Afdeling I\&A, in het bijzonder Frederik en Leon: Dank voor jullie hulp bij de technische kant van dit onderzoek.

Er zijn verschillende mensen die als co-auteur bij een artikel betrokken waren. Dank voor jullie hulp en ideeën: drs. Sandra van Abeelen, dr. Sylvia Klinkenberg, drs. Annick Laridon, Prof. dr. Matthias Rauterberg, dr. Erik van der Spek, dr. Renske Wassenberg.

Dank aan alle kinderen en ouders van CNL die deel wilden nemen aan dit onderzoek. Daarnaast fijn dat er zoveel scholen waren die enthousiast waren. De Hovenier in Montfort, Maria Goretti in Sint Joost, 't Breerke in Maasbracht, Sint Bavo in Rijsbergen, De Smelen in Valkenswaard, De Toermalijn in Bladel, De Koperakker in Rijsbergen: dankjulliewel! Een bijzonder dankjewel aan Henk Beesems, voor je enthousiasme en betrokkenheid bij het onderzoek. Ook dankjewel aan de vijf studenten die geholpen hebben met de dataverzameling: Anke, Heleen, Maud, Mila, en Kelly. Sylvie, dankjewel voor je voorwerk bij de CTAQ-studie.

Collega's van CNL, dankjulliewel voor de verwijzingen, jullie betrokkenheid bij mijn onderzoek, de belangstellende vragen en dat jullie voor me bijsprongen in de kliniek als het promotiespitsuur was.

Dank aan al mijn collega's van de GWD voor al jullie interesse en hulp! Leuk dat jullie altijd zo belangstellend zijn. Ik heb jullie wel gemist tijdens mijn periode op den Boondert!

In het bijzonder dank aan José, Rhea en Suze voor het afnemen van de game bij onze patiënten.

Caroline, dankjewel voor je steun, je luisterend oor en je humor. Zo fijn om zo'n 'mama' op de afdeling te hebben!

Lisanne, dankjewel voor je blijdschap toen mijn eerste artikel gepubliceerd werd, het feit dat ik altijd even bij je mocht mopperen als het even niet meezat, en de lol die ik 
met je gehad heb als er tussendoor ontspannen moest worden. Op naar jouw promotie, en nog vele sushi-avondjes!

Christie, Astrid, Lucia, Evelien en Desirée, dank voor jullie hulp met het inplannen van alle overleggen rondom mijn promotie. ledere keer weer een puzzel, die zonder jullie hulp zeker niet gelukt was.

De meiden van den Boondert en collega promovendi, dank voor jullie gezelligheid op onze promotiekamer en tijdens de promovendidagen. Jans, heel veel succes met de laatste loodjes van jouw promotie. Ik hoop dat je snel een nieuw kamergenootje krijgt die je van het werk kan houden! Dominique, buddy, wat fijn dat jij in hetzelfde schuitje zat. Ik ben heel blij dat ik met name het laatste jaar met je heb kunnen delen, zowel werkinhoudelijk als op persoonlijk vlak. Even sparren met elkaar, elkaar motiveren of even samen mopperen als dat nodig was. En oh, wat was ik jaloers toen je me meldde dat je je boekje af had! Positieve keerzijde was wel dat je me toen wilde helpen met allerlei kleine regeldingen die ook bij een promotie horen.

Lieve vrienden, jullie hebben op heel verschillende manieren bijgedragen aan dit boekje, vaak zelfs zonder dat jullie het weten (vermoed ik).

Jurriaan en Christel: Zoals een paar jaar geleden beloofd: een speciale vermelding in mijn dankwoord voor jullie. Dankjewel dat ik jullie inlogcodes van de UB mocht gebruiken om artikelen op te zoeken.

Suus: Fijn om jouw verhalen over promoveren te horen en zo met je te kunnen sparren. Ik heb veel aan je tips gehad!

Myrthe en Joost: Wat vond ik het jammer als ik weer eens een borrel of etentje moest overslaan omdat ik moest werken. Hopelijk is dat nu achter de rug, want etentjes met jullie zijn altijd heel lekker en vooral ook heel gezellig.

Caroline, Dieuwertje, Fleur, Janneke en Lucia: Hoewel ik jullie pas sinds de GZopleiding tot mijn vriendinnen mag rekenen, hebben we samen al veel meegemaakt en gedeeld. Gezellige etentjes, veel lachen, maar ook heel open en eerlijk naar elkaar. Ik hoop dat we nog lang samen de borrelchickies (al wordt het langzaamaan wel de borrelmama's...) mogen zijn.

Myrte, Manon en Mienke: We zijn nu 11 jaar bevriend, en ik hoop dat we daar nog ontzettend veel jaren (met leuke weekendjes!) aan vast mogen knopen. Het is altijd fijn om bij jullie te zijn. We hebben veel lol samen, maar daarnaast kan ik ook altijd bij jullie mijn verhaal kwijt. Mien, wat ben ik blij dat jij besloten had dat je me op een vrijdagmiddag 'syntaxles' ging geven. Dat heeft me heel veel tijd en moeite bespaard. Je nuchtere kijk zorgt er voor dat ik af en toe weer met de voeten op de grond wordt gezet. Wat fijn dat jij mijn paranimf wilt zijn! Myrt, van twee KBL's naar nu... Heel erg bedankt voor je prachtige ontwerp van de kaft en het feit dat ik altijd even met je kan bijkletsen over de andere heel belangrijke dingen van het leven. Manon, zullen we dan toch maar eens na gaan denken over die eigen praktijk? Ben trots op je, mevrouw de psychiater! 
Van Alpha Gamma tot Gamma Omega, wat een prachtig zooitje zijn we toch. Ben zo blij dat jullie mijn vrienden zijn!

Dit, Leon, Janine en Maud: Fijn dat jullie er begrip voor hadden als ik weer eens iets last minute af moest zeggen omdat ik echt even moest werken. Dankjulliewel voor jullie belangstelling, jullie enthousiasme als er goed nieuws was, en steun (ook voor Jaap!).

Annemarie en Tom: Jullie hebben mijn hele promotieproces van dichtbij meegemaakt. Wat fijn dat jullie er altijd voor me zijn en dat ik bij jullie helemaal mezelf kan zijn. Ammie, voor mij stond al jaren vast dat jij mijn paranimf moest zijn. Er zijn weinig mensen die me zo goed weer op de grond kunnen zetten als jij, en dan ook nog zonder kleerscheuren op te lopen. Fijn dat jij letterlijk en figuurlijk achter me staat. En dan zijn jullie ook nog eens de ouders van het allerliefste nichtje van de hele wereld!

Pap en mam: Van jullie heb ik geleerd dat alles mogelijk is als je er voor gaat. Jullie onvoorwaardelijke vertrouwen en steun hebben er voor gezorgd dat hier nu mijn proefschrift ligt. Door jullie weet ik dat het niet erg is als het niet via de makkelijkste weg gaat, maar linksom of rechtsom: uiteindelijk lukt het dan toch. Deze promotie is zeker niet alleen mijn proces geweest, maar dit hebben we samen gedaan.

Mijn lieve Jaap: Je grapt wel eens dat jouw naam ook op de kaft moet staan. Eén ding is zeker: zonder jou had ik dit nooit kunnen doen. We hebben samen de beslissing genomen om in dit avontuur te stappen en je hebt me altijd gesteund. Ik ben je niet alleen dankbaar voor je kennis van Excel, statistiek en je blik op mijn Engels, maar vooral voor het feit dat je er altijd voor me geweest bent. Jij weet altijd precies wat ik nodig heb. Met jou naast mijn zijde is mijn leven zo leuk! Wat fijn dat we dit samen hebben kunnen doen. Nu gaan we samen door naar het volgende avontuur! 
Curriculum Vitae 
CV 


\section{Curriculum Vitae}

Janneke Cornelia Anna Wilhelmina Husson Peijnenborgh werd geboren op 11 november 1984 in het Limburgse Herten. In 2004 behaalde zij haar Gymnasium diploma aan het Elzendaal College te Boxmeer. In 2004 startte zij met de bachelor Gezondheidswetenschappen aan de Universiteit Maastricht, waar ze in het tweede jaar koos voor de richting Geestelijke Gezondheidkunde. Na afronding van de bachelor vervolgde ze haar studie met de master Mental Health, tevens in Maastricht. Tijdens deze master deed zij haar klinische stage bij de Riagg Maastricht, afdeling

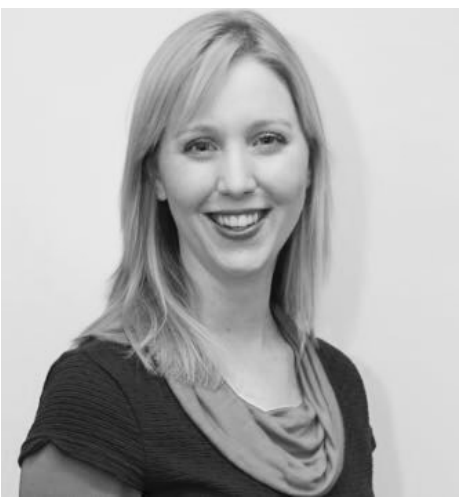
Kind \& Jeugd. Ook voerde ze hier haar onderzoeksstage uit, naar de relatie tussen sociale vaardigheden en faalangst bij kinderen met autisme. Tijdens haar studie werkte Janneke bij de Riagg Maastricht als PGB-hulpverlener, en als vrijwilliger en mentor bij de Kindertelefoon. Tevens was zij tutor van verschillende vakken van haar opleiding, en vertegenwoordigde zij de universiteit op open dagen en beurzen als lid van het promotieteam.

$\mathrm{Na}$ haar afstuderen werkte zij ruim drie jaar als basispsycholoog op de afdeling Kind \& Jeugd van Orbis GGZ, en op de afdeling Kinderrevalidatie van Orbis Medisch Centrum (het huidige Zuyderland Ziekenhuis te Sittard).

In 2012 startte Janneke op de Gedragswetenschappelijke Dienst van Kempenhaeghe. In 2013 begon hier haar promotieonderzoek, in combinatie met de opleiding tot GZpsycholoog KJ. De resultaten van dit onderzoek vindt $u$ in dit proefschrift. Haar dossioma voor het theoretische deel van de GZ-opleiding behaalde ze in 2015, de afronding van de klinische uren volgt in februari 2017.

Janneke is getrouwd met Jaap Husson. In haar vrije tijd houdt ze van piano spelen, dansen en koken.

Janneke Cornelia Anna Wilhelmina Husson - Peijnenborgh was born on November 11th 1984 in Herten (Limburg, The Netherlands). She graduated from secondary school at the Elzendaal College in Boxmeer (The Netherlands) in 2004 and subsequently started the bachelor General Health Sciences at Maastricht University, where she enrolled in the Mental Health track after her first year. After her bachelor graduation, she started the master Mental Health at Maastricht University. As part of her master program, she completed a clinical internship at the Riagg Maastricht, department Child \& Youth. She also completed a research internship at the Riagg Maastricht, examining the relation between social skills and fear of failure in children with autism. Next to her studies, Janneke worked at the Riagg Maastricht as personal mentor of several children, and as volunteer and mentor at the Kindertelefoon (a 
hotline for children who have questions). She also worked as a tutor at Maastricht University and represented the university as member of the promotion team at fairs and open days.

After her master graduation, she worked for over three years as a psychologist at the department Child \& Youth of Orbis Mental Health Care, and at the department of Child Revalidation of Orbis Medical Center (the current Zuyderland Hospital in Sittard). In 2012 Janneke started at the Behavioral Science Department of Kempenhaeghe. In 2013 she started with her PhD-research, combined with the post-graduate program Mental Health Psychologist Child \& Youth. The results of this PhD-research can be found in this thesis. In 2015 Janneke finished the theoretic part of the post-graduate program, and in February 2017 she will finish her clinical work and become a Dutch GZ-psycholoog (registered psychologist).

Janneke is married to Jaap Husson. She likes playing the piano, dancing, and cooking. 